LBL-7522

UC 96

C.2

\title{
TEST OF THE \\ PERFORMANCE AND CHARACTERISTICS \\ OF A \\ PROTOTYPE INDUCTIVE POWER COUPLING \\ FOR \\ ELECTRIC HIGHWAY SYSTEMS
}

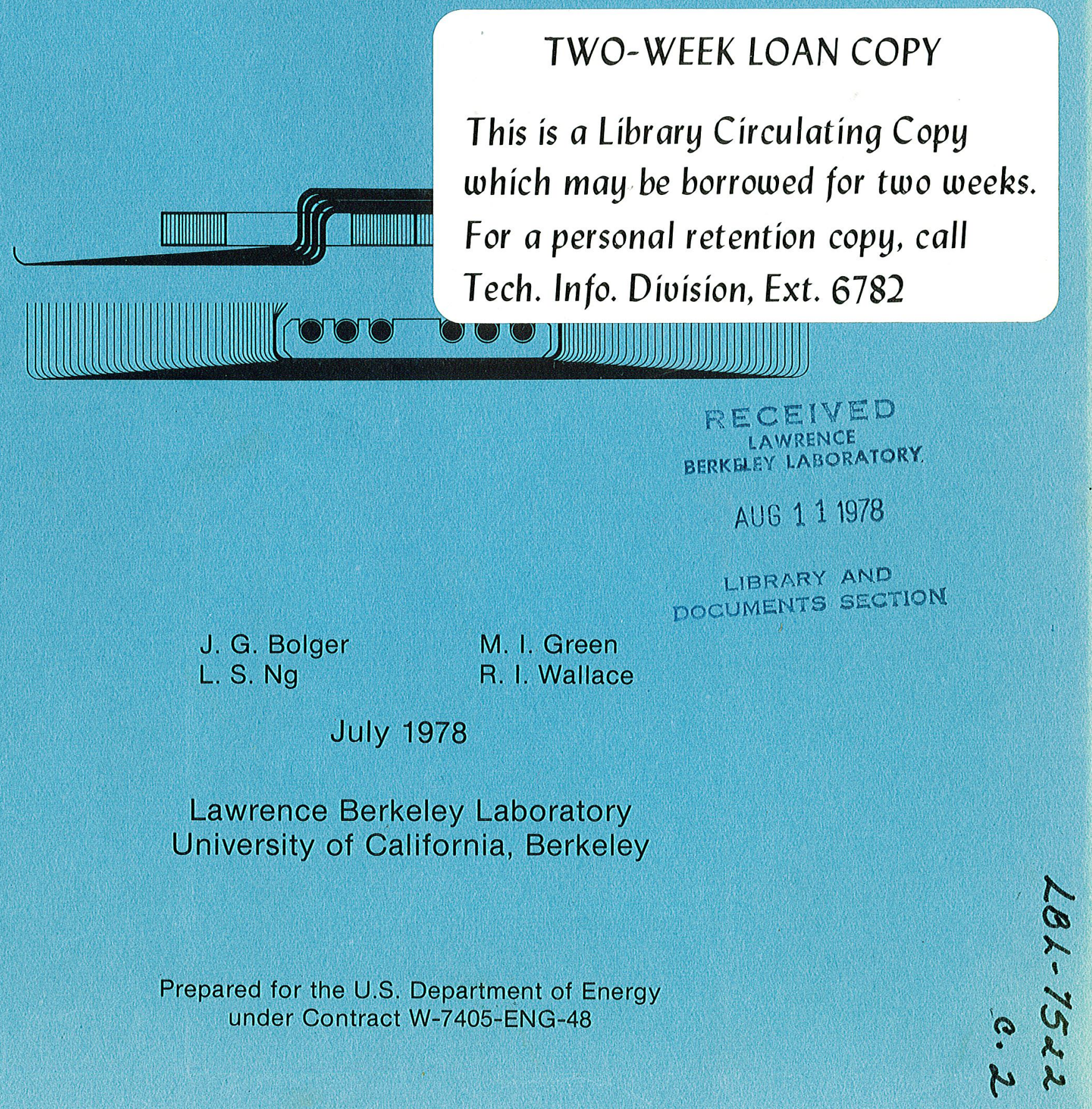


LBL 7522

UC 96

\author{
TESTS OF THE \\ PERFORMANCE AND CHARACTERISTICS \\ OF A \\ PROTOTYPE INDUCTIVE POWER COUPLING \\ FOR
}

\title{
ELECTRIC HIGHWAY SYSTEMS
}

\author{
J. G. Bolger \\ M. I. Green \\ L. S. Ng \\ R. I. Wallace \\ July 1978 \\ Lawrence Berkeley Laboratory \\ University of California, Berkeley
}




\section{ACKNOWLEDGMENTS}

The work at LBL was accomplished by personnel of numerous technical disciplines. Among the many contributors to the work were:

M. M. Baker, preparation of text drafts

J. G. Bolger, principal investigator

C. G. Dols, consultant, magnetic measurements

T. H. Entriken, administrative assistance

M. I. Green, magnetic measurements and data reduction

R. E. Hendrickson, technical editing

J. W. Knight, technical editing

D. H. Nelson, magnetic measurements and data reduction

L. S. $\mathrm{Ng}$, electrical design of prototype, electrical measurements, and data analysis

F. L: Toby, mechanical design

J. O. Turner, mechanical design

R. I. Wallace, supervisor of prototype assembly, data acquisition and reduction

R. R. Yocum, electrical component design, construction coordinator

Mr. K. F. Barber and Mr. E. Beyma are administrators of the program in the Department of Energy, Division of Transportation Energy Conservation. Mr. Beyma also contributed to the planning of some of the tests, and to the technical review of the report. 


\section{CONTENTS}

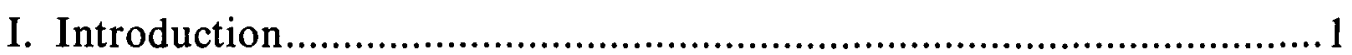

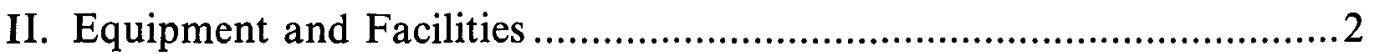

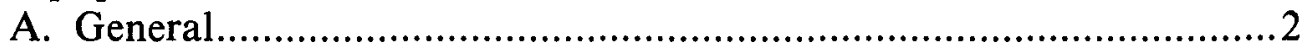

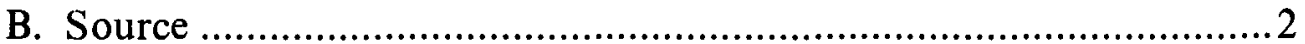

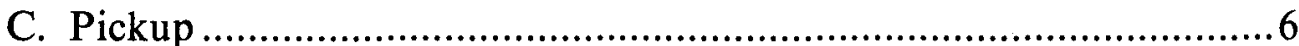

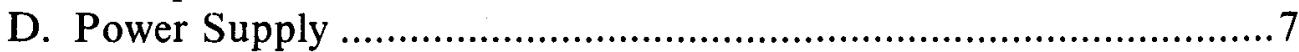

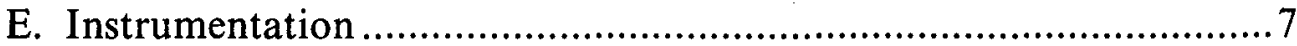

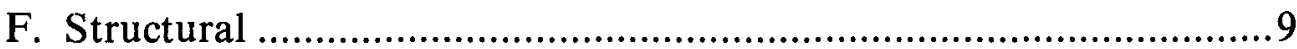

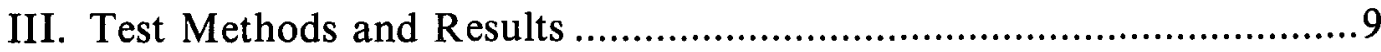

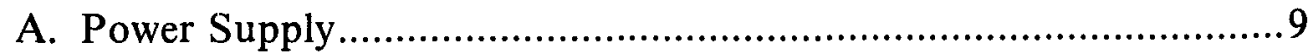

B. Magnetic Force Tests ............................................................. 11

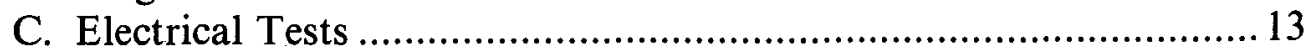

1. Electrical Characteristics of the Coupling Prototype ..................13

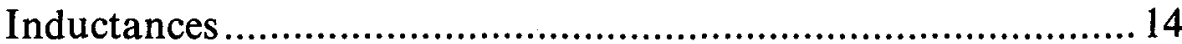

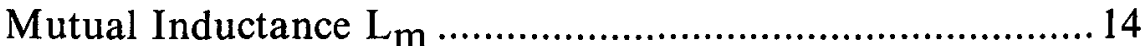

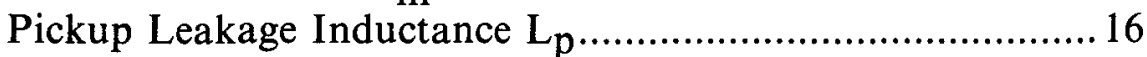

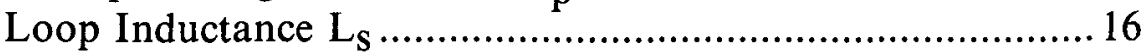

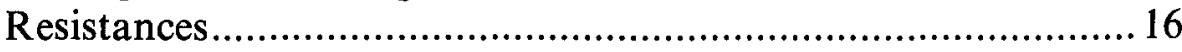

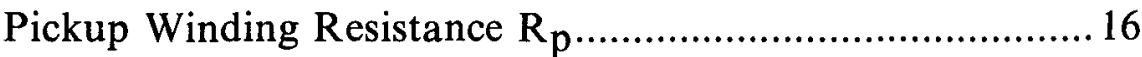

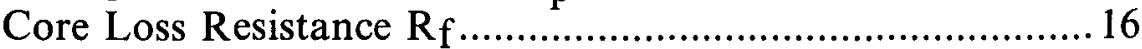

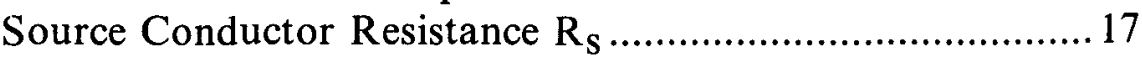

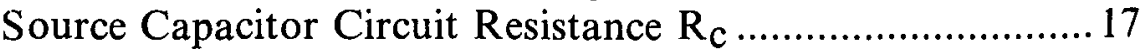

Pickup Capacitor Circuit Resistance Pr............................... 17

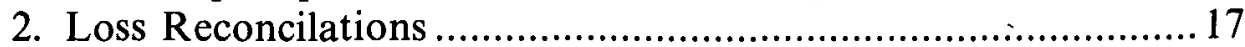

3. Controllability of Coupled Power ............................................ 19

4. Characteristics of a Battery Charging Load ..............................20

D. Magnetic Measurements ..........................................................21

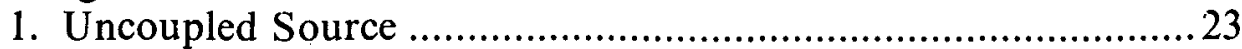

2. Source Coupled to Pickup...................................................... 24

3. Simulted Automobile Floor Pan ..............................................25

4. Flux Distribution in Source and Pickup Core Laminations ..... 25

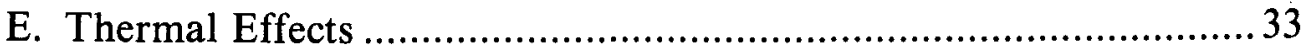

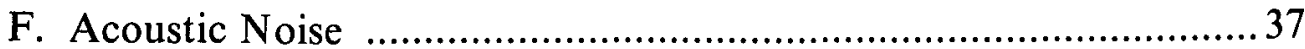


IV. Summary and Discussion of Test Results ........................................38

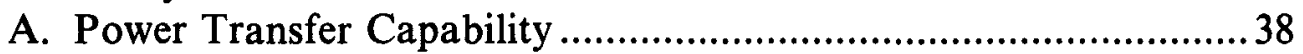

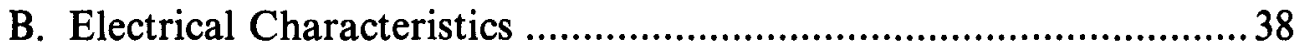

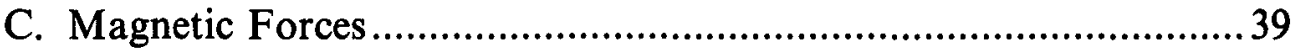

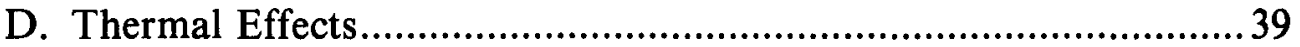

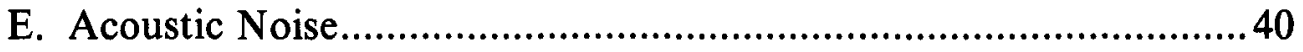

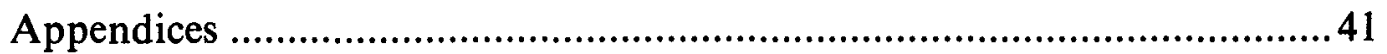

A. Power Supply Tests

Test Conditions (Figure 13) .....................................................

B. Magnetic Force Tests

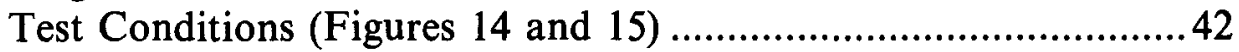

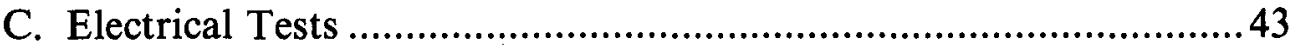

Inductance Calculations...........................................................43

Resistance Calculations .........................................................4 44

Prototype System Resistance Measurements ........................... 48

Test Conditions (Figures 18, 19, 20) .......................................49

(Figures 21, 22, 23) …...................................50

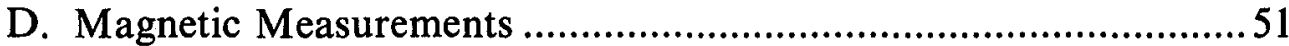

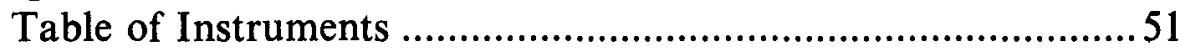

Test Conditions (Figures 29, 31) ...............................................51

(Figures 32, 33, 34) ....................................52

(Figures 35, 36, 37) .....................................53

(Figures 38, 39, 40, 43) .................................54

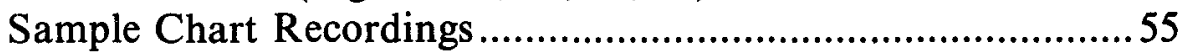

Flux Integration Plots .............................................................57

Arrangement of Windings on Pickup Core ..............................58

Arrangement of Windings on Source Core ..............................58

E. Thermal Tests ............................................................................59

Test Conditions (Figures 42, 44, 45) ......................................59

(Figures 46, 47) .............................................60

Temperature vs Time Plots for Rate of Rise Determination....61

Calculation of Power Dissipation in Steel Sheet over Source ..65

Temperature in Sheet vs Time Plots...........................................68 


\section{INTRODUCTION}

Development at the Lawrence Berkeley Laboratory (LBL) of an inductively coupled power system for highway application (Figure 1) was begun in 1976. Sponsorship was provided by the Department of Energy. Reduction in the use of petroleum in highway vehicles was the incentive to develop the power system.

The power system is designed to provide energy to vehicles that also carry a supply of stored energy, thus providing a large measure of operational flexibility to the vehicles and reducing the necessary inventory of powered roadways. The highway power system can support the high-speed, long-range portions of driving cycles, while the stored energy can meet the requirements of driving on non-powered streets. The system thus has been referred to as a 'dual-mode' system because of the use of the two sources of energy.

This report presents the results of testing a prototype coupling. No physical contact between the vehicle and the power source is required, i.e., the coupling magnetically links the power system of the vehicle to a power source in the roadway (inductive coupling).

The major deficiencies of electric vehicles that must rely exclusively on energy from batteries are well known, i.e., short range and substandard performance. These deficiencies, coupled with an increased cost of operation, will severely impede the marketability of such vehicles, and thus restrict potential petroleum savings.

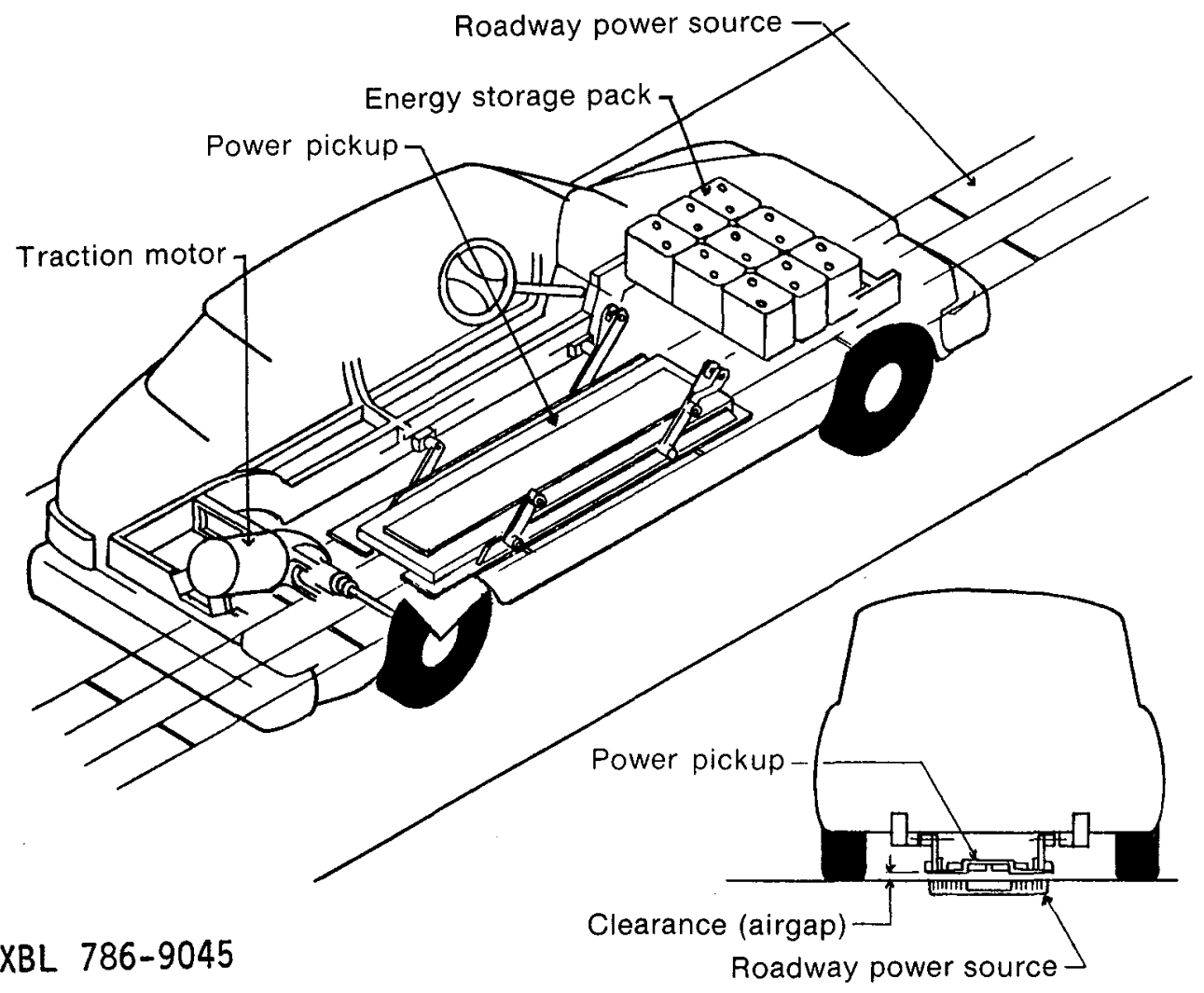

Figure 1. Roadway-powered system for electric vehicles. 
If electric power is made continuously available to vehicles from a source in freeway lanes, the utility of electric vehicles is radically changed. The vehicle is able to travel indefinitely at high speeds. It can carry a relatively small battery pack that is required to supply only the modest speed and range requirements of travel on streets. The reduction in battery-pack size and vehicle weight is highly significant, in that cost of the vehicle and its propulsion power requirements are reduced, with consequent improvements in acceleration, energy utilization, and operating costs.

The requirements for a freeway power system for vehicles are rigorous. It must accommodate the wide variations of operating skills of the motoring public. It cannot add to the hazards of highway driving. It must be environmentally acceptable, and popular with the general public. It should be compatible with existing combustion-powered highway vehicles, and be readily adaptable to electric vehicles of all sizes. These requirements were explored in a feasibility study. ${ }^{1}$ The study indicated that the prototype inductively coupled power system described in this report might satisfy all of the requirements.

A prior phase of this project investigated various designs of components for a highway power system, emphasizing trade-offs involved in the optimization of the designs. Some tradeoffs included the consideration of effects such as fringing magnetic fields, and compatibility with existing utility and highway systems. Others involved typical cost and performance interrelationships. Preliminary designs for system components were derived from this work. They are reflected in the design of the prototype of the power coupling that was tested.

It was expected that the testing program would reveal opportunities to improve the design of the coupling. This has proved to be the case. Some improvements were incorporated and tested during the work. Others will be incorporated in future component designs.

The completion of the construction and testing of the coupling prototype was a major milestone in the development of viable highway power systems. It has documented the ability of an inductive power coupling system to perform its intended function in an efficient, predictable manner. It has also revealed some characteristics of the coupling that may be very useful in instrumenting the system to monitor its performance, and in developing automatic vehicle and traffic controls that can use these characteristics to good advantage.

\section{EQUIPMENT AND FACILITIES}

\section{A. General}

The prototype assembly was installed in Building 88 at Lawrence Berkeley Laboratory. Figure 2 shows the arrangement of the equipment in the work area.

The power coupling prototype consisted of a length of roadway power-source and a short power-pickup. Figure 3 shows a cross section of this prototype, which was designed to model in full scale a section of a coupling suitable for highway use. The source core was $230 \mathrm{~cm}$ long and the pickup core was $77 \mathrm{~cm}$ long.

A pickup suitable for a compact automobile would be more than twice the length of the prototype core. Because the power capacity of the coupling is a direct function of its length, it was feasible to employ the shorter, less expensive prototype without seriously compromising the utility of the test results. Figure 4 is a schematic of the prototype power coupling, specifications of which are given in Table 1.

\section{B. Source}

The three source core sections were fabricated from "M-6" grade electrical steel sheet $(0.36 \mathrm{~mm}$ thick). As received, the sheet was $79 \mathrm{~cm}$ wide. This was trimmed to $77 \mathrm{~cm}$ to remove the irregular edges; 43 laminations were used. Three extra laminations were added to the center core section during the course of the work to reduce the flux density in the outer

\footnotetext{
'J. G. Bolger and F. Kirsten, Investigation of the Feasibility of a Dual Mode Electric Transportation System, Lawrence Berkeley Laboratory Report, LBL 6301 (1977).
} 


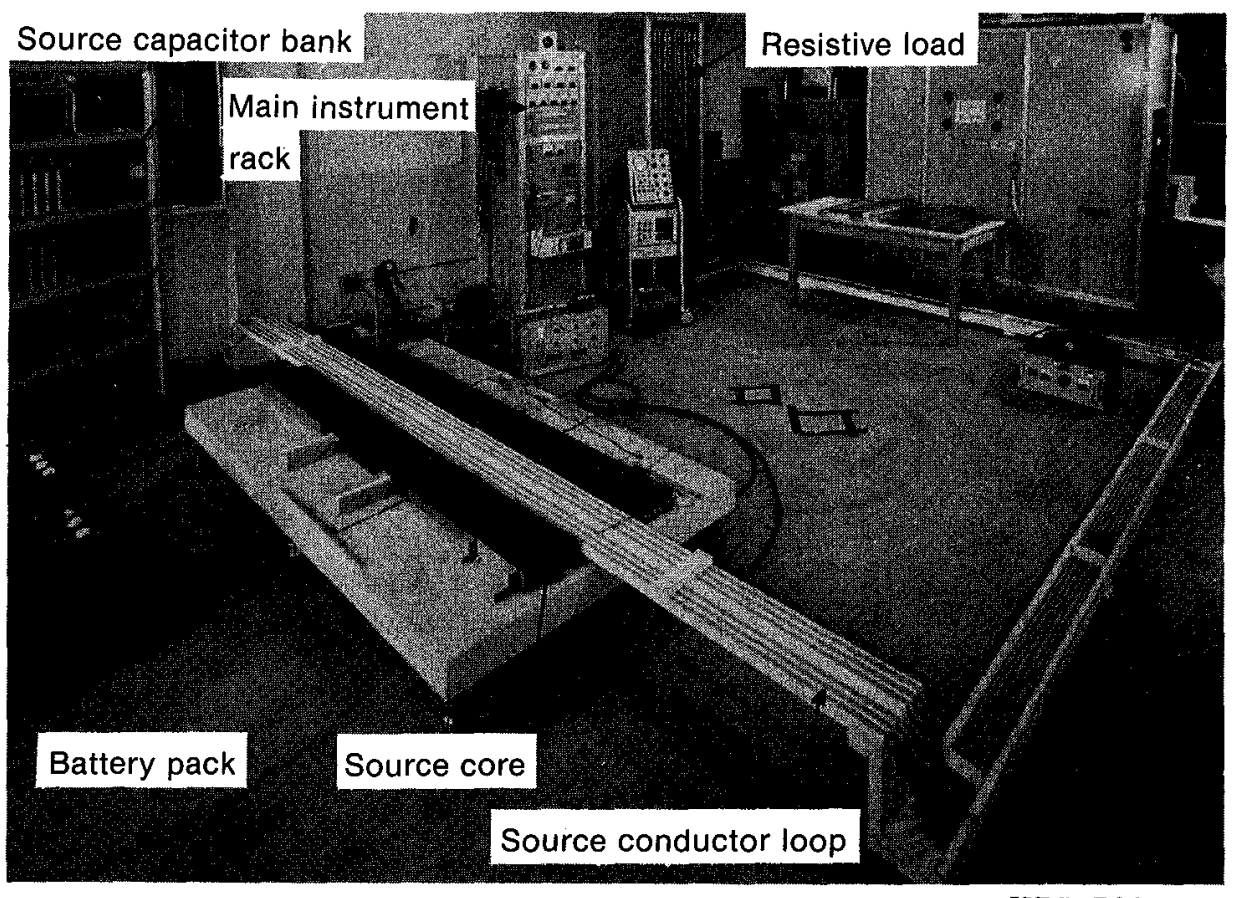

Figure 2. Arrangement of prototype and facility.

XBB $782-1153$

lamination. The grain in the laminations was at right angles to the conductor. Thus, the direction of magnetic flux in the laminations paralleled the grain, to minimize core losses. The laminations were bonded together with epoxy adhesive in a fixture that applied pressure to areas being bonded. Figure 5 is a photograph of an unbonded source core. After bonding, the laminations were found to be electrically connected at their edges. Future designs should seek to prevent this, since extra core losses result from unwanted currents in the laminations.

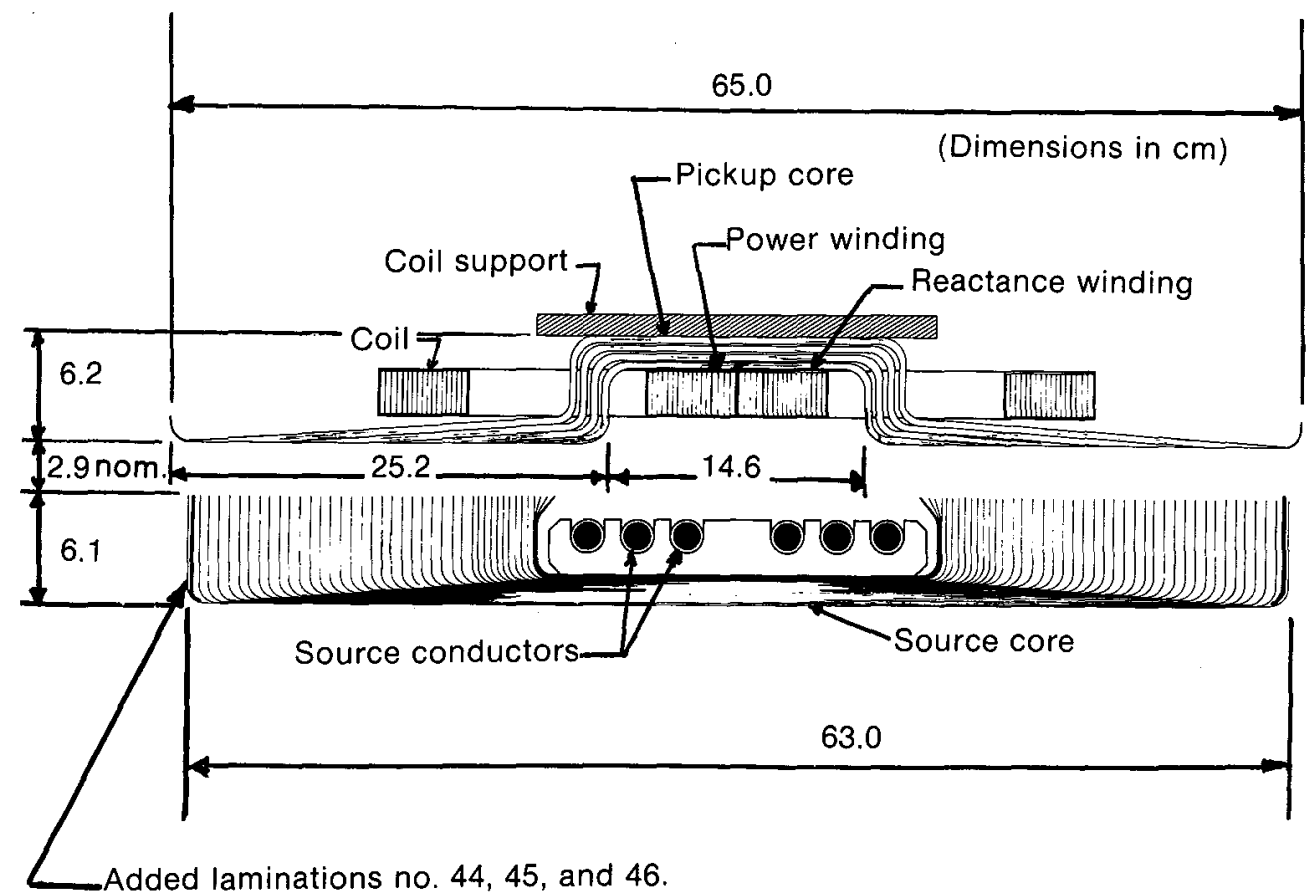

XBL $786-9046$

Figure 3. Cross section of the prototype coupling. 


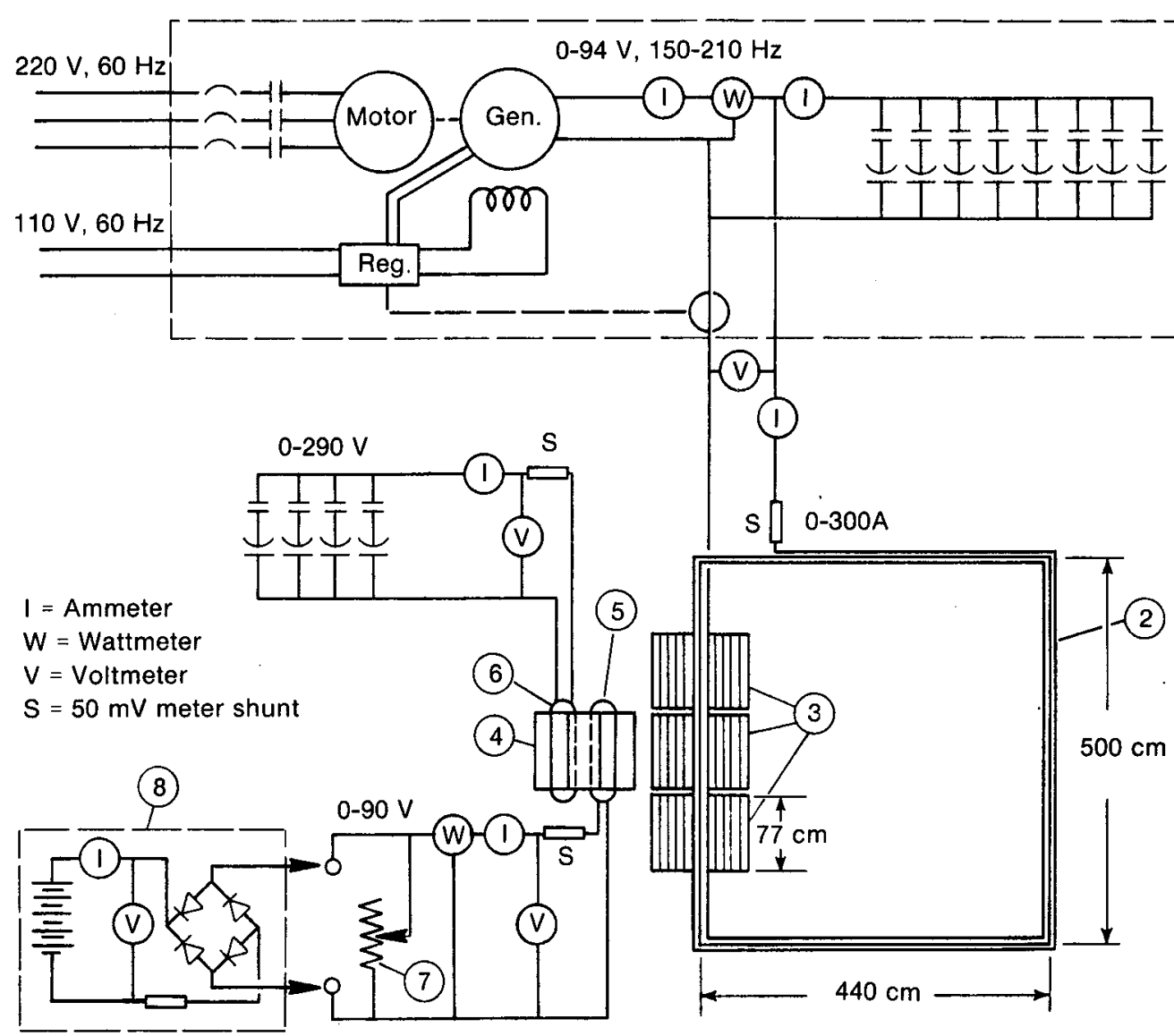

XBL $786-9180$

Figure 4. Schematic of power coupling prototype system: 1. Power supply; 2 . Source conductor loop; 3 . Source cores (3); 4. Pickup core; 5 . Power winding; 6 . Reactance winding; 7 . Resistive load; 8 . Vehicle energy storage simulator.

Table I. Specification of static power coupling prototype .

\begin{tabular}{|c|c|c|}
\hline & Units & \\
\hline \multicolumn{3}{|l|}{ Loop } \\
\hline Loop dimensions, center to center & $\mathrm{m}$ & $4.40 \times 5.00$ \\
\hline Conductor & - & 2 - parallel $2 / 0$ welding cables \\
\hline Turns in loop & - & 3 \\
\hline Loop current, nominal & A & 300 (900 A turns) \\
\hline Loop capacitors (phase correction) & - & 8 \\
\hline Control & - & Relay switching \\
\hline Values & $\mu \mathrm{F}$ & $\mathrm{Cl}=50$ \\
\hline & $\mu \mathrm{F}$ & $C 2=100$ \\
\hline & $\mu \mathrm{F}$ & $C 3=150$ \\
\hline & $\mu \mathrm{F}$ & $C 4=200$ \\
\hline & $\mu \mathrm{F}$ & $\mathrm{C} 5=500$ \\
\hline & $\mu \mathrm{F}$ & C6 $=1000$ \\
\hline & $\mu \mathbf{F}$ & $C 7=2000$ \\
\hline & $\mu \mathbf{F}$ & $C 8=4000$ \\
\hline Total & $\mu \mathbf{F}$ & 8000 \\
\hline Current, nominal & A & 240 \\
\hline
\end{tabular}


Source cores

Overall dimensions

Pole width

Weight

Laminations

Material

Power supply

Type

Motor type

Motor load

Motor speed

Voltage

Current

Generator type

Ratings, as built:

Load

Voltage

Frequency

Speed

Ratings, as applied

Load

Voltage

Frequency

Control Speed

Regulation

Generator drive

Type

Speed change method

Power pickup

Core

Core dimensions

Pole width, approx.

Laminations

Material

Coils

Power winding turns

Reactance winding turns

Electrical characteristics

Power voltage

Power current

Power

Reactance voltage

Reactance (capacitors)

Reactive current

Airgap

Resistive load

Type

Resistance

Vehicle energy storage simulator

Battery pack
Voltage
Time at 75 A
Power conditioner (input)

- $\quad 3$

$\mathrm{cm} \quad 76.8 \mathrm{~L} \times 63.0 \mathrm{~W} \times 6.1 \mathrm{H}$

$\mathrm{cm} \quad 21$

$\mathrm{kg} / \mathrm{each} \quad 45.1$

$\mathrm{kg} / \mathrm{m} \quad 58.7$

- 43 (46 in center core)

M-6 $(0.35 \mathrm{~mm})$ electrical steel sheet

- Motor-generator

- Induction

kW $\quad 11.2$

- $\quad 1760 \mathrm{rpm}$

V 230,3 phase

A, rms $\quad 38$

- Aircraft generator, separately excited

GE model 2 CM 214B2

$\mathrm{kVa} \quad 60$ at 0.75 power factor

rms V 120/208 (3 phase)

$\mathrm{Hz} \quad 380 / 420$

rpm $\quad 5700 / 6300$

kVA $\quad 18$ at $180 \mathrm{~Hz}, 0.75$ power factor

rms V 94 (single phase)

$\mathrm{Hz} 150,180$, and 210 nom.

rpm 2250, 2700, 3150 nom.

- Relay starter

- $\quad$ Output current regulated by servo control of excitation current

- Vee belt (3-banded belts)

- Pulley change

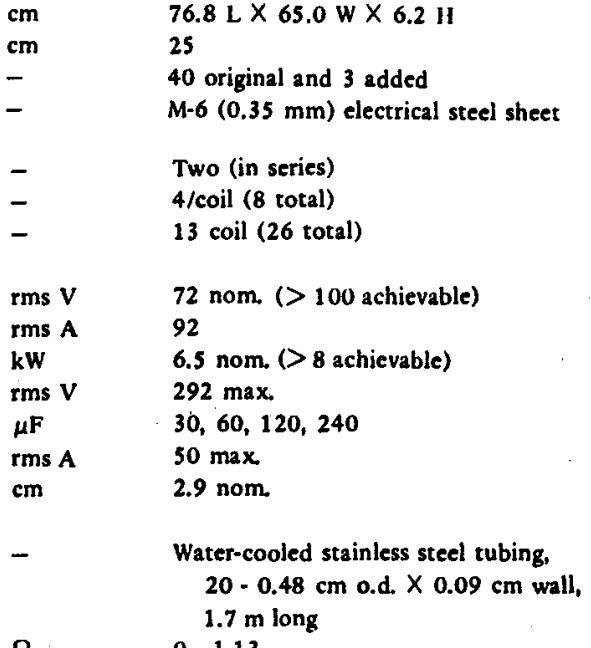

$\Omega=0 \cdot 1.13$ 


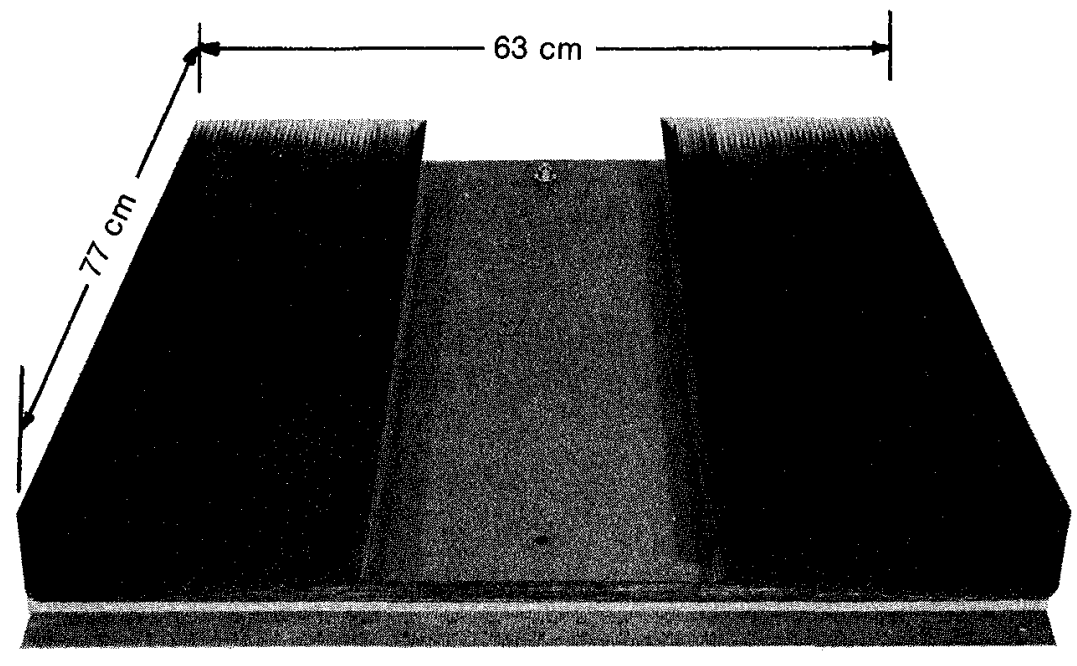

Figure 5. Unbonded source core.

XBB $778-7695$

The source conductor consisted of six $2 / 0$ welding cables that were terminated at a junction block. The cables were then connected as a three-turn loop with each turn consisting of two cables in parallel.

\section{Pickup}

The core for the power pickup was also fabricated from "M-6" electrical sheet and was 77 $\mathrm{cm}$ in length. Originally, the core consisted of 40 laminations that were bent in four groups of ten laminations. This core was also bonded with epoxy adhesive. Three laminations were added during the test program to eliminate a localized area of high flux density in the core. Figure 6 shows the laminations of the pickup before bonding. The magnetically linked conductors of the pickup consisted of two coils connected in series. Each coil contained two circuits, one of which was used for output power, and one for current from a capacitor bank that was used as a means of controlling the coupled voltage. These coils were constructed from $2.5 \mathrm{~cm}$ wide copper bar with $0.04 \mathrm{~mm}$ thick Nomex insulation and an epoxy encapsulation. Figure 7 shows the pickup assembly.

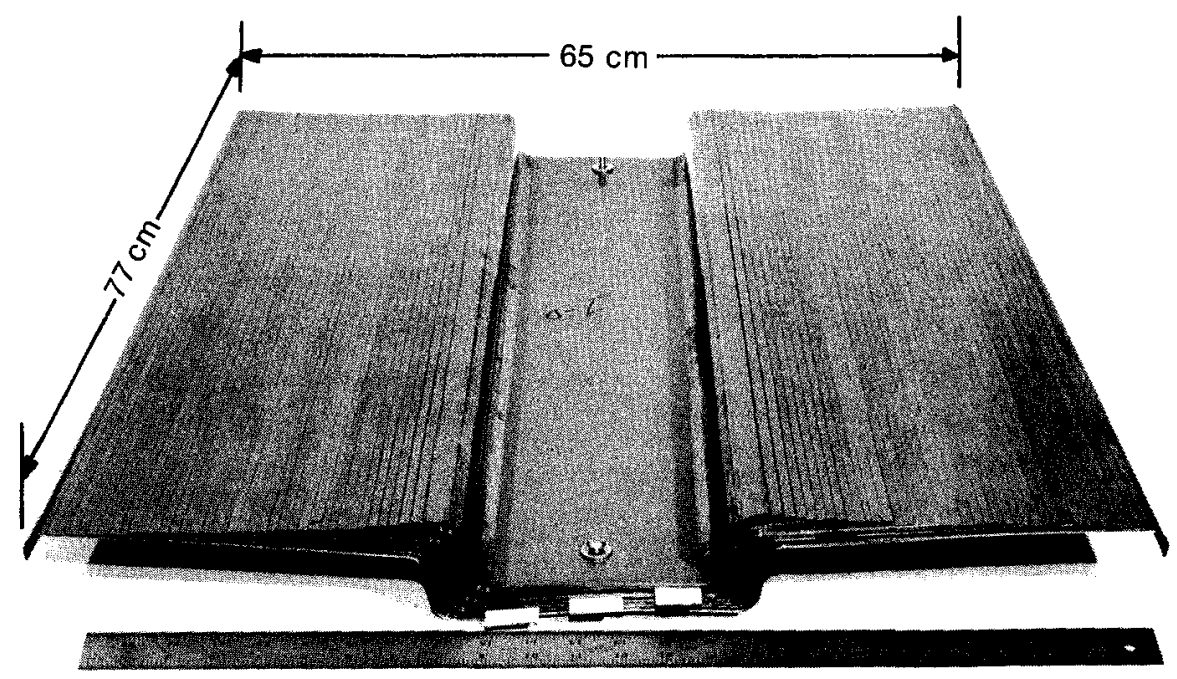

Figure 6. Unbonded pickup core. 


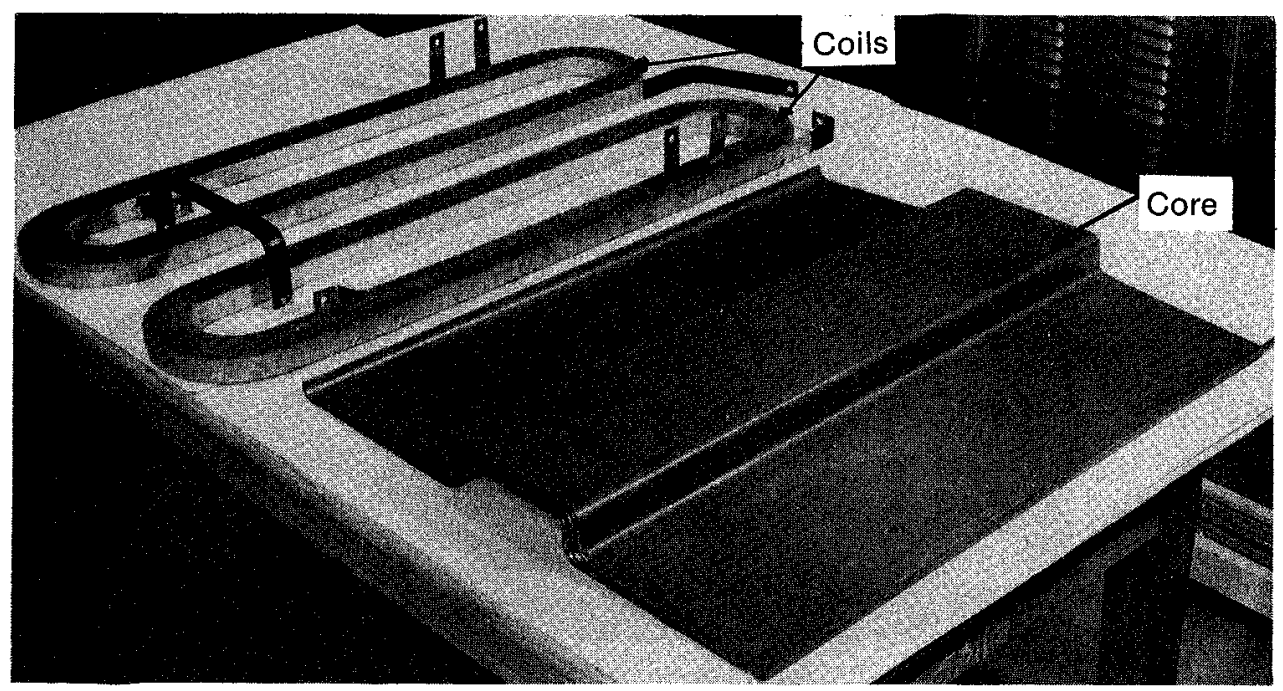

A) Disassembled pickup.

XBB 782-1154

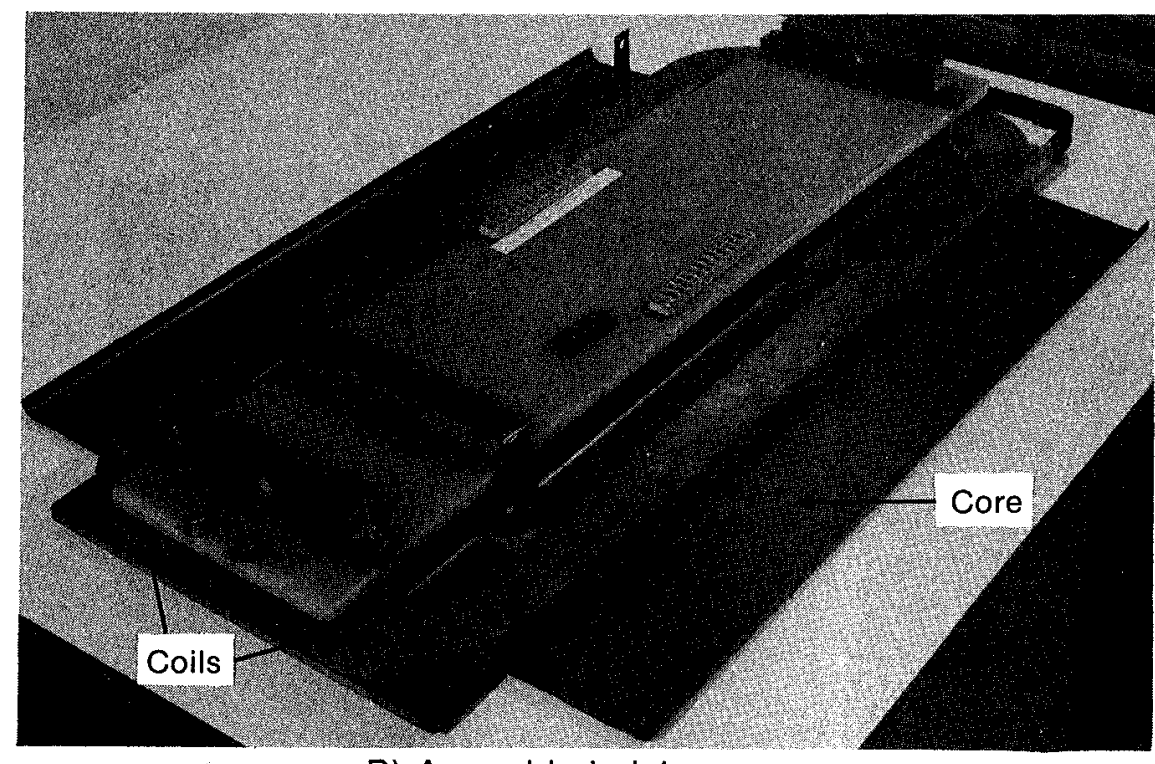

B) Assembled pickup.

XBB 7821155

Figure 7. Prototype pickup.

\section{Power Supply}

Power at the required frequencies was obtained from an aircraft generator. The generator was belt driven by a $15 \mathrm{hp}$ induction motor. The design frequency of the generator was $400 \mathrm{~Hz}$, and nominal frequencies of 150,180 , and $210 \mathrm{~Hz}$ were obtained by running the generator at reduced speeds. The motor pulley was changed to alter the speed and frequency. Figure 8 shows the motor/generator assembly.

Capacitors were provided across the generator output to compensate the highly inductive load, and thus reduced the volt-ampere load on the generator.

\section{E. Instrumentation}

Instruments were provided for electrical, magnetic, thermal, and force measurements. Most of these instruments were mounted in racks, as shown in Figures 9 and 10. Details of the instruments are discussed in following sections that relate to specific tests. 


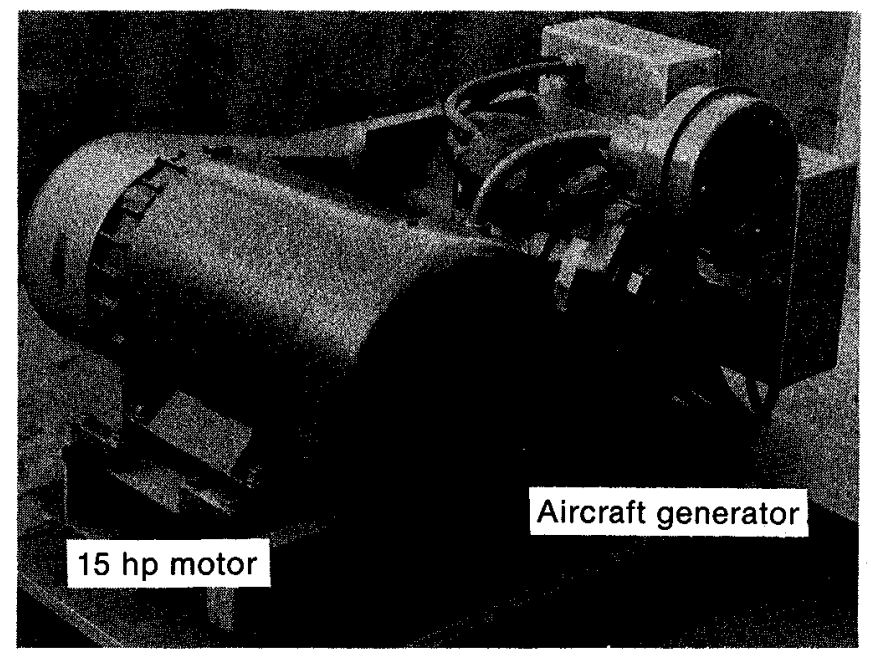

XBB 782-1151

Figure 8. Motor generator set.
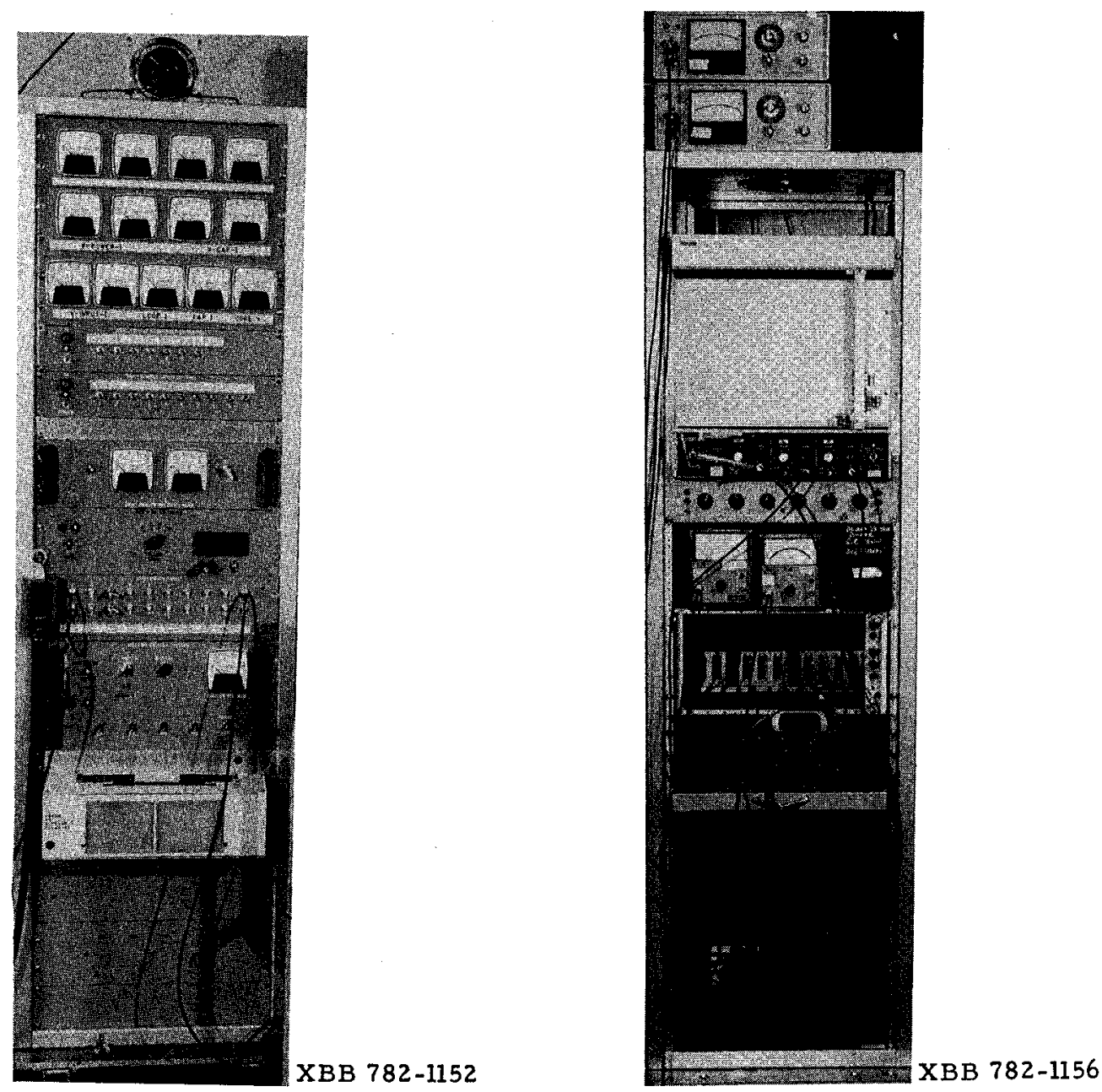

Figure 9. Main instrument rack.

Figure 10. Magnetic measurements instruments. 


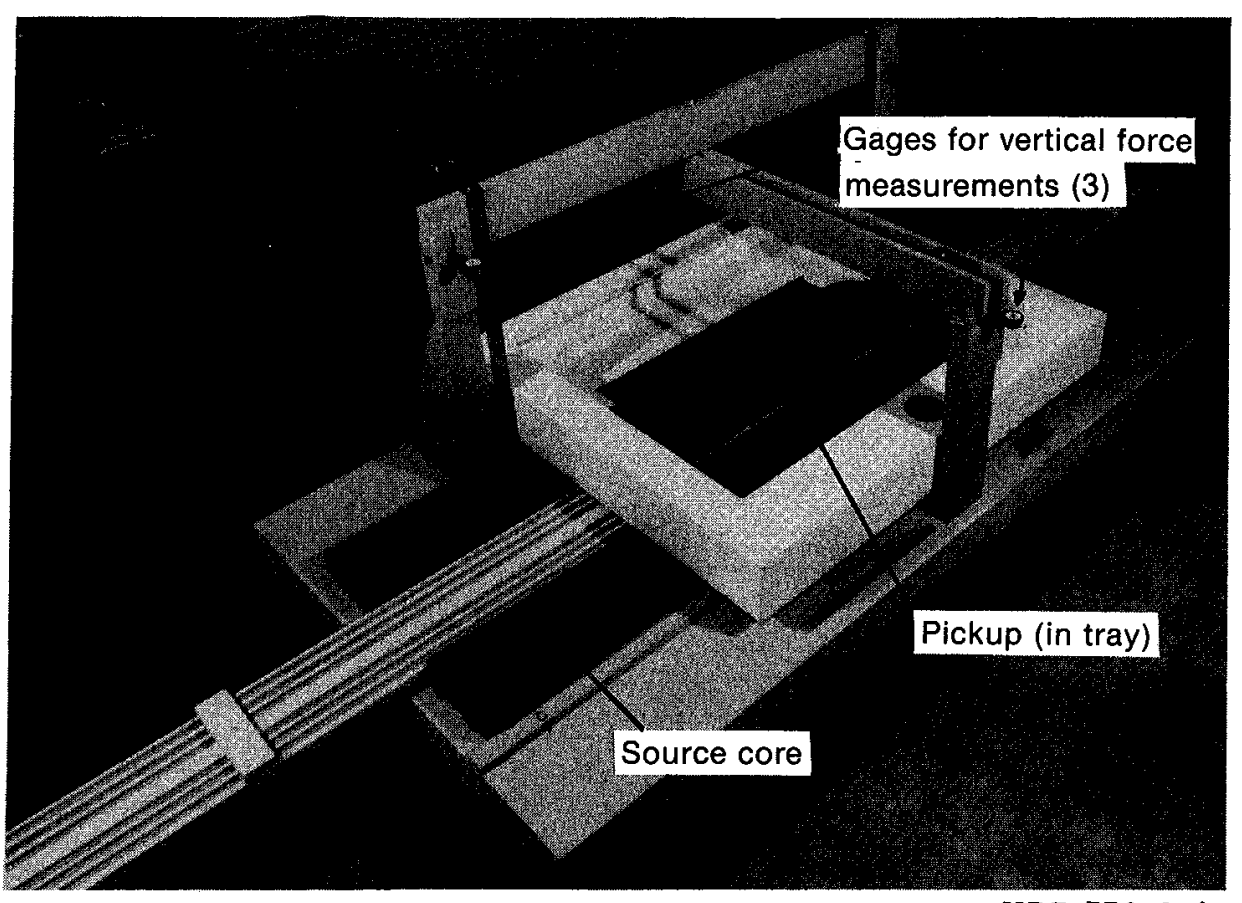

Figure 11. Support structure for the prototype coupling.

XBB 779-8968

\section{F. Structural}

The assembly of the coupling and pickup supporting structures is shown in Figure 11. The source was mounted on a level wood platform. A removable structure was attached to the platform from which the pickup was suspended. This arrangement allowed both vertical and horizontal magnetic forces on the pickup to be measured with a minimum of frictional hysteresis. Figure 2 shows the assembly with the pickup supporting structure removed.

For making electrical measurements, the pickup was supported by elastomer spacers inserted between the source and pickup poles. The airgap was established by the thickness of the spacers.

The source conductor was arranged in a three-turn rectangular loop, $4.4 \mathrm{~m}$ by $5.0 \mathrm{~m}$ between centers of conductors. The $4.4 \mathrm{~m}$ spacing approximates the width of a freeway lane, i.e., the distance between sources if they were installed in adjacent lanes.

\section{TEST METHODS AND RESULTS}

\section{A. Power Supply}

The generator was driven at approximately 2500,2700 , and $3150 \mathrm{rpm}$ in order to obtain frequencies of 150,180 , and $210 \mathrm{~Hz}$. Frequency was monitored with a solid-state counter. Actual frequencies varied slightly from nominal because available commercial pulley sizes did not exactly match desired sizes, and because motor rpm decreased with increasing load.

Initial tests of the motor-generator were made using a rheostat to control the field current of the generator. The generator output was found to drift more than could be tolerated. In order to improve the stability of the output, a controller with feedback was added. Figure 12 is a block diagram of the controller. The loop current is sensed with a current transformer and fed through an ac-dc converter and a filter that establishes the controller's time constant. The difference between the input from this current sensor and the manually adjusted set point is 


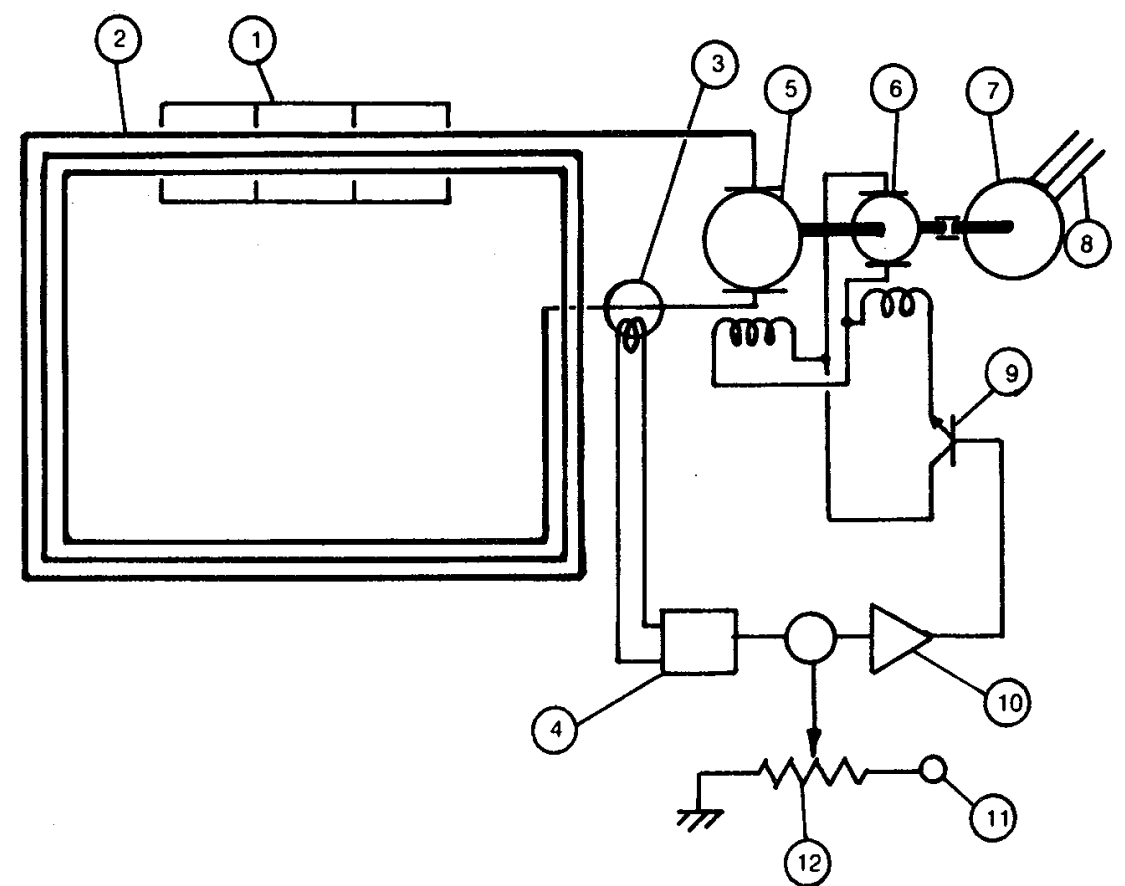

XBL $786-9047$

Figure 12. Block diagram of controller for loop current: 1. Source cores; 2 . Source conductor loop; 3. Current transformer; 4. AC-DC converter; 5. Generator; 6. Exciter; 7. Motor; 8. $220 \mathrm{~V}, 60 \mathrm{~Hz}$; 9. Output transistor; 10 . Proportional gain amplifier; 11 . Reference voltage; 12. Current control (manually set).

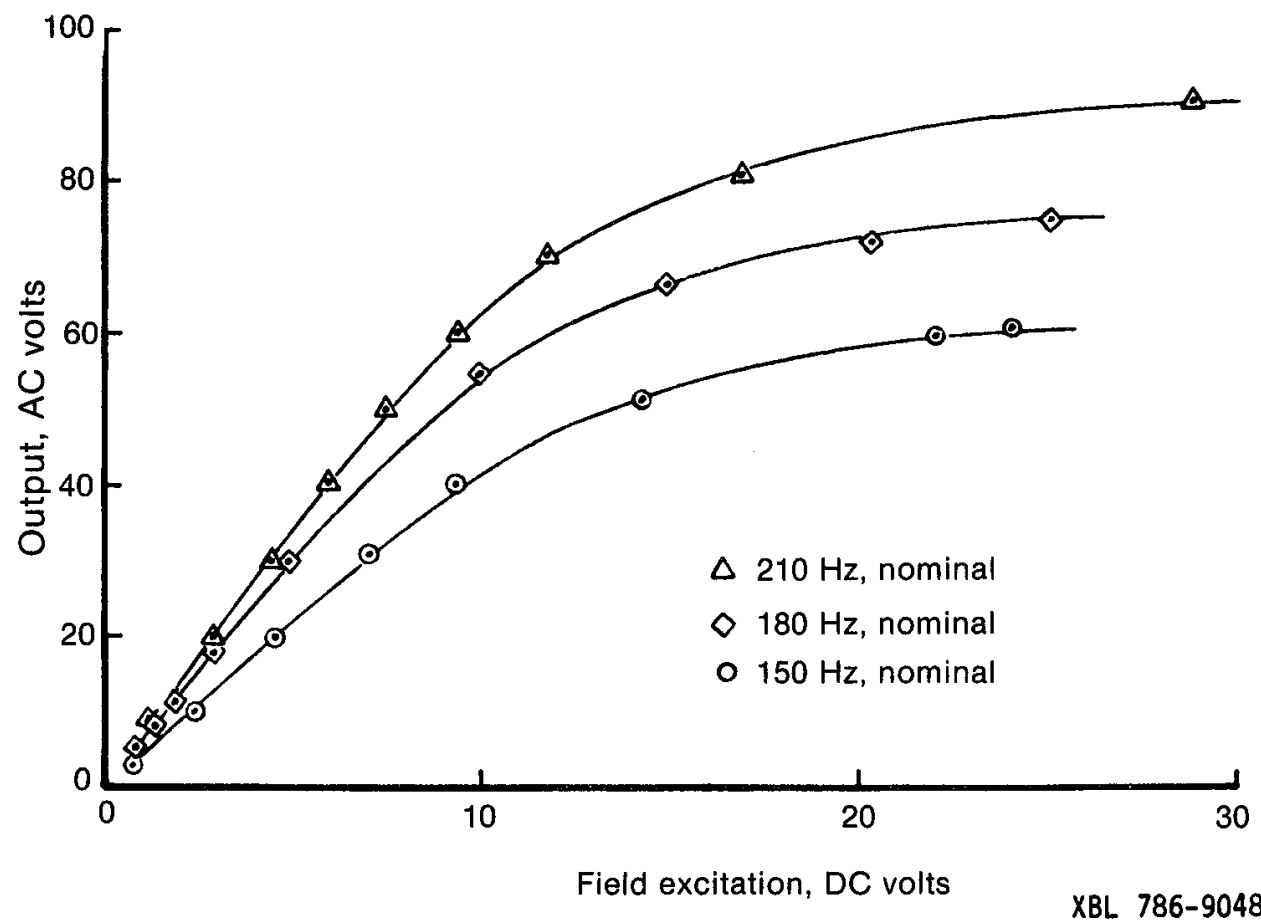

Figure 13. Generator voltage output vs field excitation voltage. 
amplified by a proportional gain amplifier. The amplifier drives the output transistor that is used to control the exciter field. With the loop gain of the controller set at approximately 100 , and the generator voltage at midrange (about $30 \mathrm{~V}$ ), the power supply was tested for about an hour with no appreciable drift.

Plots of generator output voltage vs (dc) excitation for three frequencies are shown in Figure 13. The output becomes nonlinear with excitation voltages above $7 \mathrm{~V}$.

\section{B. Magnetic Force Tests}

The objective of these tests was to determine the magnitude of the magnetic forces on the pickup. These forces are of concern because they could influence the handling and ride quality of the vehicle to which the pickup is attached and the structural requirements for the pickup's suspension.

Figure 11 shows the arrangement of the three force gages that were used to measure vertical forces in the three stainless steel straps that suspended the pickup tray. The gages supported mass loads of approximately $50 \mathrm{~kg}$; the hysteresis band of the gages approximated $\pm 1 / 2 \mathrm{~kg}$ or about $2 \%$ of total load. The dials of the gages were set to zero before power was applied. Thus gage readings represented only the magnetic forces on the pickup. The hysteresis band of the gages represented a much higher fraction of the magnetic force measured by each gage $(5 \mathrm{~kg}$ maximum), since the magnetic forces were a small part of the total load on the gages.

Figure 14 shows plots of vertical force on the pickup vs coupled voltage. Magnetic forces are a function of coupled magnetic flux. Induced voltage is directly related to coupled flux,

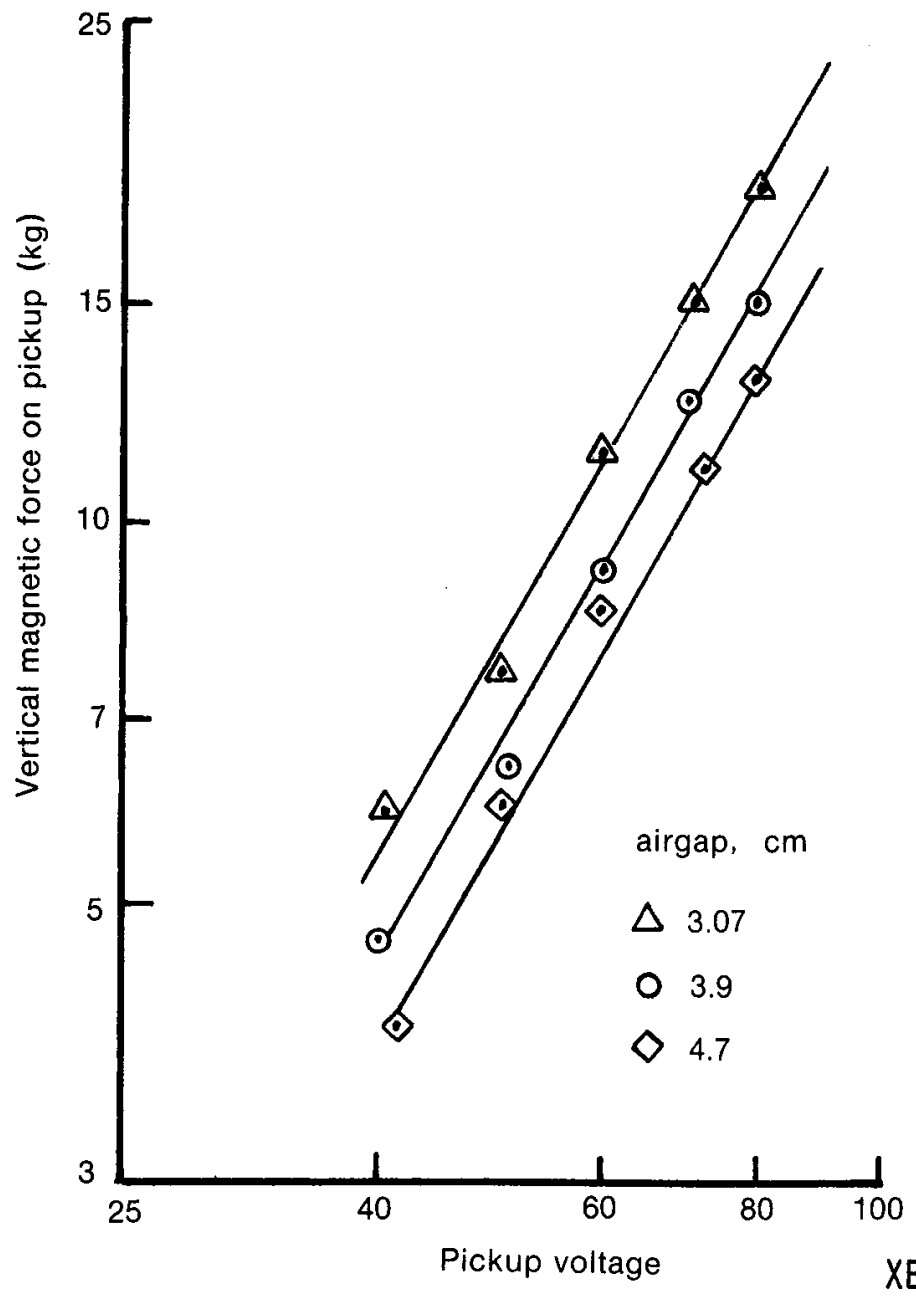

XBL 786-9049

Figure 14. Vertical magnetic force on pickup at various airgaps vs pickup voltage. 
hence the forces are plotted vs voltage. When coupling $80 \mathrm{~V}$, with an airgap of $3.07 \mathrm{~cm}$, the vertical force is $18.4 \mathrm{~kg}$, or $23.9 \mathrm{~kg} / \mathrm{m}$ of pickup length. These conditions approximate maximum power coupling through an airgap slightly greater than nominal.

Figure 14 also shows the effect of increasing airgap on vertical forces. The effective pole area of the pickup would approximate that of the source poles (i.e., would be minimum) when the pickup is very close to the source. As the pickup is moved farther from the source, the effective pole area increases as the flux spreads out over all the available pickup pole area. This phenomenon results in decreasing flux density and magnetic forces, as the airgap increases.

Horizontal forces occur that tend to pull the pickup to a centered position when the pickup is offset from the source below it. These forces were determined by mounting the pickup selected distances off center as it rested in its supporting tray, then measuring the force required to move the pickup tray away from the horizontal stops in the direction of the increasing offset. The pickup tray was suspended by three thin stainless steel straps. This suspension introduced a minimum of frictional hysteresis. The horizontal force was measured with a mechanical force gage that acted on the side of the pickup tray.

Figure 15 indicates that the horizontal forces are maximum at an offset of $8 \mathrm{~cm}$ when $80 \mathrm{~V}$ are coupled. The maximum magnitude is shown to be about $3.5 \mathrm{~kg}$, or $4.5 \mathrm{~kg} / \mathrm{m}$ of pickup length.

The curves show a change in shape as offset exceeds $8 \mathrm{~cm}$. This indicates that the distribution of flux and flux density in the cores is affected by the offset and that ampere turns must be added to the coupling to compensate for increased reluctance as pickup offset is increased.

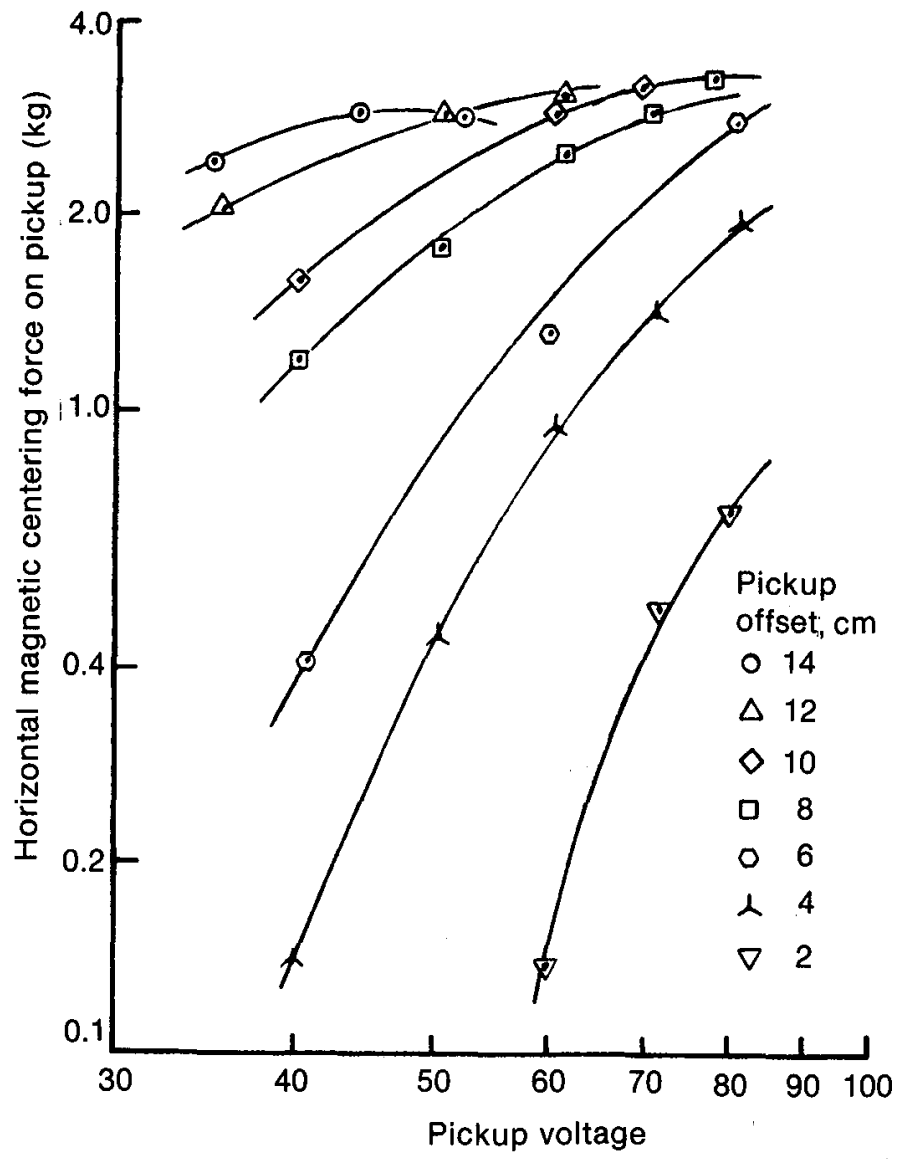

XBL 786-9050

Figure 15. Horizontal magnetic centering force on pickup at various offsets vs pickup voltage. 


\section{Electrical Tests}

The schematic of the prototype, including the instruments used for these tests, is shown in Figure 4. These instruments were used to derive the electrical characteristics of the coupling and to measure losses throughout the prototype system.

The effects on instruments of fringing magnetic fields from the loop conductors required continuous careful attention. Voltage, current, and power meters were accurate to $1 / 2 \%$. However, when current and potential transformers were added in order to adapt meters to the needed ranges, the overall accuracy was decreased. Wattmeters were often used to measure power at very low power factors; this increased the possible wattmeter errors to more than $5 \%$.

\section{ELECTRICAL CHARACTERISTICS OF THE COUPLING PROTOTYPE}

Conventional transformer testing techniques were used to determine characteristics of the coupling. Figure 16 is a loss reconciliation schematic of the prototype coupling system.

$$
\begin{aligned}
& \text { (G) } \\
& \text { Symbols } \\
& I_{s} \text { - source current } \\
& \text { 'L - load current } \\
& I_{C} \text { - pickup capacitor current } \\
& v_{i} \text { - input voltage } \\
& v_{p} \text { - pickup output voltage } \\
& V_{c} \text { - pickup capacitor voltage } \\
& V_{L} \text { - pickup load voltage } \\
& R_{S} \text { - source conductor resistance } \\
& R_{p} \text { - pickup conductor resistance } \\
& R_{L} \text { - load resistance } \\
& P_{L}-\text { load power } \\
& P_{i} \text { - input power } \\
& P_{S} \text { - loop conductor power loss } \\
& P_{C} \text { - loop capacitor power loss } \\
& P_{f} \text { - pickup and source core power loss } \\
& P_{r} \text { - pickup capacitor power loss } \\
& P_{p} \text { - pickup conductor power loss } \\
& R_{C} \text { - source capacitor resistance } \\
& R_{f} \text { - effective core loss resistance } \\
& C_{L} \text { - loss coefficient, pickup capacitors } \\
& L_{S} \text { - source loop inductance } \\
& \mathrm{L}_{\mathrm{p}} \text { - pickup inductance } \\
& \mathrm{C}_{\mathrm{S}} \text { - source capacitance (millifarad) } \\
& \mathrm{C}_{\mathrm{p}} \text { - pickup capacitance } \\
& P_{i}=P_{L}+P_{C}+P_{S}+P_{f}+P_{r}+P_{p} \\
& \text { where } \\
& P_{C}=V_{i}^{2} C_{S} / R_{C}=V_{i}^{2} C_{S} / 21.3 \\
& P_{S}=I_{S}^{2} R_{S}=I_{S}^{2} \times 0.020 \\
& P_{f}=V_{p}{ }^{2} / R_{f}=V_{p}{ }^{2 / 5.74} \\
& P_{r}=V_{C}{ }_{C} C_{L}=V_{C} I_{C}(0.024-0.19) \\
& P_{p}=I_{L}{ }^{2} R_{P}=I_{L}{ }^{2} \times 0.00746
\end{aligned}
$$

Figure 16. Loss reconciliation schematic of the prototype system. 


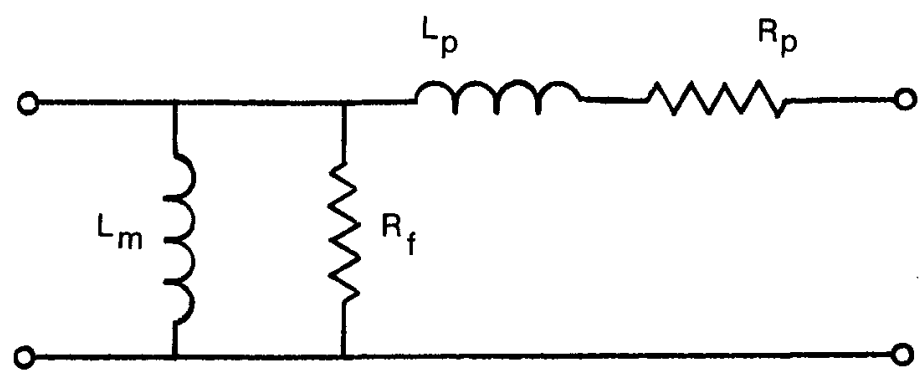

Figure 17. Equivalent circuit of the power coupling.

XBL $786-9177$

Figure 17 is an equivalent circuit of the coupling with all parameters normalized to a singleturn equivalent. Circuit parameters can be separated into three groups. Inductances describe the magnetic characteristics of the coupling. Equivalent resistances are used to describe losses in conductors, capacitors, and cores. Capacitances shown in Figure 16 are used to compensate inductive reactances in the coupling. Effects of each circuit parameter are discussed below to show their interrelationship under various conditions.

\section{Inductances*}

Mutual Inductance $\mathrm{L}_{\mathrm{m}}$. Mutual inductance is a measure of the magnetic coupling between source and pickup. It is calculated from the open circuit pickup voltage. Figure 18 is a plot of mutual inductance vs the offset of the pickup from a centered position. The relationship of mutual inductance to airgap is plotted in Figure 19. Mutual inductance decreases as the pickup is displaced from its centered position or as the airgap is increased. Figure 20 shows that mutual inductance is nearly independent of frequency in the range of 150 to $210 \mathrm{~Hz}$.

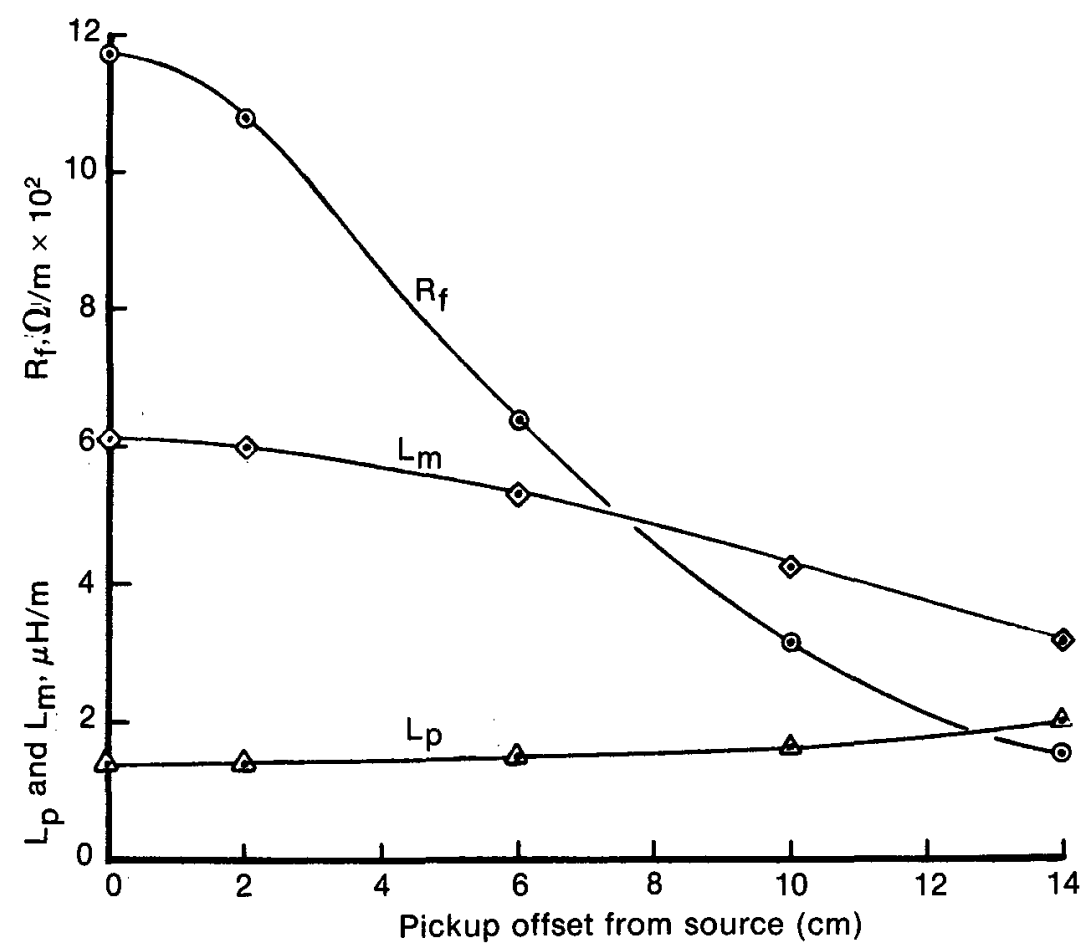

XBL $786-9178$

Figure 18. Electrical characteristics of the coupling vs pickup offset.

*Derivations for calculations are included in the Appendix. 


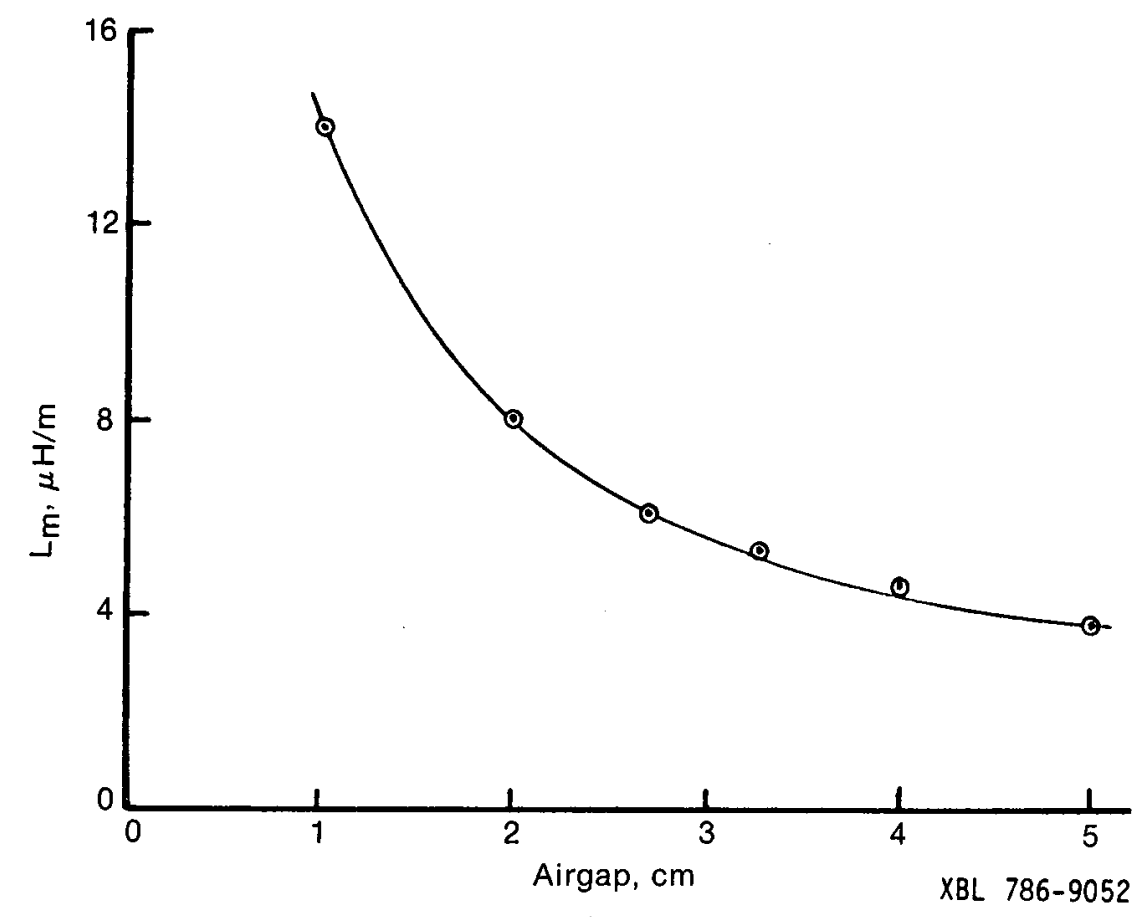

Figure 19. Mutual inductance of the coupling vs airgap.

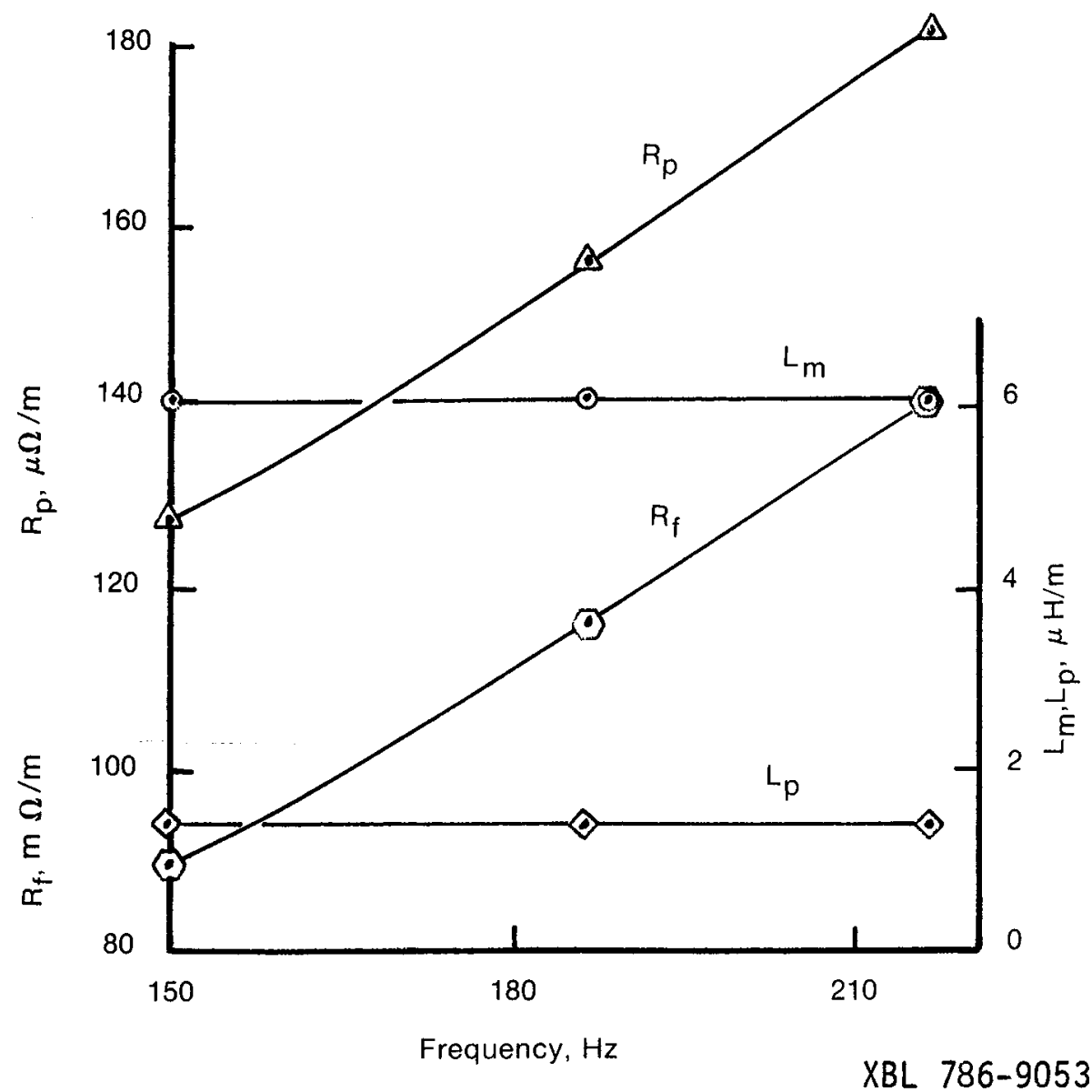

Figure 20. Electrical characteristics of the coupling vs frequency. 


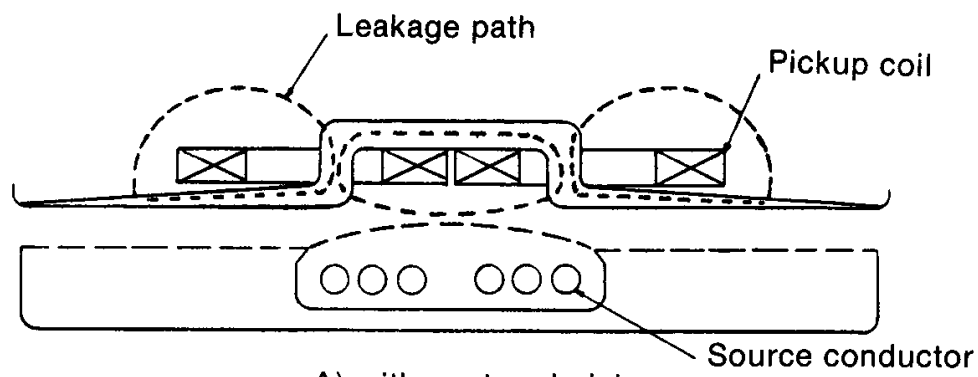

A) with centered pickup

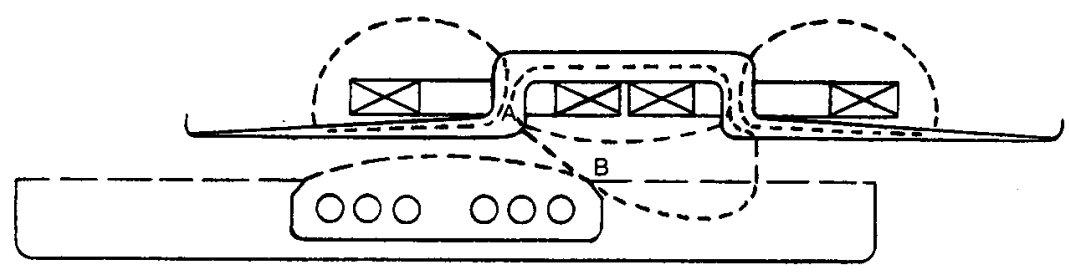

B) with offset pickup

XBL 786-9181

Figure 21. Schematic of the more significant magnetic leakage paths in the coupling.

Pickup Leakage Inductance $\mathrm{L}_{\mathrm{p}}$. This is the inductance of the magnetic flux that does not link the source conductor. It is calculated using data from short circuit tests of the pickup. There are several regions in the winding that contribute leakage flux, as schematically illustrated in Figure 21. The figure shows why the fraction of leakage flux increases as the pickup is offset from the source. The decreasing distance between points A and B results in an increasing amount of flux along that path (which does not link the source conductor); this is apparent from the plot of leakage inductance vs offset shown in Figure 18.

Loop Inductance $\mathrm{L}_{\mathrm{s}}$. This is the inductance of the loop of source conductor in an uncoupled condition. It is calculated from data from short-circuited pickup measurements. This inductance is assumed to be constant for all cases. It is of only limited use in extrapolating data for a full-scale roadway because of the large end effects of the short power source used in the prototype. For the same reason, the leakage inductance of the coupled source could not be determined exactly.

\section{Resistances}

Pickup Winding Resistance $R_{p}$. This is the ac resistance of the pickup coils. It was calculated from the power loss in the windings without the pickup core. Figure 20 shows the variation of $R_{p}$ with frequency. The increase in resistance with frequency results from the "skin effect," i.e., the tendency of alternating currents to seek the outer surfaces of conductors.

Core Loss Resistance $R_{f}$. Core loss is the sum of eddy current and hysteresis losses in the core steel. It is determined from measurements of power loss when the pickup is driven instead of the source. When this is done, magnetic flux circulates only through the coupled sections of source, and the accuracy of the core loss data is improved. As the pickup is offset with respect to the source, the number of effectively coupled source laminations decreases, and the flux density in those laminations increases. Core losses bear an exponential relationship to flux density, thus they increase significantly with offset. Figure 18 shows how the effective core loss resistance $R_{f}$ decreases with offset. Core loss is also related to frequency. Figure 20 is a plot of core loss resistance vs frequency, which shows that at constant output voltage, core loss decreases with increasing frequency, i.e., the core loss resistance increases. This is because less flux is required at higher frequencies to couple the same voltage. Although core losses increase rapidly with frequency for a given flux density, the reduction in the amount of flux (and flux density) that is required more than compensates for this effect. 
Source Conductor Resistance $\mathbf{R}_{\mathrm{s}}$. Resistive loss in the source conductor was determined from measurements of the power loss when there was no pickup coupled to the source. This loss can be assumed to be constant for all cases. It represents the largest loss in the prototype system. This loss was higher than would be the case in highway systems because of the small conductor cross section that was used (a total of $4 \mathrm{~cm}^{2}$ in the six $2 / 0$ cables). The current density in conductors would be much lower in the large conductor in highway systems.

Source Capacitor Circuit Resistance $\mathrm{R}$. The loss resistance of the source capacitor circuit was determined from measurements of the increased loss when capacitors were switched into the source loop circuit. It was assumed to be constant for all cases. This loss was found to be predominantly due to cable resistance and contact losses, rather than capacitor loss. This loss can be expected to be reduced in actual systems because of improved cabling and switches compared to the prototype.

Pickup Capacitor Circuit Resistance $\mathrm{R}_{\mathrm{r}}$. The loss in the pickup capacitor circuit is relatively small and nonlinear. Instead of representing this loss with a fixed resistance, a loss coefficient for different capacitances and voltages was determined for use in computing the losses. This loss also consists predominantly of cabling and contact losses.

\section{LOSS RECONCILATIONS}

Figure 16 is a loss reconciliation schematic of the prototype system, together with the equations that describe the losses in its components. Losses for three tests are shown in Table II. The tests were run at the approximate full power rating of the coupling. Differences

Table II. Power reconciliations

\begin{tabular}{|c|c|c|c|}
\hline & Case I & Case II & Case III \\
\hline Input voltage $v_{i}(V)$ & 62.9 & 61.5 & 61.2 \\
\hline Source current $\mathrm{I}_{\mathrm{s}}(\mathrm{A})$ & 320.6 & 319.5 & 300.3 \\
\hline Load voltage $V_{L}^{s}(V)$ & 89.2 & 89.8 & 96.2 \\
\hline Load current $I_{L}$ (A) & 90.4 & 91.7 & 84.6 \\
\hline Pickup capacitance voltage $V_{c}(V)$ & 297.1 & 298.9 & 318.3 \\
\hline Pickup capacitance current $I_{c}(A)$ & 71.7 & 71.6 & 76.7 \\
\hline Source capacitance circuit loss, $P_{c}(W)$ & 556 & 532 & 527 \\
\hline Source conductor loss $P_{L}$ (W) & 2060 & $20+2$ & 1804 \\
\hline Core losses $P_{f}(W)$ & 962 & 514 & 729 \\
\hline Pickup conductor loss $P_{p}(W)$ & 61 & 63 & 53 \\
\hline Pickup capacitance circuit loss $P_{r}(W)$ & 510 & 514 & 586 \\
\hline \multirow{3}{*}{ Power output $\mathbf{P}_{\mathbf{L}}$} & 4,138 & 3,665 & 3,699 \\
\hline & 7,970 & 8,070 & 8,000 \\
\hline & 12,108 & 11,735 & 11,699 \\
\hline Power input $\mathbf{P}_{\mathrm{i}}$ & 11,900 & 11,700 & 11,540 \\
\hline Unaccounted for & $308(1.7 \%)$ & $35(0.3 \%)$ & $159(1.4 \%)$ \\
\hline \multicolumn{4}{|l|}{ Test conditions } \\
\hline Pickup position & centered & centered & centered \\
\hline Source core & $\begin{array}{c}\text { original } \\
\text { design }\end{array}$ & $\begin{array}{l}\text { revised } \\
\text { design }\end{array}$ & $\begin{array}{l}\text { revised } \\
\text { design }\end{array}$ \\
\hline Pickup core laminations & 40 & 43 & 43 \\
\hline Capacitance, pickup circuit & $210 \mu \mathrm{F}$ & $210 \mu \mathrm{F}$ & $210 \mu \mathrm{F}$ \\
\hline Pickup load resistance & $0.99 \Omega$ & $0.96 \Omega$ & $1.12 \Omega$ \\
\hline Airgap & $2.7 \mathrm{~cm}$ & $2.7 \mathrm{~cm}$ & $2.7 \mathrm{~cm}$ \\
\hline Frequency (approx.) & $178 \mathrm{~Hz}$ & $178 \mathrm{~Hz}$ & $178 \mathrm{~Hz}$ \\
\hline
\end{tabular}




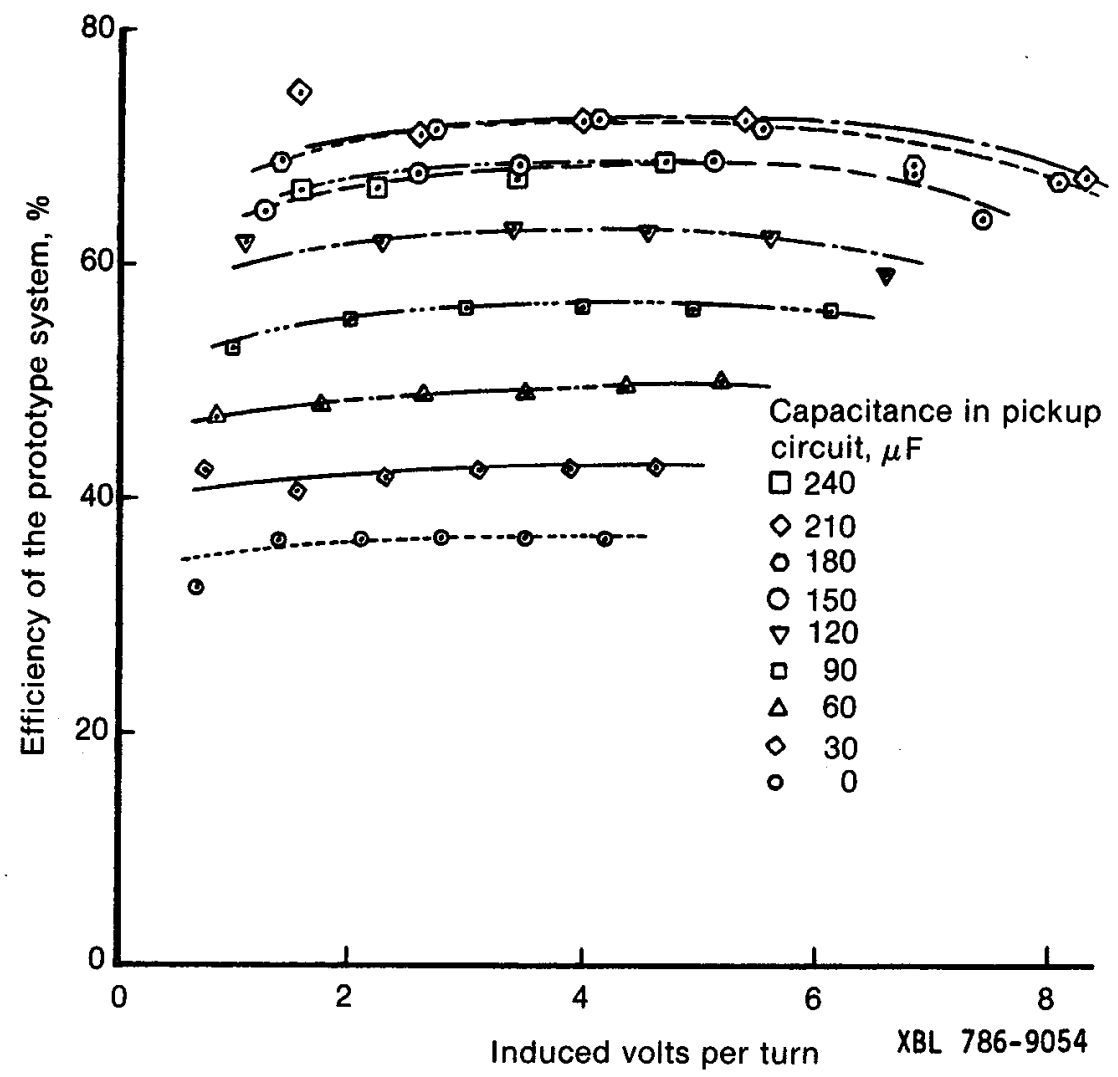

Figure 22. Prototype system efficiency vs induced volts per turn in coupling with various capacitances in the pickup circuit.

in the tests include the effects of modifications that were made in the pickup core to reduce core losses. The sum of all the losses and output power are slightly more than the input power. The difference is within the magnitude of probable instrument errors.

Figure 22 is a plot of the prototype system efficiency vs induced voltage (i.e., induced volts/turn) with different capacitive loadings on the reactance winding of the pickup.

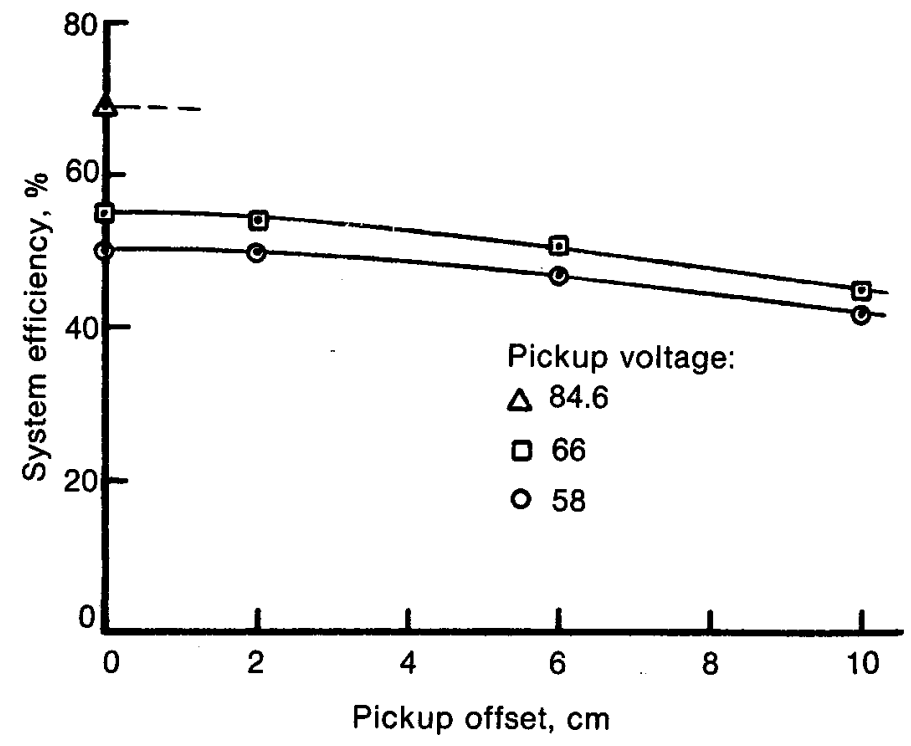

Figure 23. Prototype system efficiency vs pickup offset. 
Note that the efficiency is slightly dependent on voltage and strongly dependent on the amount of capacitance.

Improving the impedance match between source and pickup reduces the induced source voltage for the same output voltage, so that both the core loss and the source capacitor loss are minimized.

Efficiency vs pickup offsets are plotted in Figure 23. Two curves for constant pickup output voltages of $58 \mathrm{~V}$ and $66 \mathrm{~V}$ are shown for offsets from 0 to $10 \mathrm{~cm}$. Efficiencies range from $42 \%$ to $54 \%$ with power output levels of $2.5 \mathrm{~kW}$ to $3.23 \mathrm{~kW}$. With no offset, a pickup voltage of $84.6 \mathrm{~V}$, and $8.0 \mathrm{~kW}$ output power, the efficiency was $69.3 \%$. Higher efficiencies of up to $72 \%$ have been obtained at lower source currents of 450 amp-turns and corresponding lower pickup voltages.

\section{CONTROLLABILITY OF COUPLED POWER}

The power transferred through the coupling can be regulated by varying the capacitive reactance in the pickup circuit. This is of particular significance to the potential use of the coupling in transportation systems, where the varying power requirements of a number of vehicles coupled to a common section of power source can be controlled by each vehicle.

Tests were made to determine the relationship between capacitance and output voltage. Figure 24 shows the test results. In this case, a resistive load was used, so coupled power was proportional to the square of output voltage. Some of the data used in constructing this plot were normalized from data for other operating conditions. These data were used to determine the shape of the curve and are not shown in the plot. This curve shows that the output voltage could be changed from 36 to $100 \mathrm{~V}$ by varying the pickup capacitance.

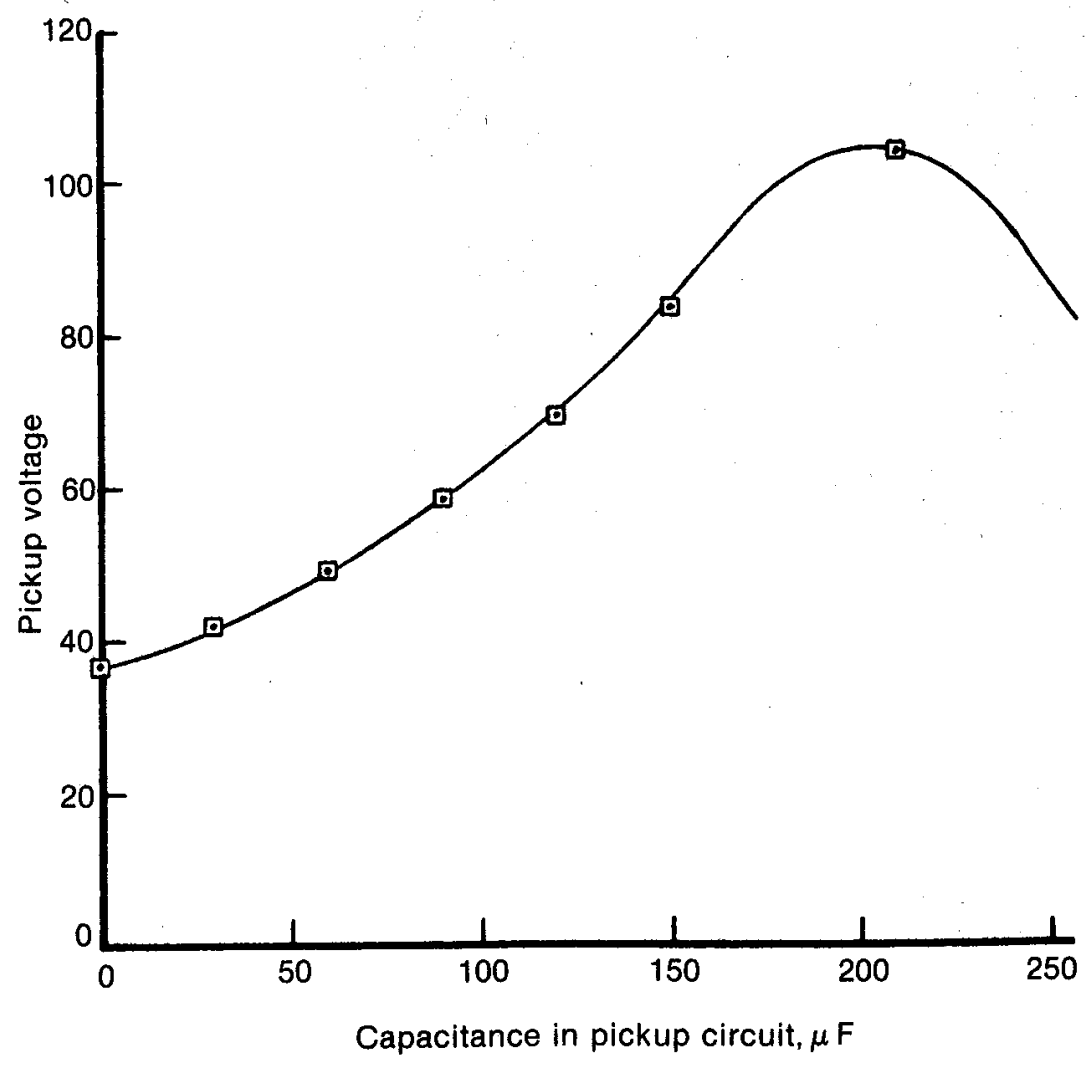

XBL 786-9182

Figure 24. Pickup voltage vs capacitance in pickup circuit. 


\section{CHARACTERISTICS OF A BATTERY CHARGING LOAD}

The coupling was used to charge a lead-acid battery pack consisting of $12,6-\mathrm{V}$ batteries in series, i.e., a $72-\mathrm{V}$ pack. The circuit, shown in Figure 25, was designed to simulate the operation of an electric vehicle's power system. The $1.3 \Omega$ resistance simulated the propulsion load of a vehicle traveling on a powered roadway. The battery pack could be charged in parallel with this load, thus simulating the ability of a "dual mode" vehicle to recharge its battery pack as it travels on a powered roadway.

Photographs of oscilloscope traces of current and voltage waveforms during battery charging cycles are also shown in Figure 25. These waveforms are similar to those typical of full-wave battery chargers. The conduction angle is a function of the ac voltage and the battery voltage. The voltage drop through the pickup circuit, and the voltage regulation of
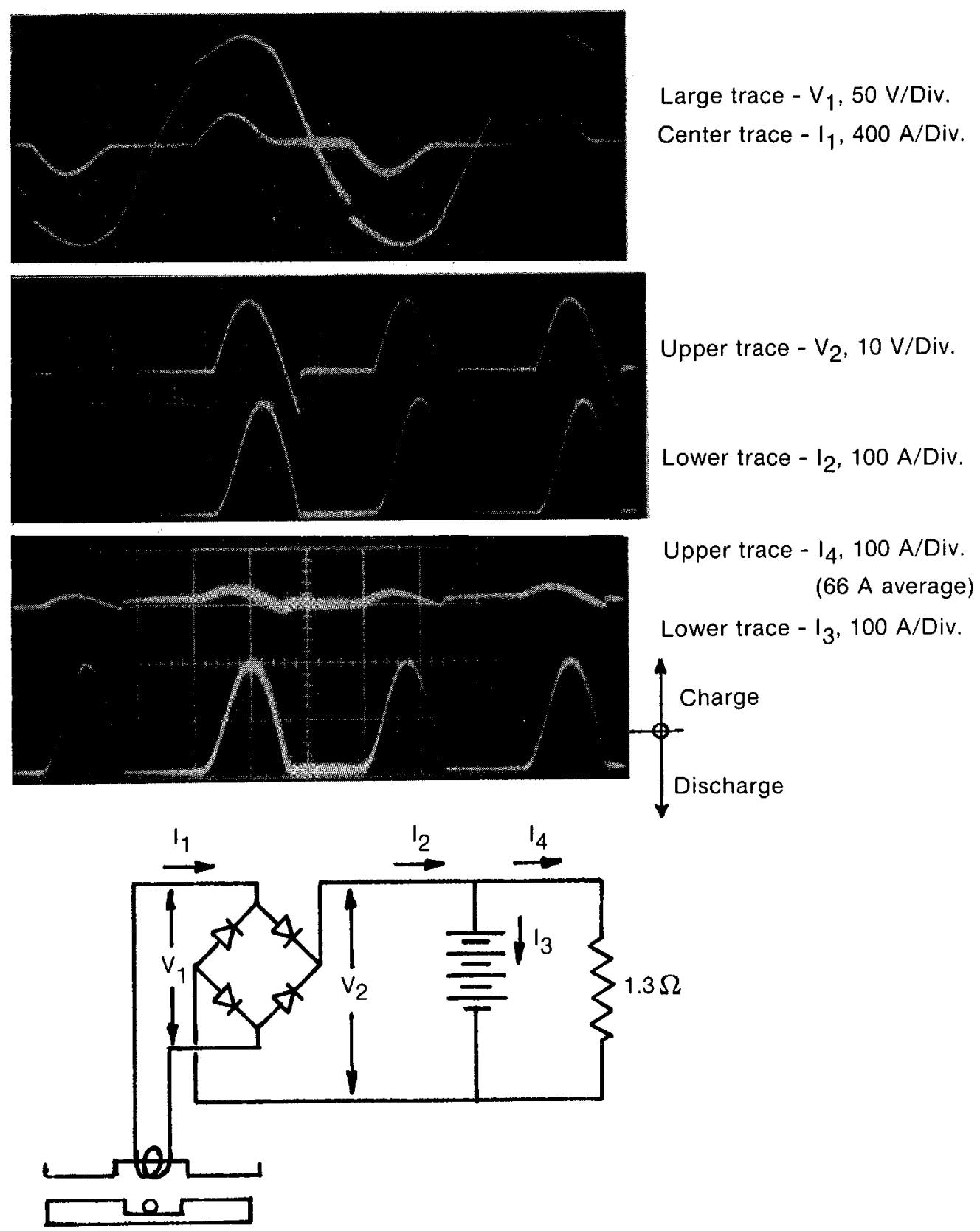

Figure 25. Battery charging current and voltage waveforms, and circuit schematic. 
the coupling, lowered the peaks of the ac voltage, and thus limited the peak charging current as shown in photograph $\mathrm{A}$. The inductance of the long battery cables delayed the turnoff of the rectifier diodes, and allowed voltage $\mathrm{V}_{2}$ at the rectifier output to drop below battery voltage. This is seen as a voltage spike in the upper trace of photograph B.

The lower trace of photograph $\mathrm{C}$ shows the battery current waveforms. The flat-bottomed portions of the waveforms show current being supplied to the load from the battery at constant battery voltage. The cyclic peaks are contributed by the power coupling; the battery is charged during these peaks because the coupled voltage exceeds the nominal battery voltage.

\section{Magnetic Measurements}

The purpose of these preliminary measurements was twofold. First, as an aid in analyzing the power coupling process between the source and the pickup, and second, as a guide for developing methods for making more precise measurements in the future.

Rough measurements of two components of the magnetic field in the vertical plane of symmetry were made at several elevations. Measurements were made with the source uncoupled (i.e., without the pickup), with the source coupled to a pickup, and with a 22 gage $(0.75 \mathrm{~mm}$ thick) steel sheet (simulating the floor pan of an automobile) $23 \mathrm{~cm}$ above the source.

A flux plot was made using measured data from tests of an uncoupled source.

Figure 10 shows the rack-mounted instrumentation used for these measurements. A table of the specific instruments used is included in the Appendix.

Field measurements were made with two Hall-effect probes and a "point coil." The use of the two types of transducers was an aid to checking calibrations. Fields were mapped with the use of a probe positioner that provided an electrical analog output relating to probe position. Figure 26 shows details of the construction of the positioner assembly and Figure 27 is a schematic of the positioner and related instruments.

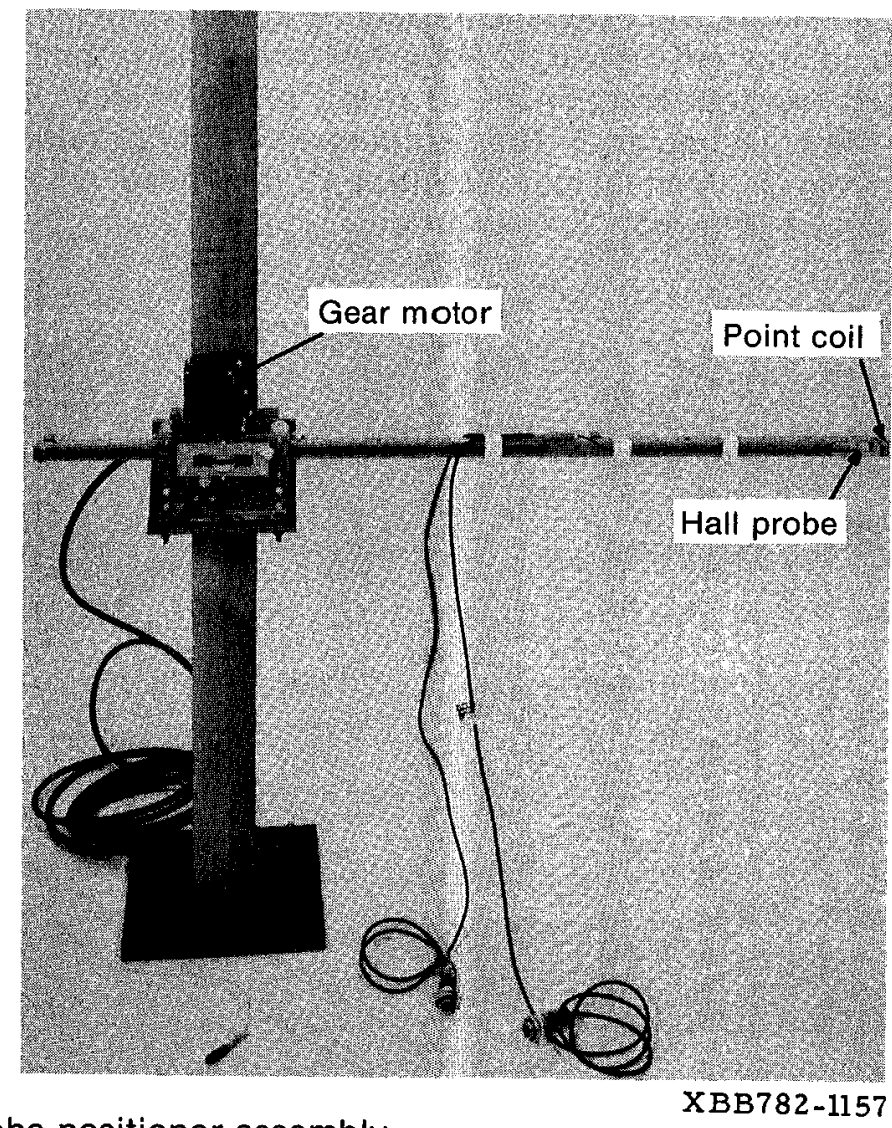

Figure 26. Probe positioner assembly. 
The flux in selected core laminations or groups of laminations was determined by wrapping coils of magnet wire around them. The voltage output of the coil is a function of the total flux in the section circumscribed by the coils.

Figure 33 shows the peak flux density in the laminations of the source and pickup cores with the pickup centered over the source. The source core in this plot contained 46 laminations, three more than the $\mathbf{4 3}$ that were in the core as originally constructed. A region of low flux density is apparent in the sixth through the fifteenth laminations. These laminations were more closely spaced than the rest in an attempt to compensate for expected flux concentrations when the pickup is not centered above the source. The data indicate that the compensation was excessive, i.e., the flux density in these laminations is lower than necessary under all conditions of offset.

The figures also show a considerable random variation in flux density between laminations. Small differences in lamination height (i.e., airgap) and lamination-to-lamination spacing are responsible for these variations.

Figure 34 shows the peak flux distribution in the coupled source core before and after the three extra laminations were added. The flux density in the original outer lamination was

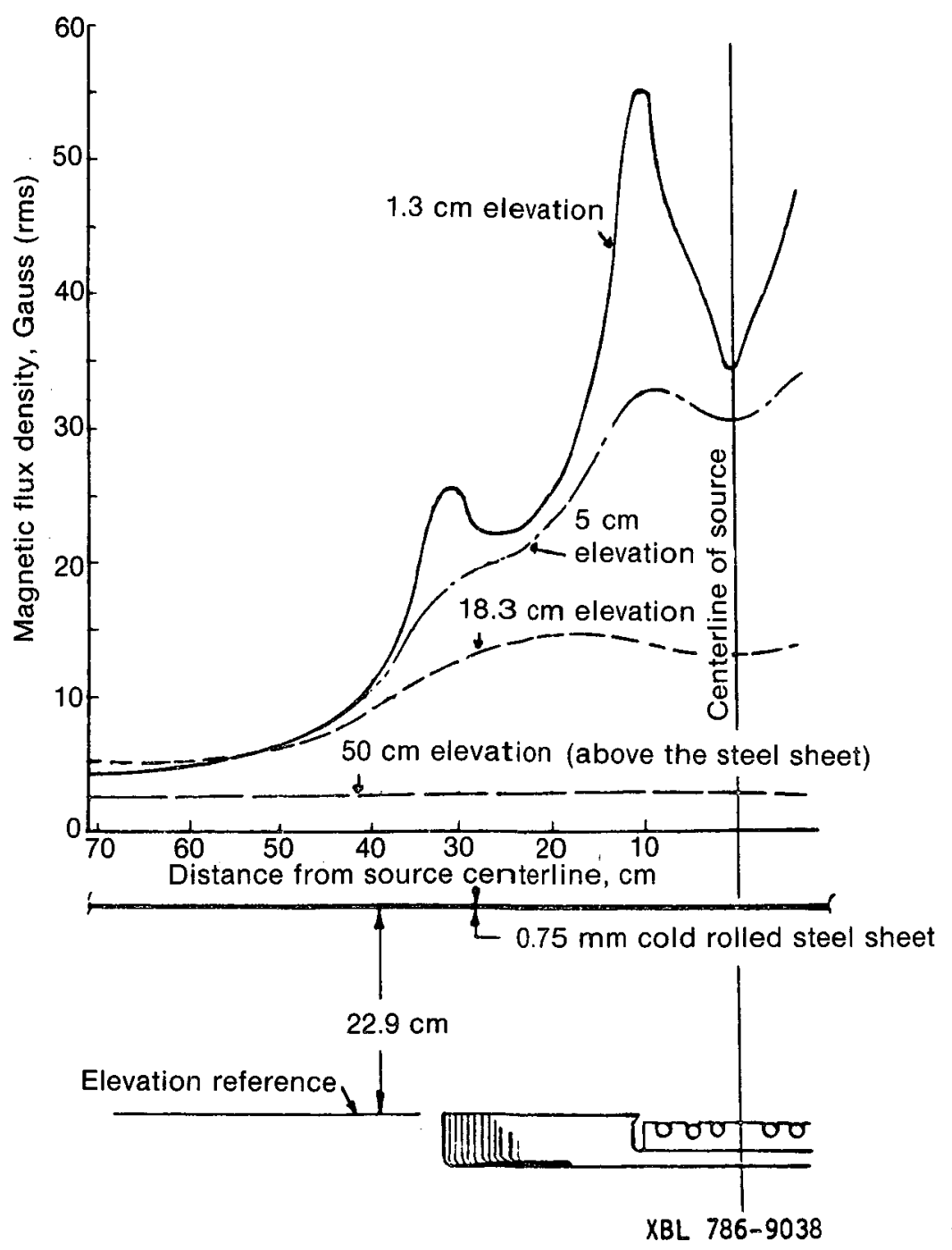

Figure 32. Magnetic flux density with a steel sheet over the source vs distance from the souce centerline, at various elevations. 
more than twice that in other laminations. The three added laminations alleviated the flux concentration that was caused by the entry of flux into the sides of the source core. The variation in density in the three added laminations was lessened by increasing their heights progressively from the outermost to innermost of the three laminations.

Another region of high flux density is shown in Figure 35 in the pickup core. At this point there were originally two laminations that were found to be overloaded by flux entering the vertical flanges and upper surface near the edges of the pickup core. Figure 35 shows the comparative flux distribution before and after three laminations were added. The altered flux distribution is seen to be relatively uniform.

Figures 36 and 37 show the flux distribution in both the source and the pickup cores (before laminations were added to the pickup), when the pickup is offset from the source by

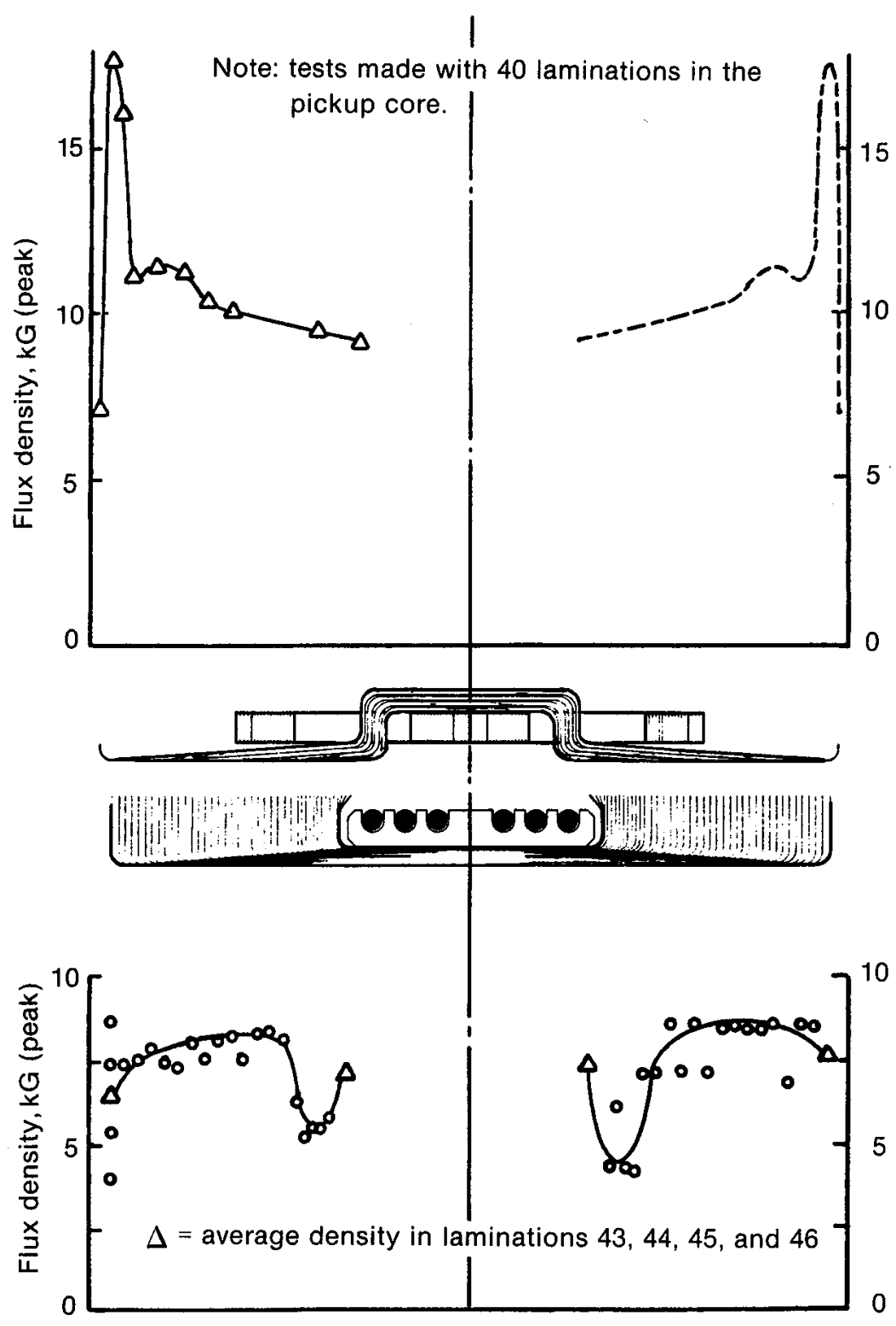

XBL 786-9039

Figure 33. Magnetic flux density in source and pickup core laminations with centered pickup. 


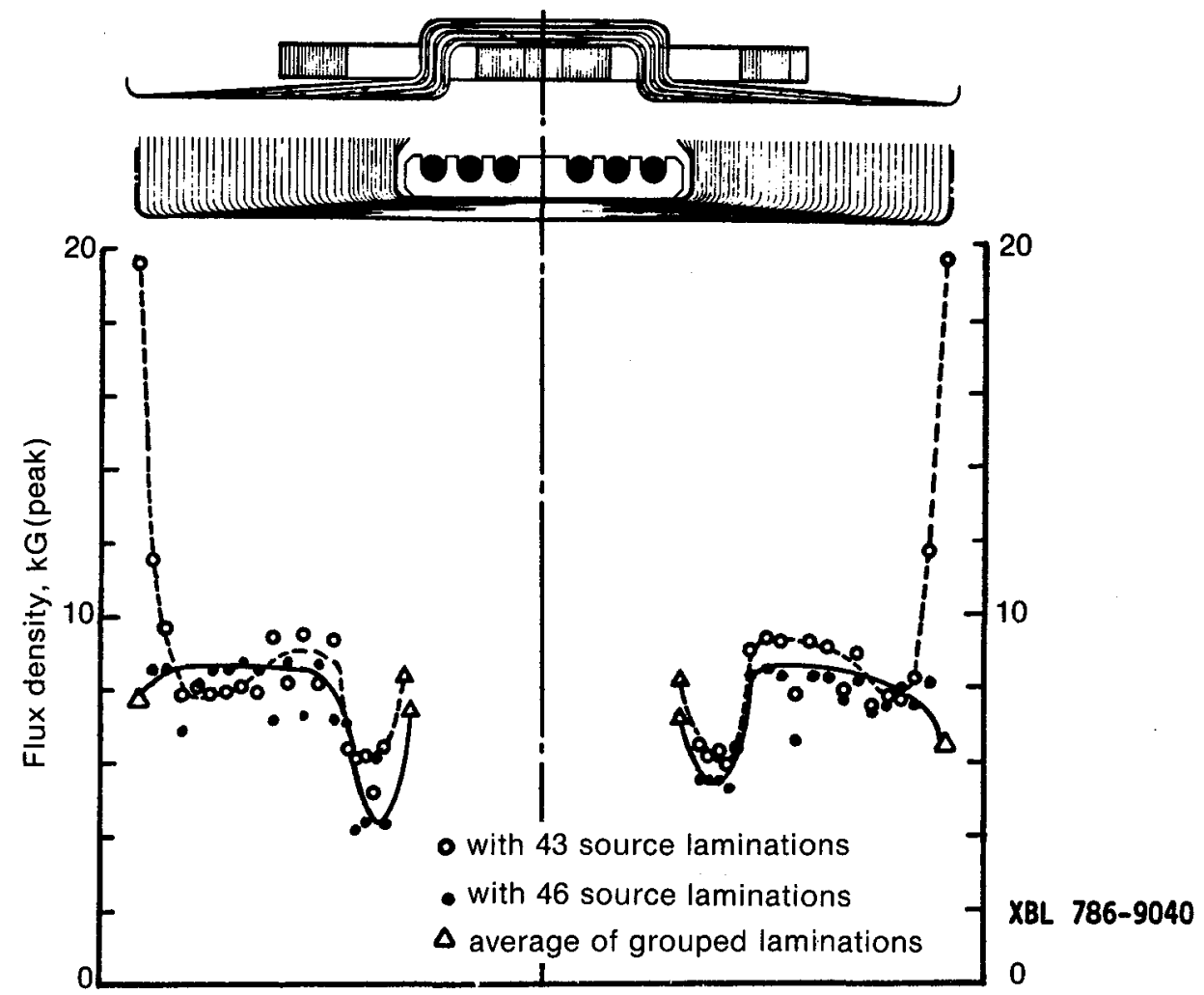

Figure 34. Magnetic flux density in source laminations with centered pickup, before and after adding extra laminations.

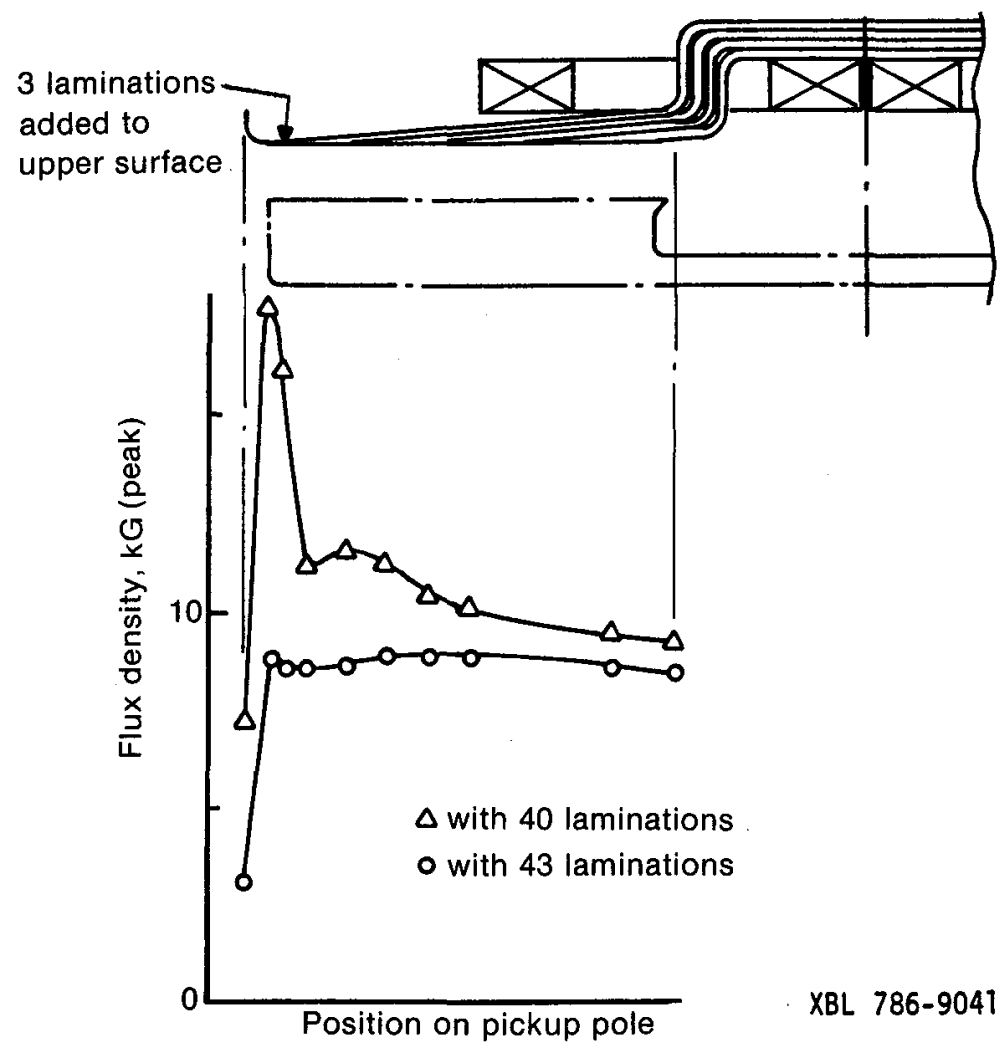

Figure 35. Magnetic flux density in pickup core laminations before and after adding extra laminations. 
4 and $8 \mathrm{~cm}$, respectively. The curves do not represent exactly the same conditions because of the limited increments of available pickup voltage control; however, the curve shapes are indicative of how the flux is distributed.

Figure 38 shows the flux density in laminations of the source without a pickup present, i.e., uncoupled. Although the inner and outer laminations are much more heavily loaded than the others, the maximum density is only $2.1 \mathrm{kG}$.

The source core was designed to be filled with grout (i.e., mortar) or similar material in order to create a durable and rugged surface with frictional characteristics similar to concrete for automobile tires to run on. It was felt that some magnetic permeability in the region nearest the pole surfaces would be of value in evening out variations in flux density in laminations and in decreasing the reluctance of the magnetic circuit.

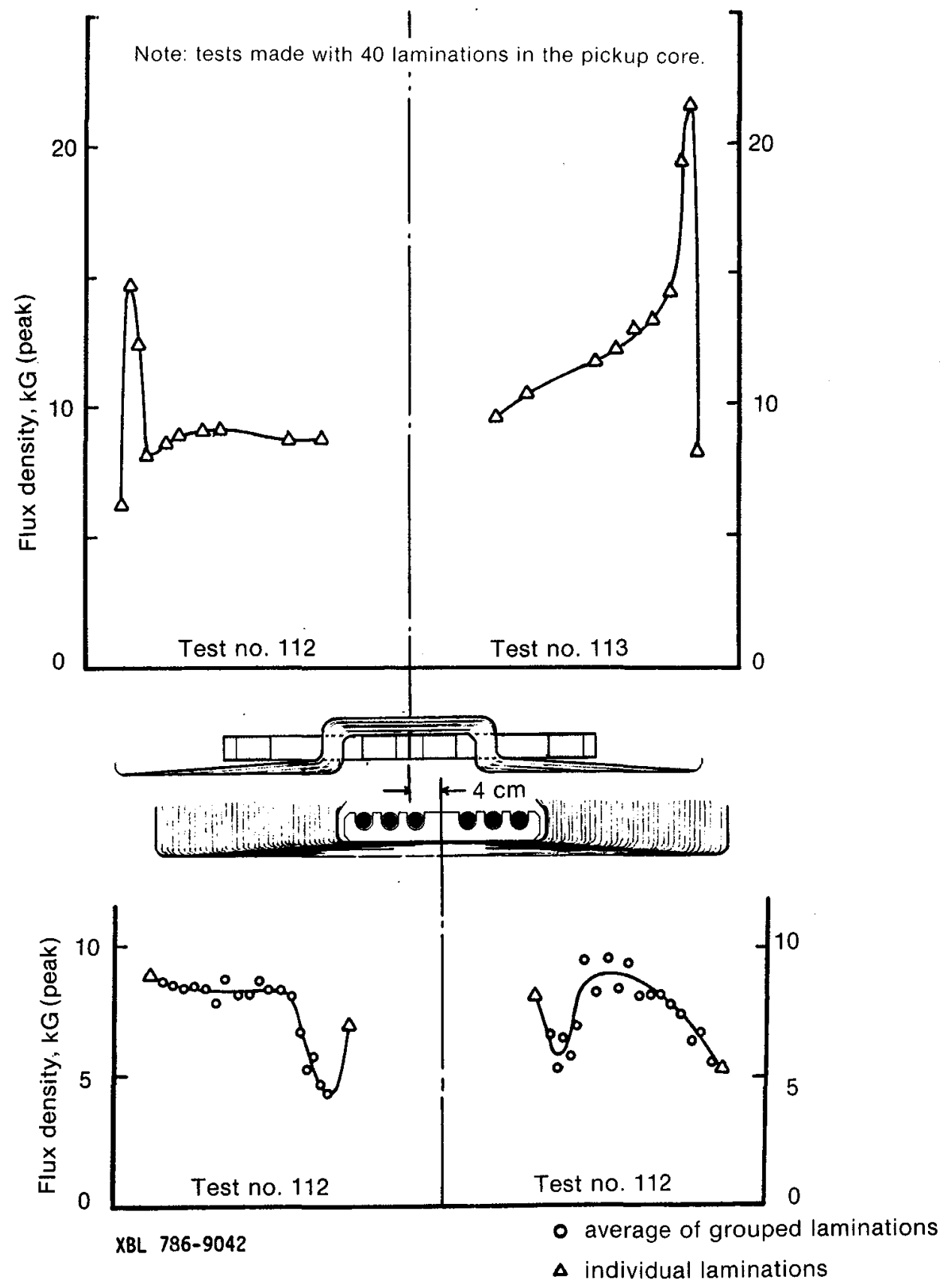

Figure 36. Magnetic flux density in source and pickup core laminations with $4 \mathrm{~cm}$ offset of pickup. 
The middle of the three source core sections was filled with magnetite $\left(\mathrm{Fe}_{3} \mathrm{O}_{4}\right)$ powder to assess the validity of this hypothesis. Figure 39 shows the results of this test. The variation in flux density in laminations is shown to have been reduced significantly. The reluctance of the magnetic circuit also decreased by approximately $8 \%$ (the data used for developing Figure 39 were for two tests with slightly different total flux in the core).

A modified source core was designed and constructed using the data above. Figure 40 shows that the flux distribution in this core design is more uniform than the original design.

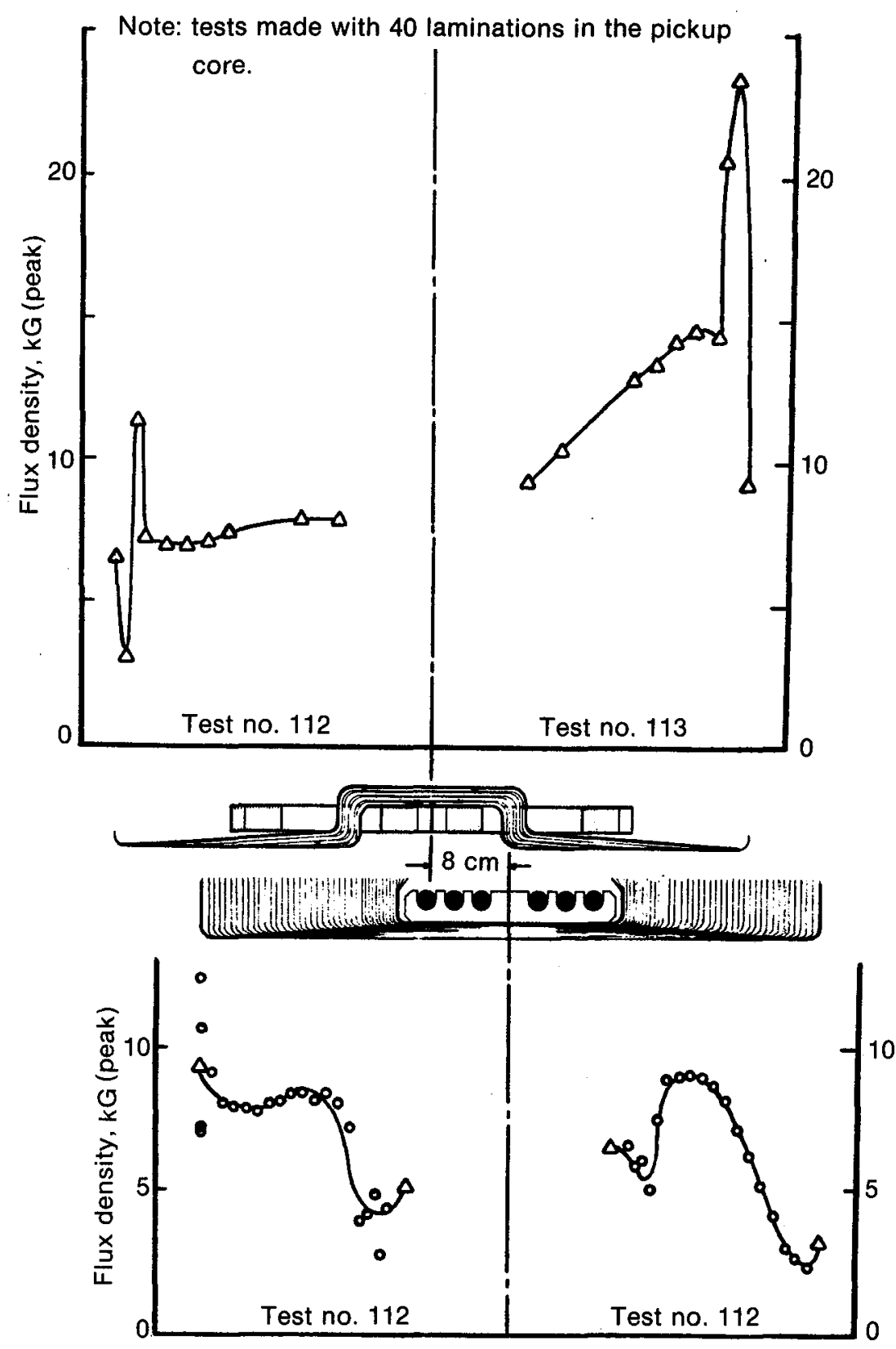

XBL 786-9042A

- flux density in individual laminations

$\Delta$ average flux density in grouped laminations

Figure 37. Magnetic flux density in source and pickup core laminations with $8 \mathrm{~cm}$ offset of pickup. 

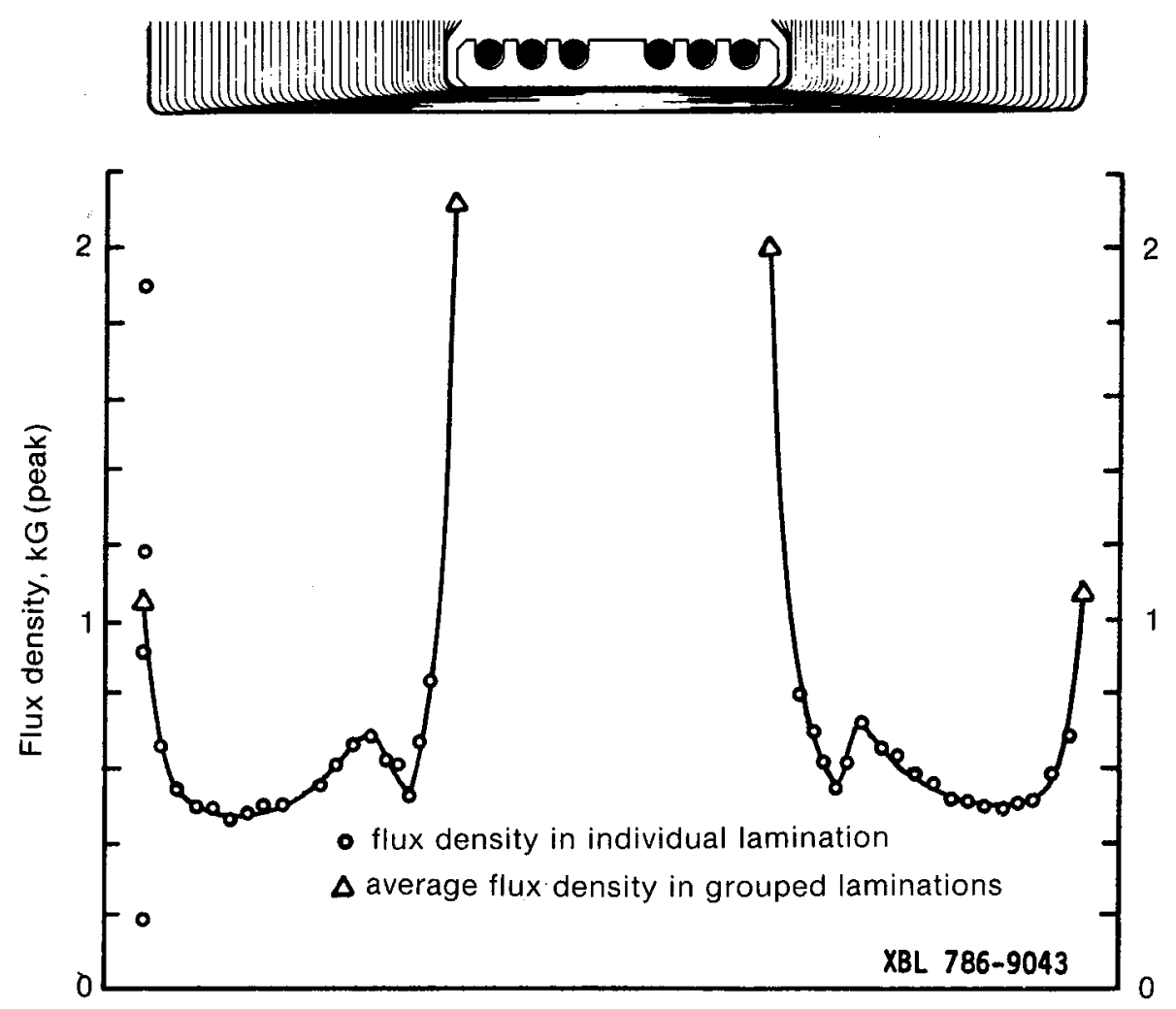

Figure 38. Magnetic flux density in source core laminations without presence of pickup (uncoupled).

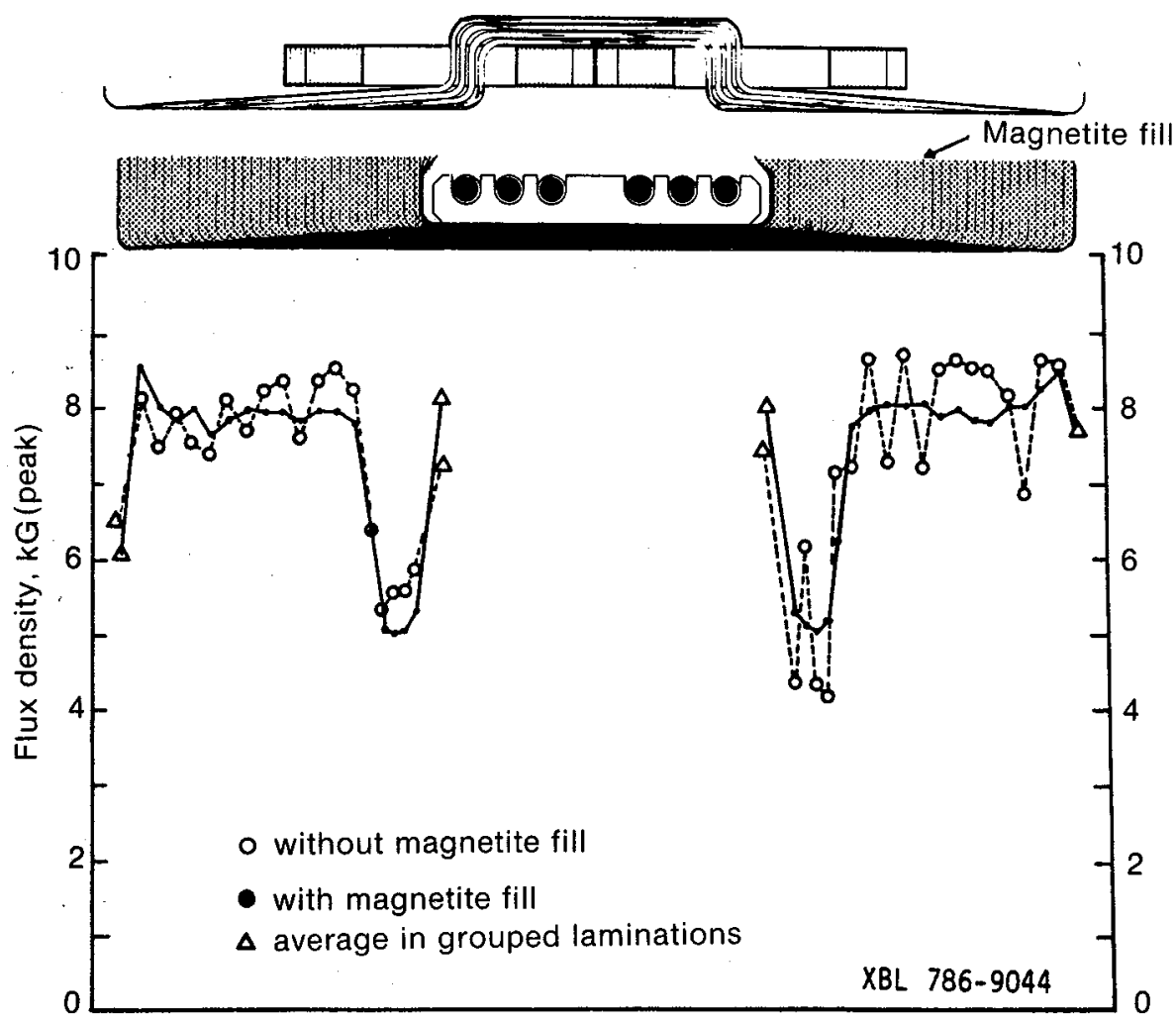

Figure 39. Magnetic flux density in source core laminations with centered pickup, with and without magnetite fill. 


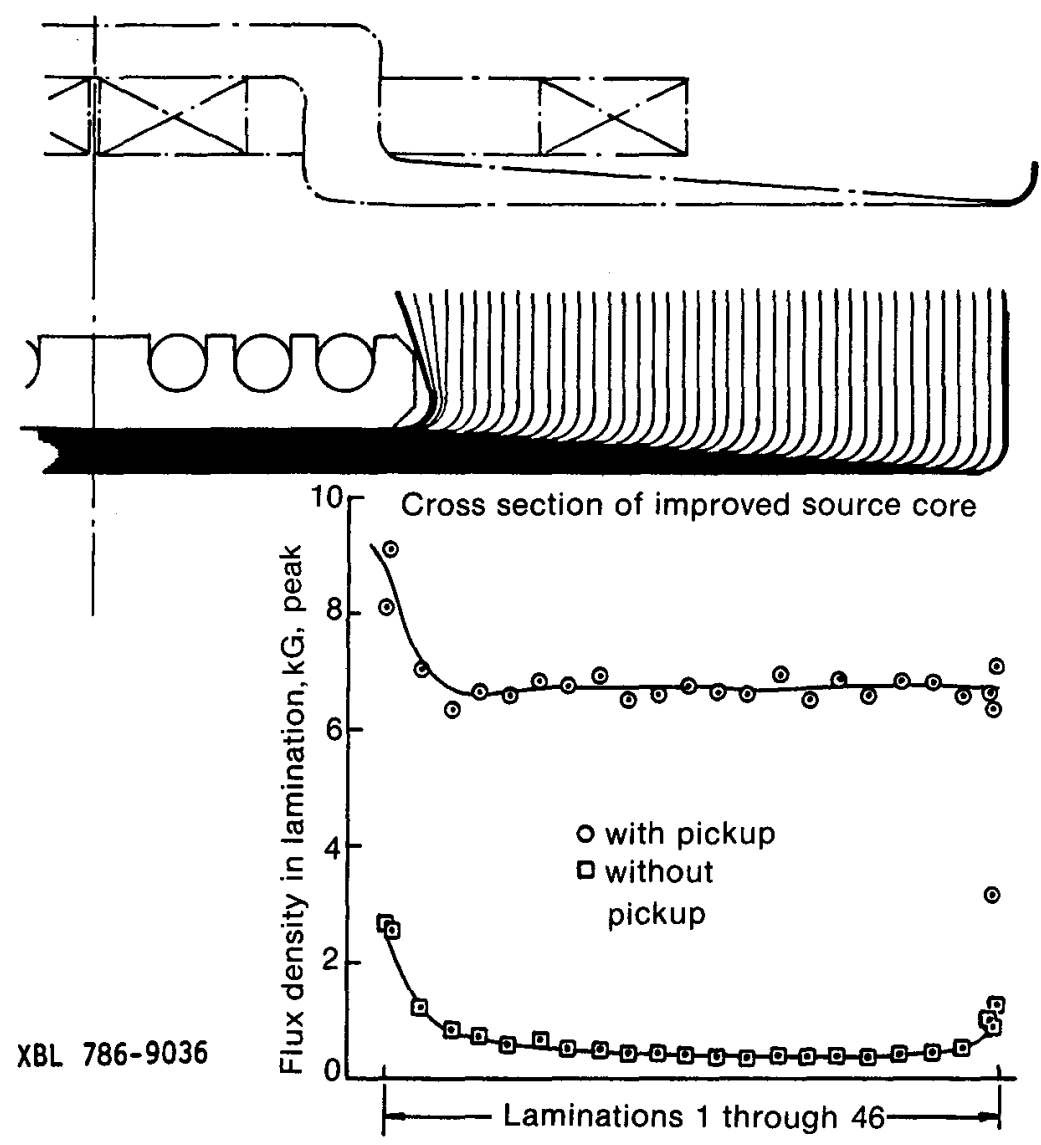

Figure 40. Magnetic flux density in laminations of improved source core.

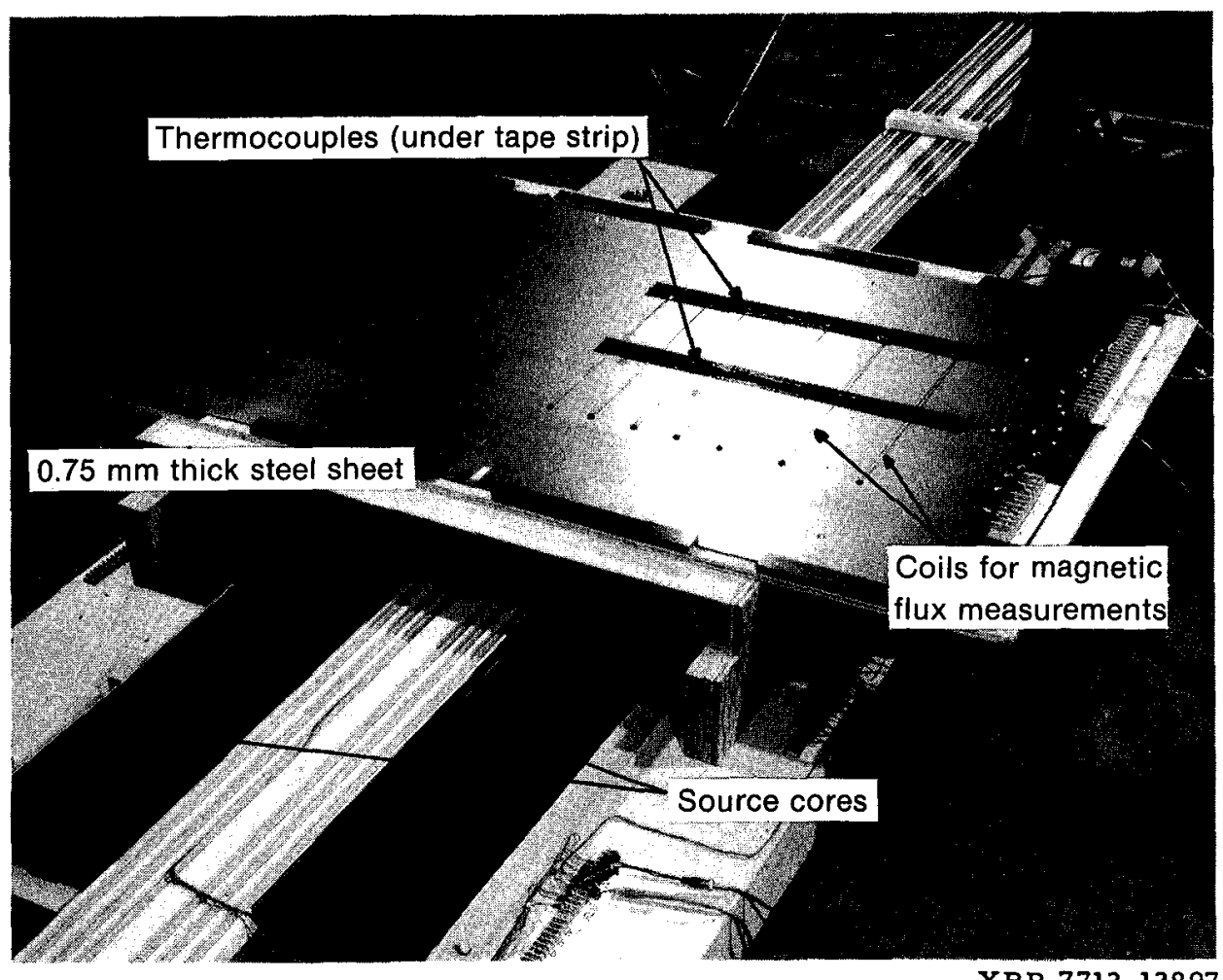

Figure 41. Arrangement of steel sheet over source for thermal tests. 


\section{E. Thermal Effects}

Alternating magnetic fields cause energy losses in conductive materials through which they pass because of eddy currents that are generated. If the material is ferromagnetic, additional energy is dissipated because of magnetic hysteresis. These losses are of concern in applications of the inductive power coupling. The sheet metal structures of vehicles operating over a power source will absorb energy from it, and metal parts that lie on the source will be heated.

A 22-gage $(0.75 \mathrm{~mm}$ thick) steel sheet was supported over the source prototype at various elevations. The sheet was equipped with thermocouples at several locations, and coils were wound longitudinally around part of the sheet's cross section at those locations, i.e., coil turns were passed through holes in the sheet. The arrangement is shown in Figure 41. These sensors were used to determine the rate of temperature rise and the magnetic flux in the sheet.

A calculation of power dissipation in the sheet was based on the rate of temperature rise in the sheet at the time of starting the test. At that time the whole sheet was at ambient temperature, so neither thermal conduction through the sheet nor convective losses from the sheet was involved. Since no heat-transfer process is involved, incoming energy can only raise the temperature of the sheet. Sample sets of curves are included in the Appendix. Figure 42 shows the calculated power dissipation in the sheet for various offset distances from source centerline, as the sheet was positioned at several elevations.

Figure 43 shows the flux density in the sheet at several elevations. Note that the central portion of the sheet was apparently saturated when the sheet rested on the surface of the source poles.

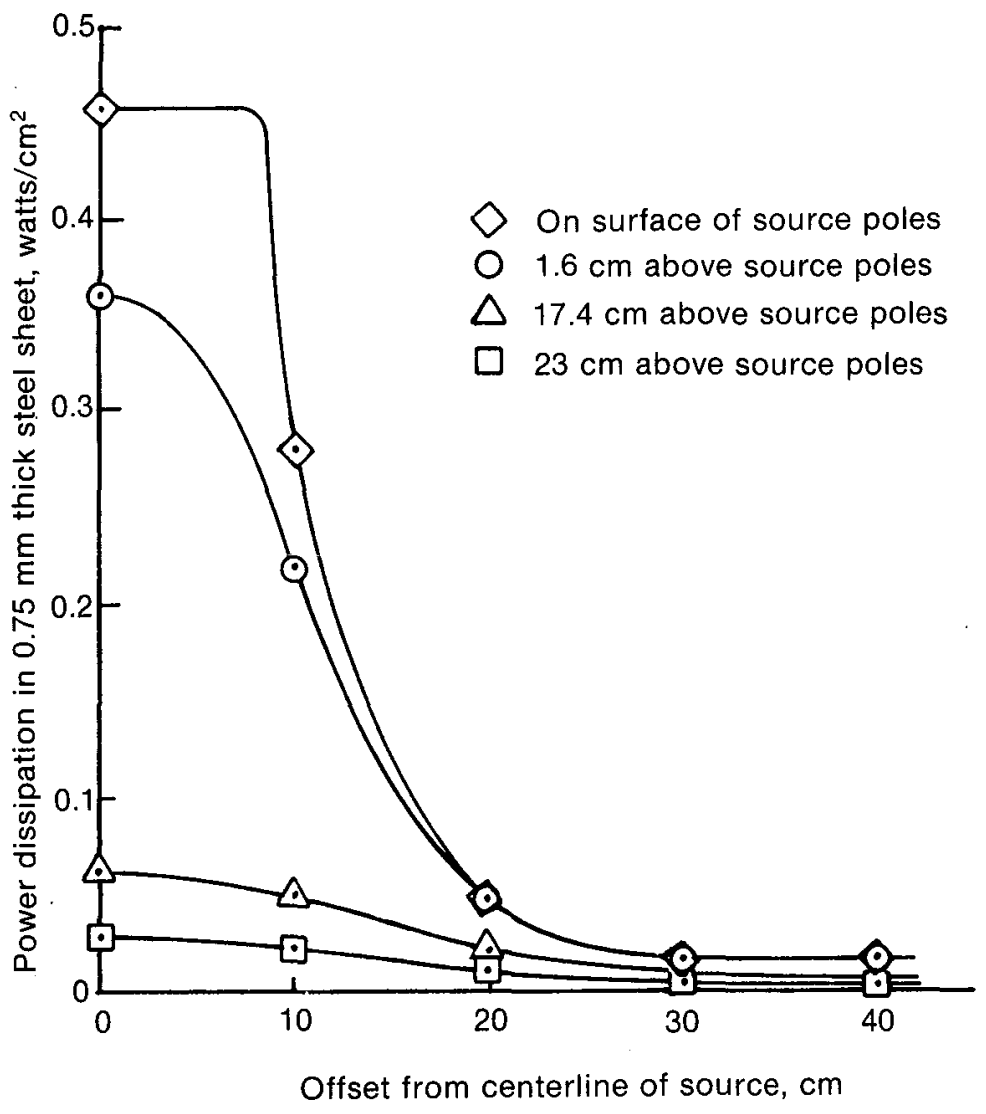

XBL $786-9035$

Figure 42. Power dissipation in a $0.75 \mathrm{~mm}$ thick steel sheet above the source vs offset from source centerline. 


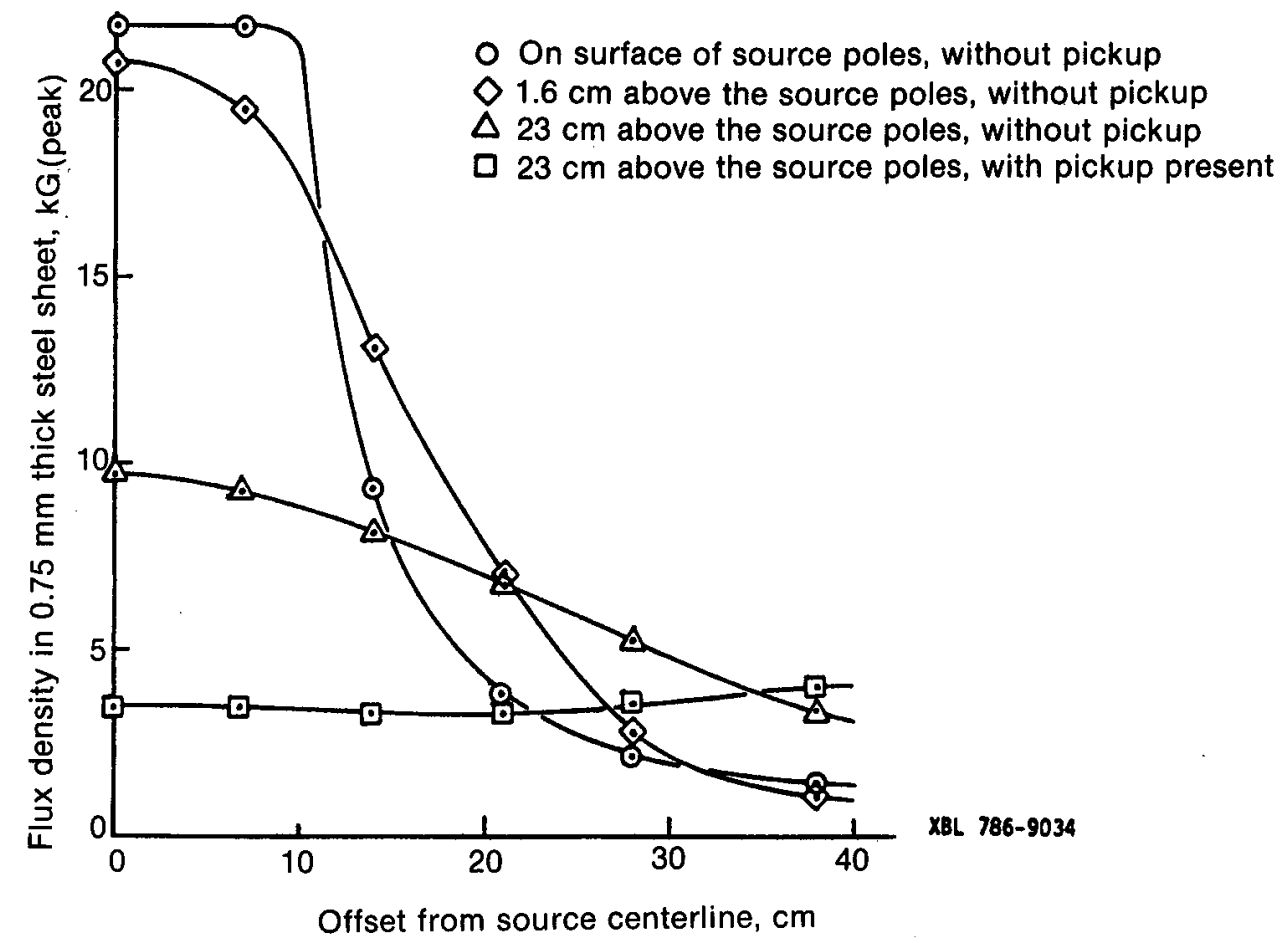

Figure 43. Magnetic flux density in a $0.75 \mathrm{~mm}$ thick steel sheet above the source vs offset distance from source centerline.

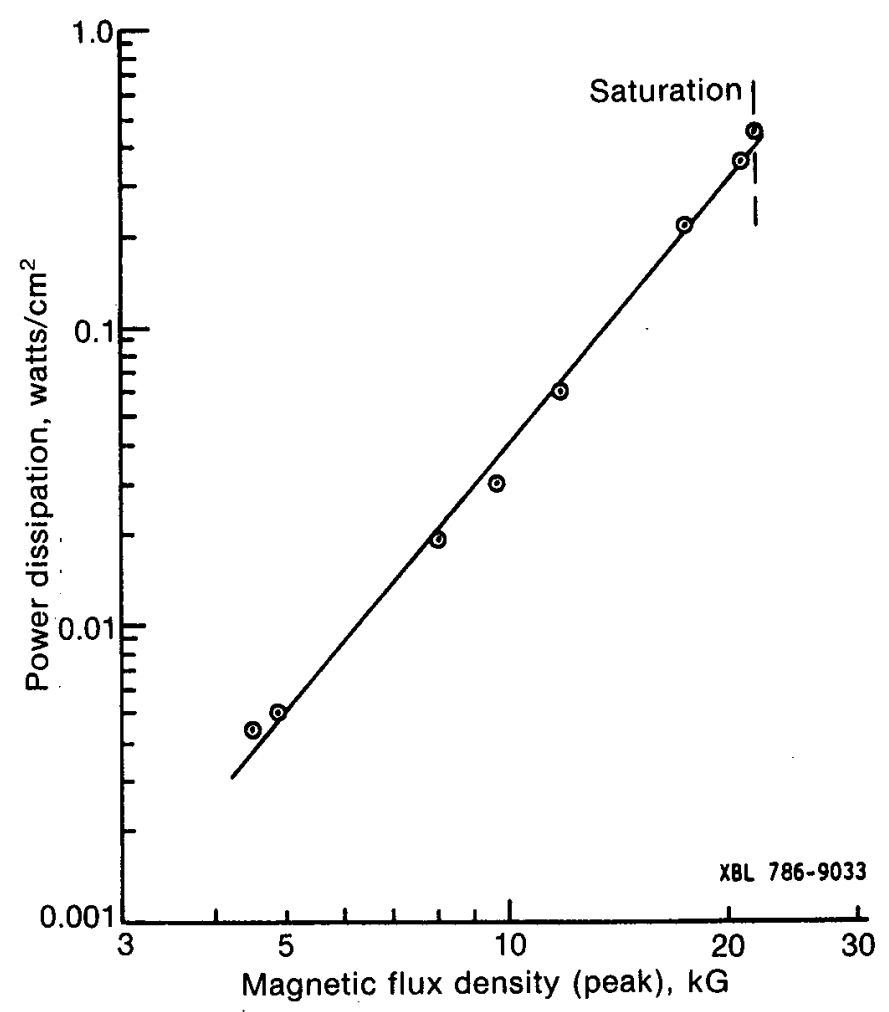

Figure 44. Power dissipation at a frequency of $180 \mathrm{~Hz}$ in a $0.75 \mathrm{~mm}$ thick cold rolled steel sheet vs magnetic flux density. 
The relationship of power dissipation to flux density was calculated from the data shown in Figures 42 and 43. The relationship is shown in Figure 44. The power dissipation in magnetically saturated 22 -gage steel sheet is shown to be $0.46 \mathrm{~W} / \mathrm{cm}^{2}$.

Figure 45 shows the variation of temperature at the centerline of the sheet vs elevation above the source, after steady state conditions were reached. The figure also shows the temperature of the sheet when it was positioned above the pickup at a height typical of vehicle-floor road clearance.

A steel sheet resting directly on the source would reach a temperature of about $192^{\circ} \mathrm{C}$. The temperature involved is of little concern with respect to igniting ordinary materials.

The heating of a steel fuel tank slung below a vehicle could be of concern if its lower surface were close to the road. A preliminary test was made of the effectiveness of a magnetic shield in reducing the thermal input. Figure 46 shows the arrangement and results of this test. The position and material of the shield were not optimized. The temperature rise in the $0.75 \mathrm{~mm}$ steel sheet above the shield reached a maximum of $23^{\circ} \mathrm{C}$; without the shield, temperature rise would have been $35^{\circ} \mathrm{C}$. The test indicated that simple shields ("expanded metal" steel sheet was used in the test) can be employed to advantage in areas were local heating is of concern.

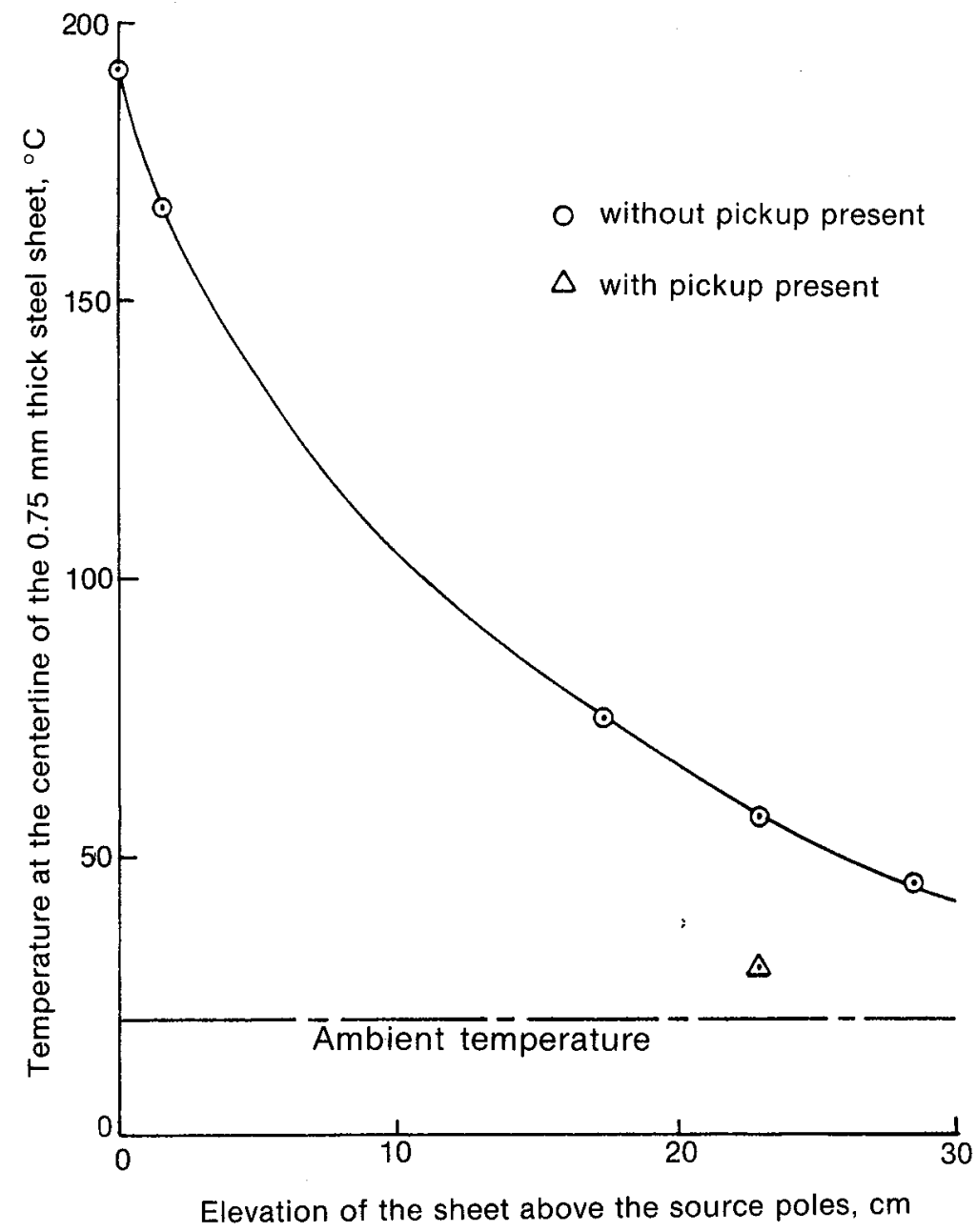

XBL 786-9032

Figure 45. Temperature at the centerline of a $0.75 \mathrm{~mm}$ thick steel sheet above the source vs elevation of the sheet. 
A test was also run to assess the effect of the source's magnetic field on a steel belted tire. The tire was placed in a vertical plane that included the centerline of the source. This condition simulated a vehicle stopped on a powered freeway in an offset position, with two wheels in the center of the lane. This represents a "worse case" with respect to power dissipation in the steel belt. The steel belt acts as a shorted turn of an air core transformer. Figure 47 shows the temperature of the steel belt during the test. Only the region nearest the source was heated; there, temperature rose $20^{\circ} \mathrm{C}$ in an hour, and apparently would have eventually stabilized at a temperature increase of $27^{\circ} \mathrm{C}$ in three hours. The thermal pattern may indicate that the wires in the belt do not form continuous circuits around the circumference of the tire, but create more localized electrical circuits because of oppositely biased winding patterns in adjacent layers of the steel belt.

The eddy current energy dissipation in aluminum was also investigated. A $41 \times 51 \mathrm{~cm}$ piece of 0.6-mm-thick aluminum was placed on the source with one $41 \mathrm{~cm}$ edge flush with the outside of one pole (i.e., the piece bridged the conductor slot and extended part way across the opposite pole). The temperature over the center of the source had a temperature rise of $24^{\circ} \mathrm{C}$. The temperature rise at the center of the pole was $18^{\circ} \mathrm{C}$.

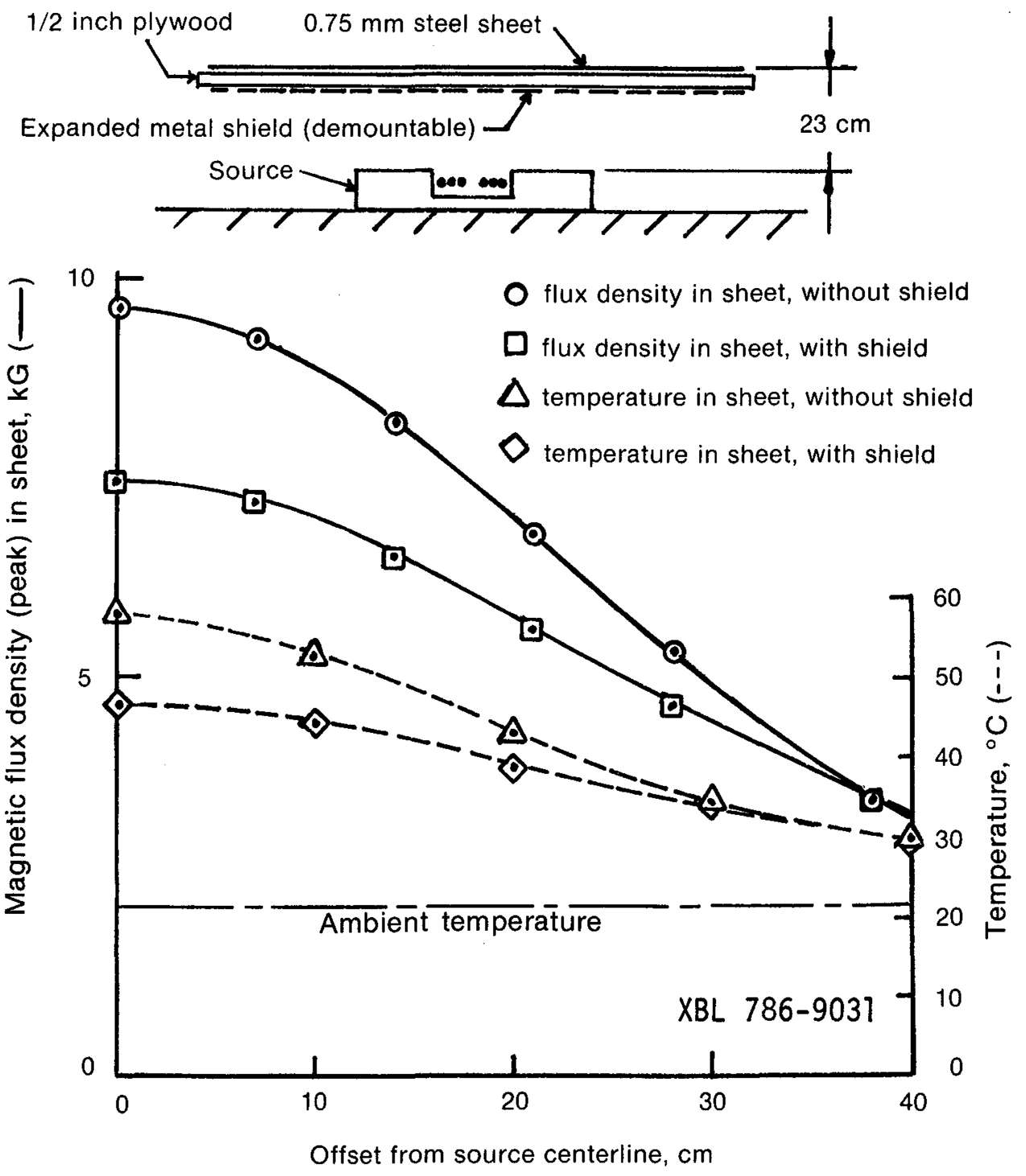

Figure 46. Magnetic and thermal effects of an expanded metal magnetic shield. 
A second test of thicker aluminum (3.2-mm thick) was run with a panel $22 \times 48 \mathrm{~cm}$, positioned as above. The maximum temperature rise in this panel was only $11.5^{\circ} \mathrm{C}$ at the source centerline, and $9.5^{\circ} \mathrm{C}$ above the center of the pole.

\section{F. Acoustic Effects}

The coupling was first operated with the pickup resting in the plywood tray that was used for magnetic force measurements. In this arrangement, the noise output in some places exceeded $90 \mathrm{~dB}$ as measured with a standard sound meter. The noise level varied widely in the confines of the small room, two walls of which were bare concrete. Moving a few feet could make the difference between a moderate sound level and a severe one.

The coupling was subsequently tested after removing the pickup from the plywood tray and resting it on resilient spacers between the pickup and source poles. The sound level dropped to a moderate level. The outer edges of the pickup core, the vertically cantilevered laminations of the source core, and the plywood platform on which the core rested were the remaining major noise sources. Results of attempts to measure the vibration amplitude of the noise sources were not satisfactorily repeatable. The vibration instrument that was available was highly susceptible to the stray magnetic field from the coupling, as were most other electronic instruments.

The noise from laminated steel cores is known to result from magnetostrictive motion of the laminations. The noise is a function of flux density; a change of $10 \mathrm{~dB}$ would typically require a reduction of approximately $40 \%$ in flux density. This effect was demonstrated by adding laminations to the pickup core. Figure 35 showed the high flux density that existed in the pickup core near its outer edges before and after three full-width laminations were added.

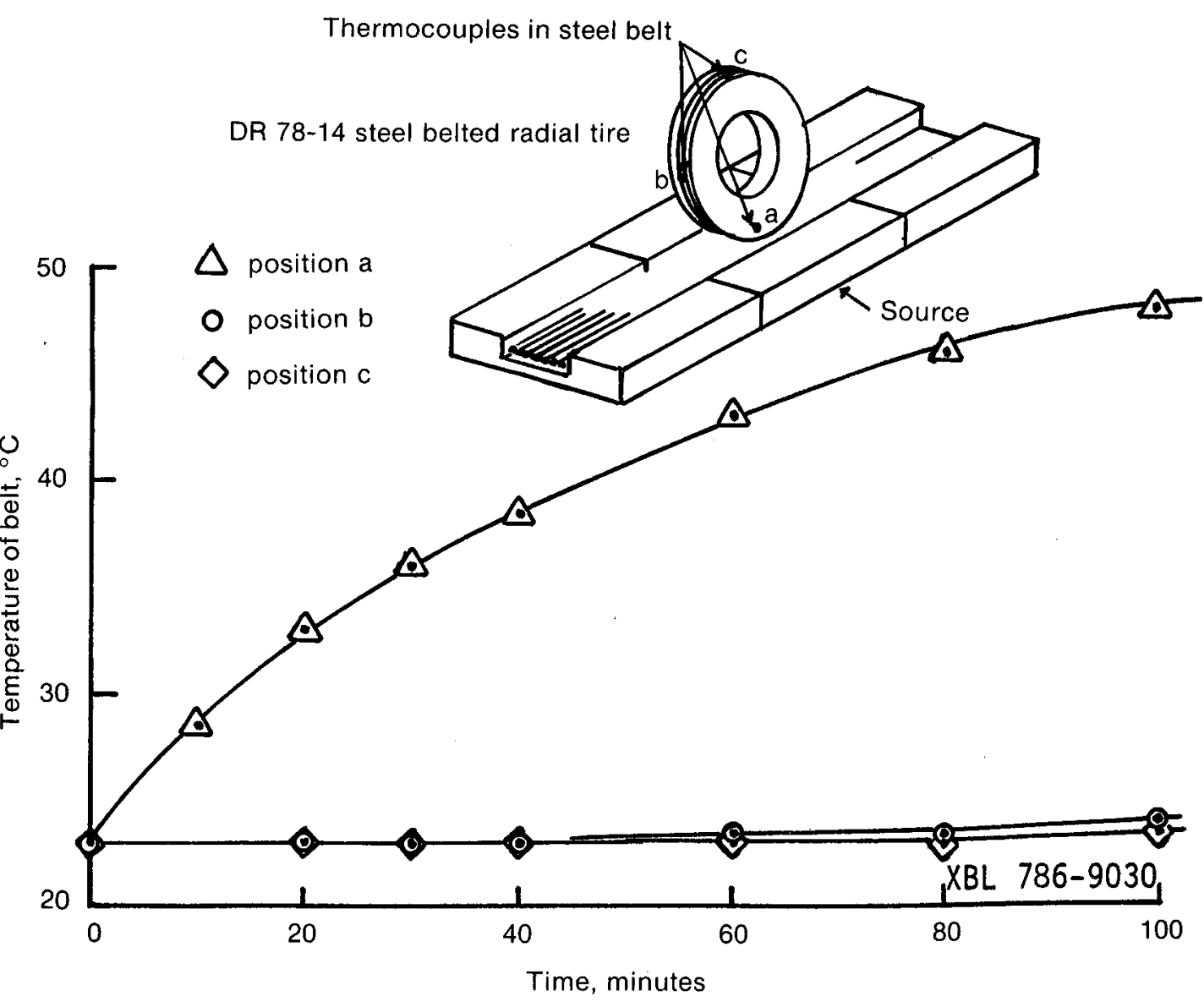

Figure 47. Temperature rise in a steel belted tire positioned above the source. 
The resulting reduction in vibrational amplitude of the outer regions of the pickup was audibly and tactually obvious.

Filling the source cores with grout (i.e., a mixture of magnetite and cement) could be expected to yield a further reduction in noise level. The tests performed with magnetite fill involved packing the center source core with loose magnetite powder. The loose powder was observed to "grow" whiskers toward the pickup above when power was turned on. To prevent this, a layer of plywood was placed over the poles. Vibrations of the plywood prevented meaningful assessment of the damping effect of the magnetite on core-lamination vibration.

\section{SUMMARY AND DISCUSSION OF TEST RESULTS}

The power coupling prototype and the test program were designed to provide an initial set of data relating to characteristics that are most important to system and vehicle designers. The tests have confirmed the technical feasibility of this type of non-contacting electrical power coupling, and have demonstrated that its components are suited to ordinary materials and manufacturing processes. Reconciliations of test results with expected performance indicate that projections of roadway power systems of high efficiency, moderate cost, and rugged construction are likely to be realized.

The test results were found to be consistent with expected characteristics in all important respects. The amount of acoustic output from the coupling was the only unexpected phenomenon. Experiments performed during the tests indicated that this is a problem peculiar to the static prototype assembly and will not occur in similar magnitude in actual roadway installations.

An expanded insight regarding the effects of fringing magnetic fields was another important product of the tests. The effects on electrical and electronic instruments, and the methods needed to control them, as well as thermal effects on metallic objects near the source, were of particular interest.

\section{A. Power Transfer Capability}

The prototype coupling was able to transfer the power for which it was designed. A compact automobile would require approximatley $20 \mathrm{~kW}$, using a pickup approximately $2 \mathrm{~m}$ in length. Budgetary constraints limited the prototype coupling to a length of $0.8 \mathrm{~m}$. Scaling the power rating of the coupling to maintain the same power density in the coupling resulted in a design power of $8 \mathrm{~kW}$ for the prototype.

The $8 \mathrm{~kW}$ rating of the prototype was achieved, but required approximately $7 \%$ more source current than was anticipated. One factor that contributed to this difference was the anisotropic permeability of the source cores, i.e., the vertical laminations in the poles were spaced apart so that the effective air gap between pickup and source was more than the physical separation between them. This effect was lessened when the spacings between laminations were filled with magnetite powder that provided some transverse permeability.

The most significant shortcomings of the prototype equipment were in the cores of the source and pickup. Local regions of excessive flux density were found in these cores near their outer edges as a result of fringing fields in those regions. These flux concentrations caused extra losses and reluctance, which in turn required extra power input. The three laminations which were added to the pickup and source cores largely remedied this shortcoming. A 'second generation' source core was also tested. The results demonstrated a much more even flux distribution than was the case in the original core.

\section{B. Electrical Characteristics}

Measurements of the electrical characteristics of the coupling showed that actual inductances agree with analytical predictions.

Although detailed analytical predictions of loss components in the coupling had not been 
made in earlier work, the total measured losses were of the same magnitude as previous estimates of that total. Resistive losses in loop (source) conductors were the largest loss in the prototype system. These losses were higher than would occur in an actual roadway system because the current density in the relatively small cables used in the prototype was approximately four times higher, and the length of the cables was proportionally longer than would be the case in an actual installation.

The next highest loss was in the cores. Tests and experiments indicated that this loss can be reduced to predicted levels when flux concentrations in laminations, and electrical shorts between laminations are eliminated.

Losses in capacitor circuits were found to be predominantly resistive losses in cables and switchgear rather than in the capacitors. Losses in capacitors were found to be so small that accurate measurements were not possible with available instruments.

Resistive losses in the windings of the pickup coils were shown to be very small, i.e., of the order of $60 \mathrm{~W}$. Subsequent pickup designs can be made lighter through the use of smaller coil cross sections without seriously affecting the efficiency of the coupling.

The tests indicated that with careful attention to design details, efficiencies can be provided similar to those predicted in earlier analyses, i.e., approaching $90 \%$ in duty cycles similar to traffic loads on freeways. Although the prototype system demonstrated efficiencies of approximately $40 \%$ to $70 \%$, the system included many losses that either would not exist in a roadway system, or that were excessive because the prototype could not replicate the proportions of an actual installation. Among these losses were capacitor cabling and switching losses of approximatley $0.5 \mathrm{~kW}$, excessive source conductor losses due to the small cables and extra cable lengths, and added core losses from flux concentrations and interlamination shorts.

\section{Magnetic Forces}

Vertical magnetic forces on the pickup were significantly less than those computed in an earlier study of a slightly different coupling configuration. The prototype coupling was constructed with wider poles than those used in the earlier study and the power density was less. The resulting increase in pole area and decrease in total flux per unit length reduced the magnetic flux density at the poles. This caused a corresponding reduction in vertical magnetic force on the pickup. When differences in the two configurations were normalized, the predicted and actual forces were in close agreement. The vertical force was found to be less than $20 \mathrm{~kg}$ when full voltage was coupled. Scaling this force to a pickup $2 \mathrm{~m}$ long for a compact car would result in an expected vertical force of $50 \mathrm{~kg}$.

The horizontal magnetic force on the pickup had been only roughly estimated from earlier computer output. Tests of the prototype coupling showed this force to be less than $4 \mathrm{~kg}$. The force on a full length pickup would approximate $10 \mathrm{~kg}$; forces of this magnitude should cause little concern for the directional stability of coupled vehicles.

\section{Thermal Effects}

The conductive sheet metal parts of vehicles that are operated over a power source, or metal that lies on the source, will absorb energy from the source's alternating magnetic field. In the case of aluminum parts, this energy will result from eddy currents induced in them. Two sheets of aluminum were placed on the poles of the source to determine the magnitude of this effect. The temperature rise was $24^{\circ} \mathrm{C}$ in a $0.6 \mathrm{~mm}$ thick sheet, and $11.5^{\circ} \mathrm{C}$ in a $3.2 \mathrm{~mm}$ thick sheet.

Steel sheets above the source provide a low reluctance path for magnetic flux from the source. This alternating flux causes both hysteresis and eddy current losses in the sheet. The flux collects from the source pole on one side and exits the sheet to the pole on the other side. Hence it is maximum above the centerline of the source. At the elevation of the floor of a typical automobile, i.e., about $23 \mathrm{~cm}$, a stationary bare steel sheet with natural convective 
cooling only on its upper surface reached a temperature of $58^{\circ} \mathrm{C}$. The temperature rise was larger than predicted by an earlier analytical approximation. The difference is largely attributable to the use of plywood support below the test sheet that virtually eliminated heat transfer from the lower surface.

A meaningful correlation to the conditions in actual vehicles would be complex. The thermal input to the floor pan of an automobile would differ because the pan is ribbed and irregular in cross section, and the temperature rise would be influenced by its thermal impedance. The impedance will differ from the bare sheet because the pan is painted and overlaid with carpet, but is vigorously cooled by convection from its lower side. A more meaningful test will be to park and/or drive an instrumented automobile over an operating source. The measured power dissipation closely matched the value predicted by the earlier analyses, i.e., $0.2 \mathrm{~W} /$ in. $^{2}$, or $0.03 \mathrm{~W} / \mathrm{cm}^{2}$ at the height of the vehicle floor.

A preliminary test was made of the effectiveness of an unoptimized, expanded-metal steel shield in reducing the thermal input into a steel sheet over the source. This shield reduced the temperature rise of the sheet by about one third.

A thin steel sheet that rested directly on the source was heated to $192^{\circ} \mathrm{C}$. This temperature is below the ignition temperature of the more flammable common materials, but would burn the skin if touched. The ignition temperature of wood, for example, is approximately $273^{\circ} \mathrm{C}$. The sheet creates a magnetic "short circuit" between the source poles and as a result is saturated with flux in the region between the poles.

\section{E. Acoustic Noise}

The prototype configuration was found to be an inadvertant but effective example of how to maximize acoustic output from the coupling. The following factors contributed to the noise output:

(1) The source and pickup were initially supported on plywood structures that amplified vibrations.

(2) The thin source laminations were cantilevered vertically with no transverse damping.

(3) Flux concentrations occurred near the thin outer edges of the pickup that increased magnetostriction amplitudes and consequent vibrations of the pickup edges.

(4) The prototype was installed in a small room with bare walls.

The noise output under the original conditions was great enough that ear protectors were required when the prototype was operated at full voltage (approximately $90 \mathrm{~dB}$ ). During the course of the tests, the plywood support was removed from under the pickup, and flux concentrations in the pickup core were remedied. These changes reduced the noise output to a moderate level. In an actual roadway system the remaining noise sources, i.e., the plywood platform under the source cores and the cantilevered source laminations, would not be present. The noise output under these conditions can be expected to be very small. 


\section{APPENDICES}

\section{A. POWER SUPPLY TESTS}

Test Conditions:

Figure 13

Actual frequencies of generator output:

$150 \mathrm{~Hz}$ nominal; $152.1-150.1 \mathrm{~Hz}$

$180 \mathrm{~Hz}$ nominal; $186.4-184.7 \mathrm{~Hz}$

$210 \mathrm{~Hz}$ nominal; $216.5-215.1 \mathrm{~Hz}$

Generator connection:

Voltage output is that of one of the three output phases.

Figure 13 shows no-load characteristics. For powering the prototype system two phases were connected in series and then paralleled with the third phase.

AC voltages are rms. 


\section{B. MAGNETIC FORCE TESTS}

\section{Test Conditions:}

Figure 14

Test No. 102

Frequency - $180 \mathrm{~Hz}$ (nominal)

Pickup in centered position

Source ampere turns - 900 (capacitive ampere turns in pickup varied with pickup voltage).

Pickup load - varied (did not affect forces).

Method: Pickup was suspended in a plywood tray. Three mechanical force gages (W.C. Dillon \& Co., model 'U', 0-100 kg) were used to measure vertical forces in the three steel straps that supported the tray. Forces were measured at various voltages and airgap settings.

\section{Figure 15}

Test No. 100

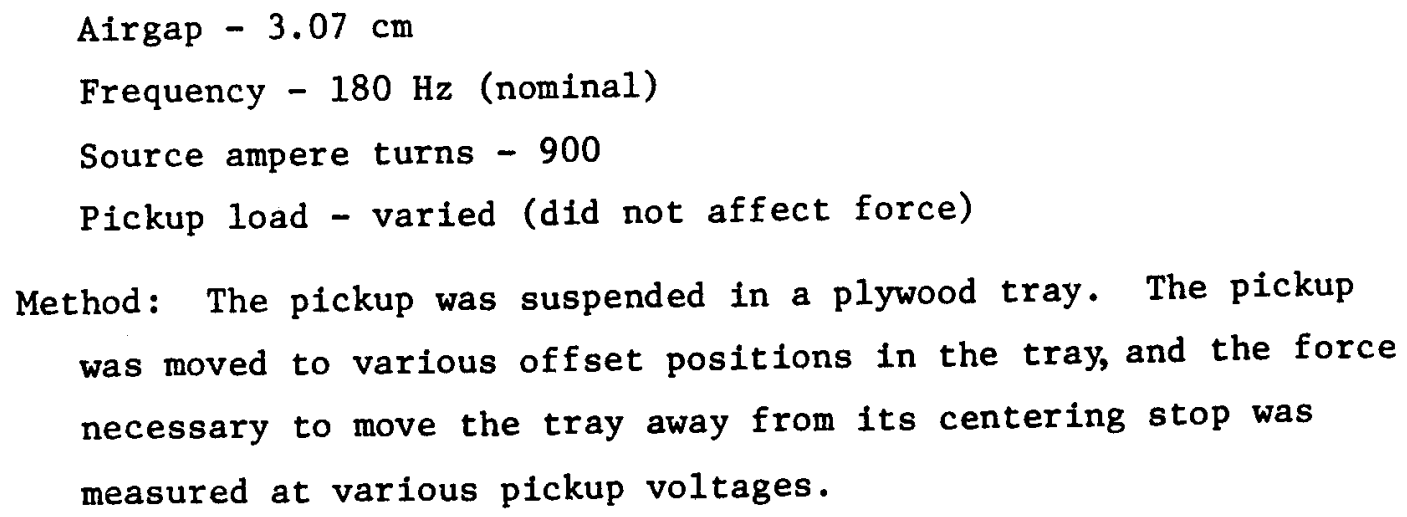


INDUCTANCE CALCULATIONS

$L_{m}$ - Mutual inductance, henries

V - Pickup short circuit voltage,

$R_{f}$ - Core loss resistance, ohms

$L_{p}$ - Pickup leakage inductance, henries

$R_{p}$ - Pickup winding resistance, ohms

$V_{0}$ - Open circuit voltage, volts

$\omega$ - Radian frequency, $2 \pi f$

I - Input current, amps

$I_{1}$ - Pickup short circuit current

$I_{2}$ - Effective core loss current

$\mathrm{I}_{3}$ - Effective mutual inductance

All parameters normalized to one turn.

(1) Mutual Inductance $\mathrm{Lm}$

(use open circuit data)

$Z=L_{m} / / R_{f}$

$=\frac{V_{0}}{I}$

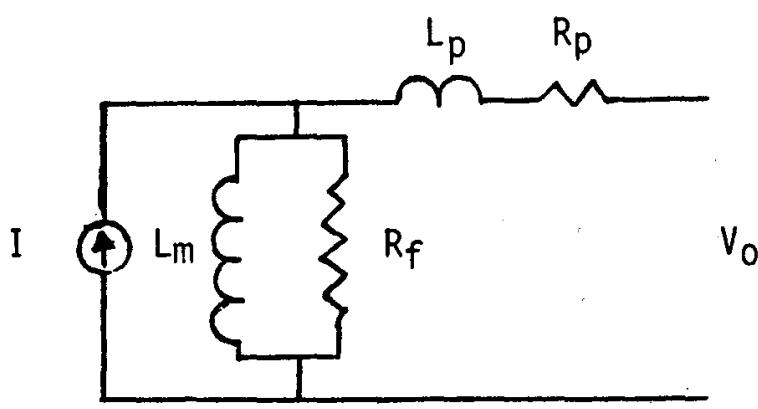

$Z$ = slope of line through all $V_{0}$ vs I data points, then $\left(\frac{1}{Z}\right)^{2}=\frac{1}{\left(\omega L_{m}\right)^{2}}+\frac{1}{R_{f} 2^{2}} \rightarrow L_{m}=\left[\left(\frac{1}{Z^{2}}-\frac{1}{R_{f}}\right) \omega^{2}\right]^{-1 / 2}$

(2) Leakage Inductance $L_{p}$ (use short circuit data)

$V=I_{1}\left(j \omega L_{p}+R_{p}\right)$

$I_{2}=\frac{I_{1}\left(j \omega L_{p}+R_{p}\right)}{R_{f}}$

$I_{3}=\frac{I_{1}\left(j \omega L_{p}+R_{p}\right)}{j \omega L_{m}}$

$I=/ I_{1}+I_{2}+I_{3} /=/ I+\frac{I_{1}\left(j \omega L_{p}+R_{p}\right)}{R_{f}}+\frac{I_{1}\left(j \omega L_{p}+R_{p}\right)}{j \omega L_{m}} /$

$=I_{1} /\left(1+\frac{R_{p}}{R_{f}}+\frac{L_{p}}{L_{m}}+j\left(\frac{\omega L}{R_{f}}-\frac{R_{p}}{\omega L_{m}}\right) /\right.$

$\frac{I^{2}}{I_{1}^{2}}=\left(1+\frac{R_{p}}{R_{f}}+\frac{L_{p}}{L_{m}}\right)^{2}+\left(\frac{w L_{p}}{R_{f}}-\frac{R_{p}}{\omega L_{m}}\right)^{2}$

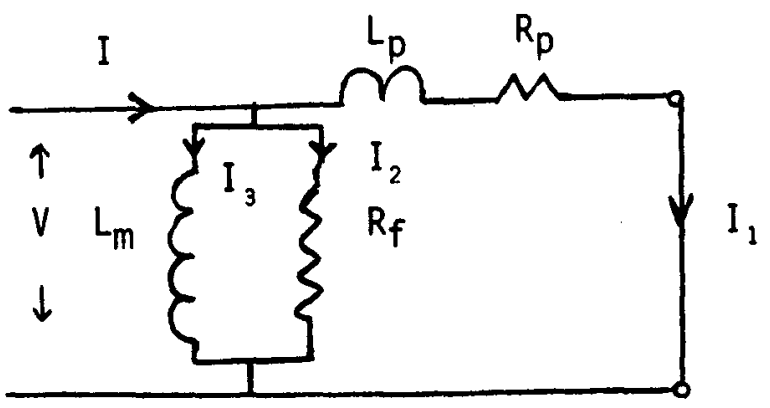




$$
\begin{aligned}
\frac{I^{2}}{I_{1}^{2}} & =\left(1+\frac{R_{p}}{R_{f}}\right)^{2}+2\left(1+\frac{R_{p}}{R_{f}}\right) \frac{L_{p}}{L_{m}}+\frac{L_{p}^{2}}{L_{m^{2}}}+\frac{\omega^{2} L_{p}^{2}}{R_{f}^{2}}-2 \frac{\omega L_{p} R_{p}}{R f \omega L_{m}}+\frac{R_{p}^{2}}{\omega^{2} L_{m}^{2}} \\
& =L_{p}^{2}\left(\frac{\omega^{2}}{R_{f}^{2}}+\frac{1}{L_{m}^{2}}\right)+2 \frac{L_{p}}{L_{m}}+\left(1+\frac{R_{p}}{R_{f}}\right)^{2}+\frac{R_{p}^{2}}{\omega^{2} L_{m}^{2}} \\
& \rightarrow L_{p}^{2}+\frac{2}{L_{m}\left(\frac{\omega^{2}}{R_{f}^{2}}+\frac{1}{L_{m}^{2}}\right)} L_{p}+\frac{\left.\left.R_{p}\right)^{2}+\frac{R_{p}^{2}}{R_{f}}\right)^{2}-\frac{I^{2}}{I_{1}^{2}}}{\frac{\omega^{2}}{R_{f}^{2}}+\frac{1}{L_{m}^{2}}}=0
\end{aligned}
$$

Equation 1

Equation 1 is a quadratic equation and can be solved for $L_{p} . w, L_{m}, R_{f}$, and $R_{p}$ are all known parameters. $\frac{I}{I_{1}}$ is computed from the slope of the line through all I vs $I_{1}$ short circuit data points.

3) Loop Inductance $L_{S}$

(use short circuit pickup data)

$\omega L_{S} \gg R_{S}$

Therefore,

$$
\begin{aligned}
& \frac{V}{I} \approx \omega L_{s} \\
& L_{s}=\frac{V}{I \omega}
\end{aligned}
$$

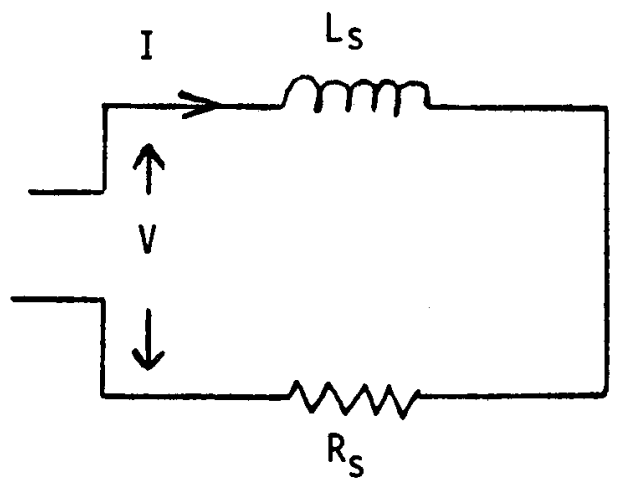

RESISTANCE CALCULATIONS

(1) Pickup Winding Resistance $R_{p}$

(with winding removed from pickup core)

$$
R_{p}=\frac{P}{I^{2}} \quad \begin{aligned}
& P \text { - winding power loss } \\
& I \text { - current through winding }
\end{aligned}
$$

44 
(2) Core Loss Resistance $R_{f}$

(use power loss data when pickup is driven)

$$
\begin{aligned}
& Z=L_{m} / / R_{f} \text { (obtained from open circuit pickup data) } \\
& V=I \times Z
\end{aligned}
$$$$
P_{R_{f}}=\frac{V^{2}}{R_{f}}=\frac{I^{2} Z^{2}}{R_{f}}
$$

where $P_{R_{f}}$ is the power loss in $R_{f}$.

Therefore,

$$
R_{f}=\frac{1^{2} Z^{2}}{P_{R_{f}}}
$$

$\frac{I^{2}}{P_{K_{f}}}$ is from power loss data when pickup is driven.

(3) Loop Resistance $R_{L}$ and Source Capacitor Loss Resistance $R_{C}$

The combined loss resistance $R_{L}$ of the source capacitors with leads and loop resistance is calculated from data without the pickup.

$$
\begin{aligned}
& P_{L}=V_{S}^{2}\left(\frac{1}{R_{C}}+v_{L}\right) \\
& \mathrm{P}_{\mathrm{L}}=\text { power loss } \\
& Y_{L}=\text { loop conductance } \\
& \frac{1}{R_{C}}+Y_{L}=\frac{P_{L}}{V_{S}^{2}}
\end{aligned}
$$

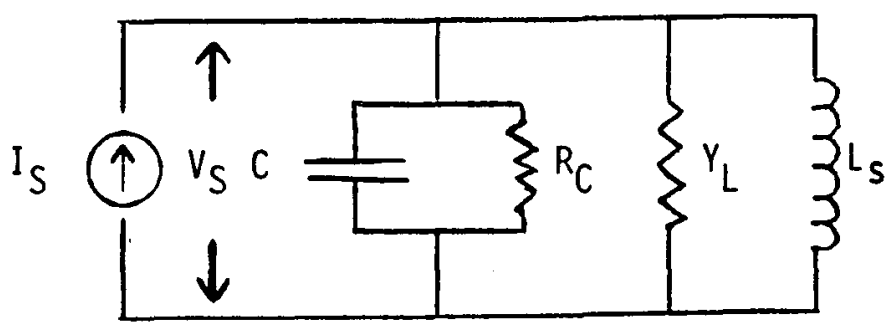

45 
$Y_{L}$ is a fixed number and $\frac{1}{R_{C}}$ is linearly proportional to capacitance $C$ as additional capacitors are switched ${ }^{R_{C}}$ into the circuit:

$\frac{1}{R_{C}} \times C+Y_{L}=\frac{P_{L}}{V_{S}^{2}} \quad$ where $R_{C}{ }^{1}$ is the loss resistance per unit capacitance. If $\frac{P_{L}}{V_{S}^{2}}$ is plotted against capacitance, then $Y_{L}$ will be the intersection of the $\frac{P_{L}}{V_{S}^{2}}$ axis and the slope of the line will be $\frac{l}{R_{C}^{1}}$.

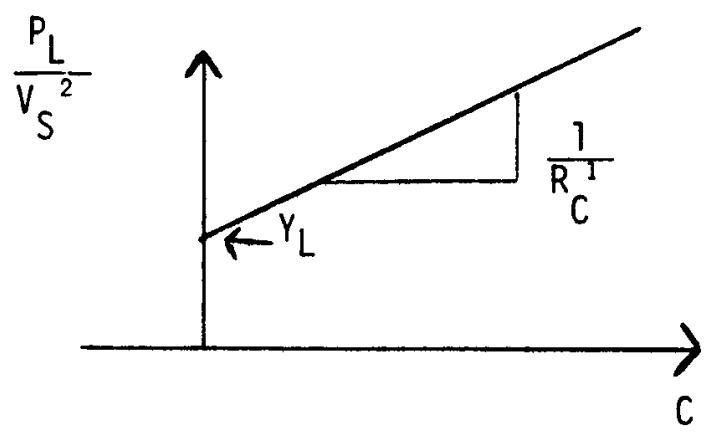

A calculator is used to fit a straight line to all data points and then to calculate both the slope and loop conductance $Y_{L}$. This loss conductance of the loop is in parallel with the loop inductance $\mathrm{L}_{\mathrm{s}}$.

Very often, a series loss resistance is more desirable in order to calculate the loss in the system. The following relationship can be used:
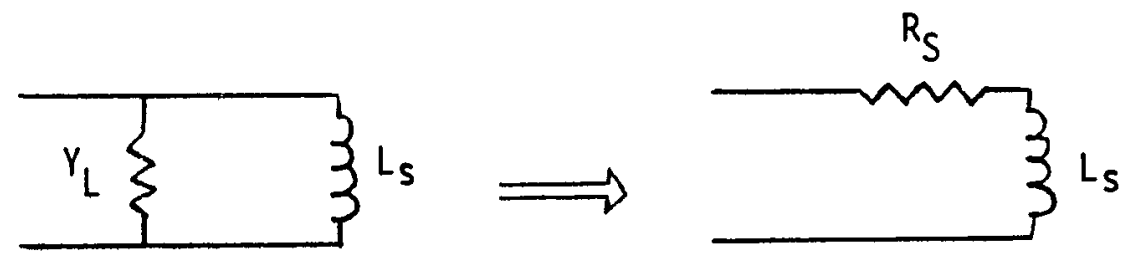

$$
R_{S} \ll L_{S}
$$

Therefore, $L_{s}$ is about the same in both cases.

$$
\frac{1}{Z}=\frac{1}{Y_{L}}+\frac{1}{j \omega L_{s}} \Longrightarrow Z=\frac{Y_{L} j \omega L_{s}}{Y_{L}+j L_{s}}
$$




$$
\begin{aligned}
R_{S} & =R_{e}[Z] \\
& =R_{e}\left[\frac{Y_{L} j \omega L_{S}}{Y_{L}+j \omega L S}\right]=R_{e}\left[\frac{Y_{L} \omega^{2} L_{S}^{2}+Y_{L}^{2} j \omega L}{Y_{L}{ }^{2}-\omega^{2} L_{S}}\right] \\
& =\frac{Y_{L} \omega^{2} L_{S}^{2}}{Y_{L}{ }^{2}-\omega^{2} L_{S}{ }^{2}}
\end{aligned}
$$

(4) Pickup Capacitor Loss Coefficient $C_{1}$

This loss in the pickup capacitor is highly nonlinear and cannot be characterized by a single resistor. Here, this loss is plotted against the voltampere load of the capacitors and the ratio is used as the loss coefficient in the loss reconciliation calculation. 

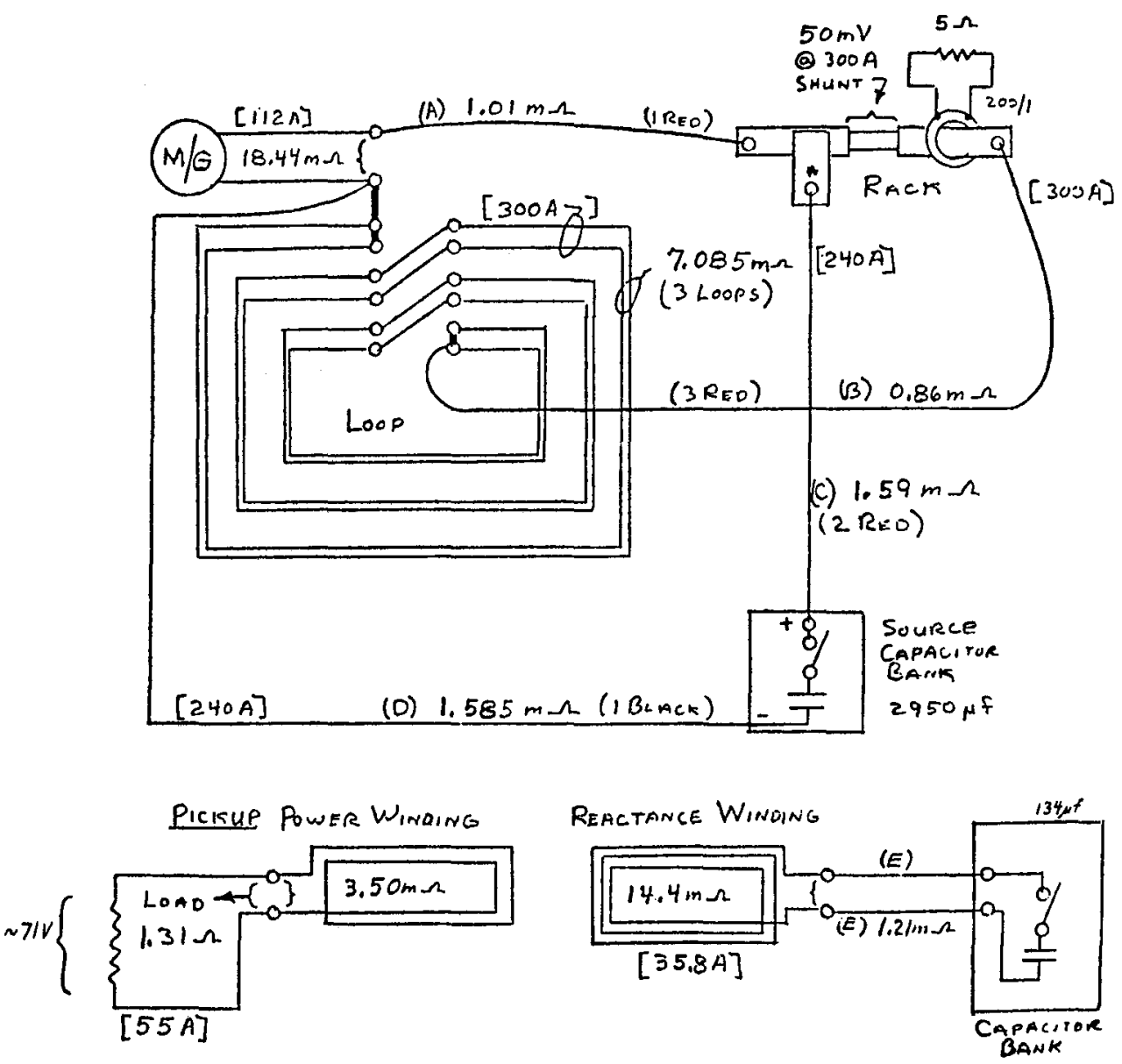

+ Test point

[ ] - Typilal Currents... From Test \#100

Prototype System Resistance Measurements. 


\section{Test Conditions:}

\section{Figure 18}

Tests No. 136 through 139

Airgap - $2.7 \mathrm{~cm}$

Frequency - $180 \mathrm{~Hz}$ nominal

Method: Mutual inductance and pickup inductance were derived from measurements of power input, voltages and currents. Measurements of these parameters were made at from 150 to 900 source ampere turns, and at the offsets indicated in the figure. Open circuit, short circuit, and driven pickup tests were used.

\section{Figure 19}

Test No. $140,143,144,147$ and 184

Pickup position - centered

Frequency - $180 \mathrm{~Hz}$ nominal

Method: As in figure 18 above, except that data was taken at several airgaps with the pickup centered. The primary tests were open pickup circuit tests.

Figure 20

Tests No. $169,170,171$

Airgap - $2.7 \mathrm{~cm}$

Pickup position - centered

Method: As in figure 18 above, except that measurements at nominal frequencies of 150,180 and $210 \mathrm{~Hz}$ were used to determine the variations in parameters due to frequency. The tests were similar to those for figure 18 . 


\section{Figure 22}

Test No. 152

Pickup - centered

Airgap - $2.7 \mathrm{~cm}$

Frequency - $180 \mathrm{~Hz}$ nominal

Source ampere turns - varied from 150 to 900 ampere turns

Pickup load - 0.96 ohm

Method: Efficiency was calculated from measurements of power

input and power output. Induced volts per turn was derived

from measurements of pickup voltage. Pickup volts were

varied by changing capacitive loading on the pickup

reactance winding, and by varying the source ampere turns.

\section{Eigure 23}

Test No. 202

Airgap - $2.7 \mathrm{~cm}$

Frequency - $180 \mathrm{~Hz}$ nominal

Source current - 900 amp-turns

Power output - $3.2 \mathrm{~kW}$

Load resistance $-1.33 \Omega$

Method: System efficiency was calculated from measurements at two selected voltages and pickup positional offsets up to $10 \mathrm{~cm}$.

\section{Figure 24}

Test No. 152

Pickup - centered

Airgap - $2.7 \mathrm{~cm}$

Frequency - $180 \mathrm{~Hz}$ nominal

Pickup load - $1.33 \Omega$

Source ampere turns - 900

Method: Pickup voltage was measured with selected capacitive

loadings on the pickup reactance winding. 
D. MAGNETIC MEASUREMENTS

Table of Instruments

Motor

Motor Control

Point Coil

Dekavider

DVM

Axial Probe

Ext. CBL 1

Gaussmeter 1

Transverse Probe

Ext. CBL 2

Gaussmeter 2

RMS V.M. 1

RMS V.M. 2

Bias Module

xyy' Plotter
Bodine $1 \mathrm{rpm}$, reversible

Reversing switch

B-157, Area $=823.5 \mathrm{~cm}^{2}, R=545$ ohms

ESI Mode1 RV622A, AEC No. 107603, set at 0.10603

Fluke Model 8000A, S/N 0625275

F.W. Bell Model FAK4-1815, S/N 109830

F.W. Bell Model X0Q4-0025, S/N 99258

F.W. Bell Model 620, AEC No. 195737

F.W. Bell Model STL4-0402, S/N 103108

F.W. Bell Model X0Q4-0025, S/N 85217

F.W. Bell Model 620, AEC No. 501586

Hewlett Packard Model 3400A, AEC No. 154333

Hewlett Packard Model 3400A, AEC No. 151761

Dwg. No. 6V8032

Moseley Model 2FRA, AEC No. 217750

$y=B_{x}$ (horizontal)

$y^{\prime}=B_{y}$ (vertical)

Test Conditions:

Figure 29

Source ampere turns - 900

Chart recording sample - page 55

Method: Hall probe data was recorded on a $x-y$ recorder (ref. figure 27 and figure 28) at several elevation planes. The vectorial sum of the horizontal and vertical components of the field measurements (i.e., $\sqrt{\left.\mathrm{Bx}^{2}+\mathrm{By}^{2}\right)}$ was plotted in the figure.

Figure 31

Source ampere turns - 900

Chart recording sample - page 56

Method: Reference figure 29 above. 


\section{Figure 32}

Source ampere turns - 900

Chart recording sample - page 57

Method: Reference figure 29 above. A steel sheet was supported over the source at an elevation chosen to roughly approximate the floor of a typical present-day automobile.

\section{Figure 33}

Test No. 112

Source laminations - 46

Pickup load volts - 73.0

Pickup laminations - 40 Pickup power $-3.95 \mathrm{~kW}$

Airgap - $2.8 \mathrm{~cm}$ Frequency - $181.8 \mathrm{~Hz}$

Source ampere turns - 900

Method: Record RMS voltages from windings around individual

laminations (or groups of laminations). Flux density was calculated using the relationship: $\quad E=2 \pi N f(B A) 10^{-8}$

$\mathrm{N}=$ number of turns in coil

$f=$ frequency $(181.8 \mathrm{~Hz})$

$\phi=$ total flux in lamination

$A=$ lamination area $(=.035 \mathrm{~cm} x$

See page 58 for arrangement of windings on the pickup core.

See page 58 for arrangement of windings on the source core.

Figure 34

No. laminations

Test 104

Test 112

Airgap, cm

43

46

Pickup volts

3.07

2.8

Source ampere turns

79.9

73.0

900

900

Method: See figure 33 test conditions. 
Figure 35

Test $111 \quad$ Test 182

No. laminations

Airgap, cm

40

2.8

43

Source ampere turns

900

2.7

Pickup volts

71.5
900

71.46

Method: Reference method for figure 33. Three close fitting 'U'-shaped laminations, number 44, 45, and 46, were slipped around the middle source core (i.e., the source core that was magnetically coupled to the pickup), and a new set of voltage readings were taken.

\section{Figure 36}

Source laminations

Pickup laminations

Airgap, cm

Pickup volts

Source ampere turns
Test 112 (Source and one pickup pole)

40

2.8

65.9

900
Test 113

(Second pickup pole) 46

40

$$
2.8
$$

73.5

900

Method: Reference method for figure 33. The data from Test 112 was normalized to the pickup voltage of Test 113 (73.5 volts). Because only one pickup pole was equipped with diagnostic coils, it was necessary to shift the pickup $4 \mathrm{~cm}$ in both directions to obtain the distribution in both pickup poles, thus both Test 112 and 113 were required.

Figure 37

Test 112

Pickup laminations

Source laminations

Airgap, cm

Source ampere turns

Pickup volts
40

43

2.8

900

70.5
Test 113

40

43

2.8

900

70.5

Method: Reference method for figure 36 . 


\section{Figure 38}

Test No. 182

Source ampere turns - 900

Method: Reference method for figure 33.

\section{Figure 39}

$\begin{array}{lcc} & \text { Test } 112 & \text { Test } 188 \\ \text { Source laminations } & 46 & 46 \\ \text { Source ampere turns } & 900 & 900 \\ \text { Source fill material } & \text { none } & \begin{array}{l}\text { Magnetite powder } \\ \text { (Hoeganaes Corp. grade MC 30) } \\ \text { Pickup voltage }\end{array} \\ \text { T3.0 } & 73.26\end{array}$

Method: Reference method for figure 33 .

\section{Figure 40}

Test No. 197

Source ampere turns - 900.6

Airgap, cm - 2.7

Pickup voltage - 70.7

Method: Reference method for figure 33 .

\section{Figure 43}

Tests No. 157, 158, 159, 160 and 161 (see figure 42).

Method: Figure 41 shows how diagnostic coils were wound around part of the sheet cross section at various distances from the source and sheet centerline. Voltages induced in these coils is directly related to the flux in the sheet (reference methods used for figure 33). The voltages in each coil were recorded and used to calculate the flux density in the sheet. 


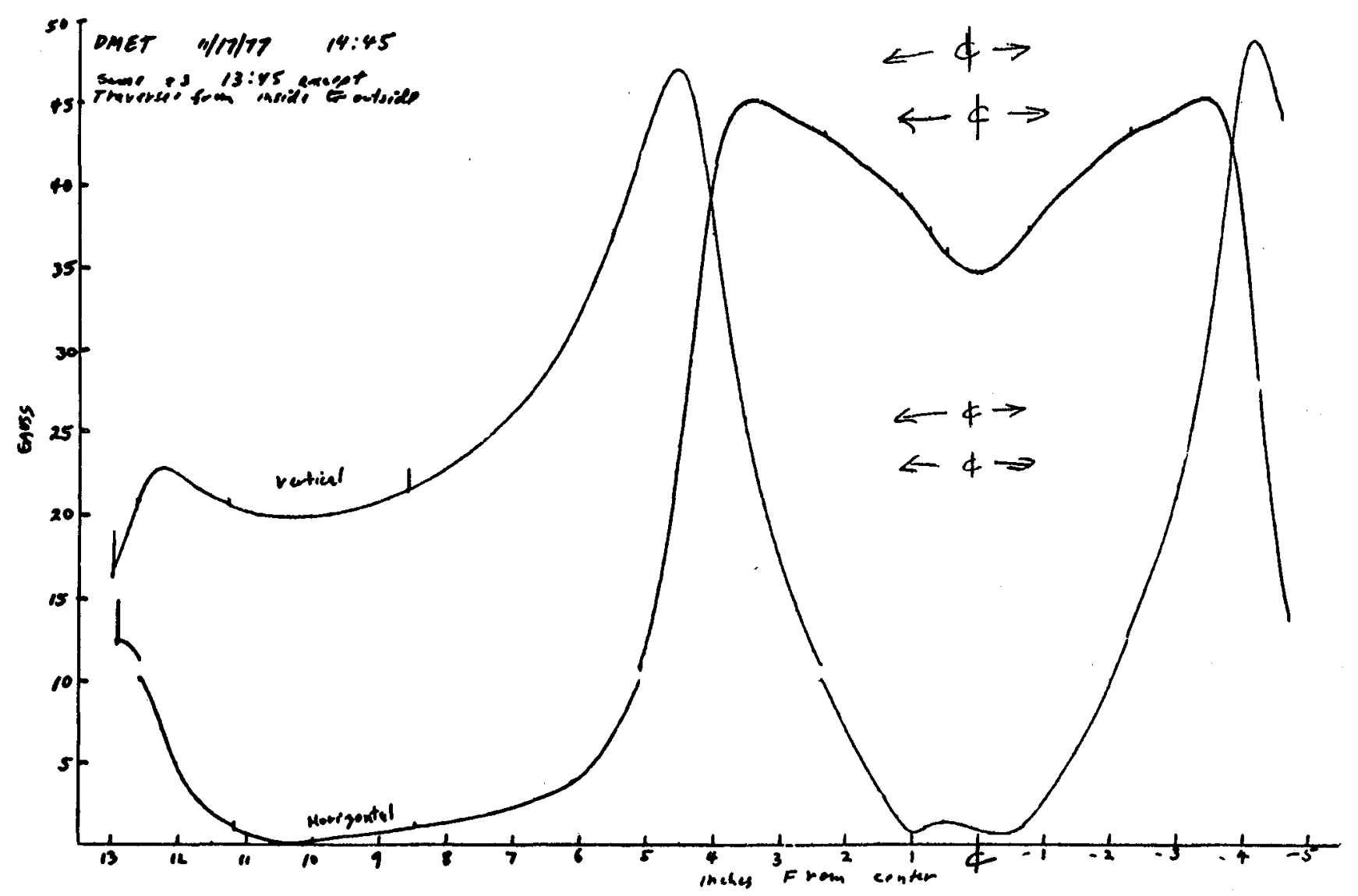

Chart Recording of (Hall probe) Magnetic Field Measurement Above the Uncoupled Source.

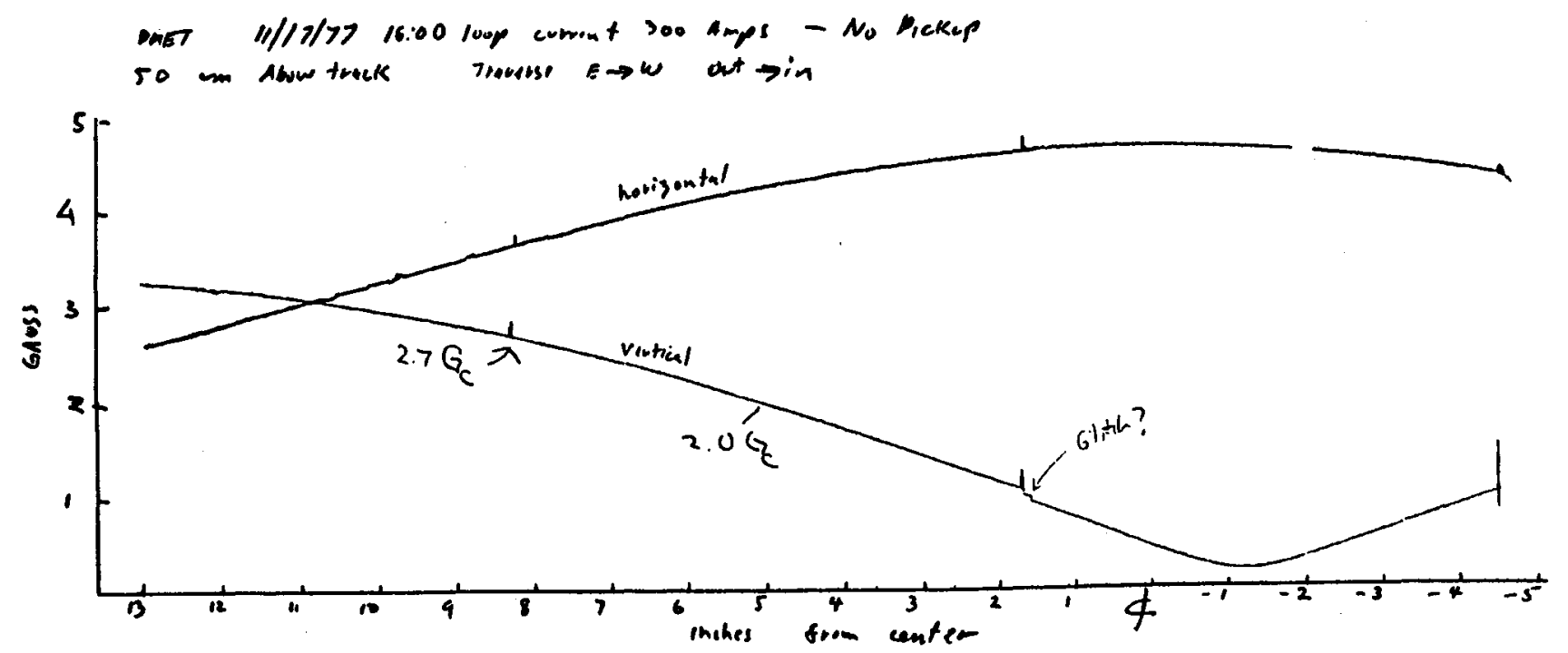

Chart Recording of (Hall probe) Magnetic Field Measurement $50 \mathrm{~cm}$ Above the Uncoupled Source. 


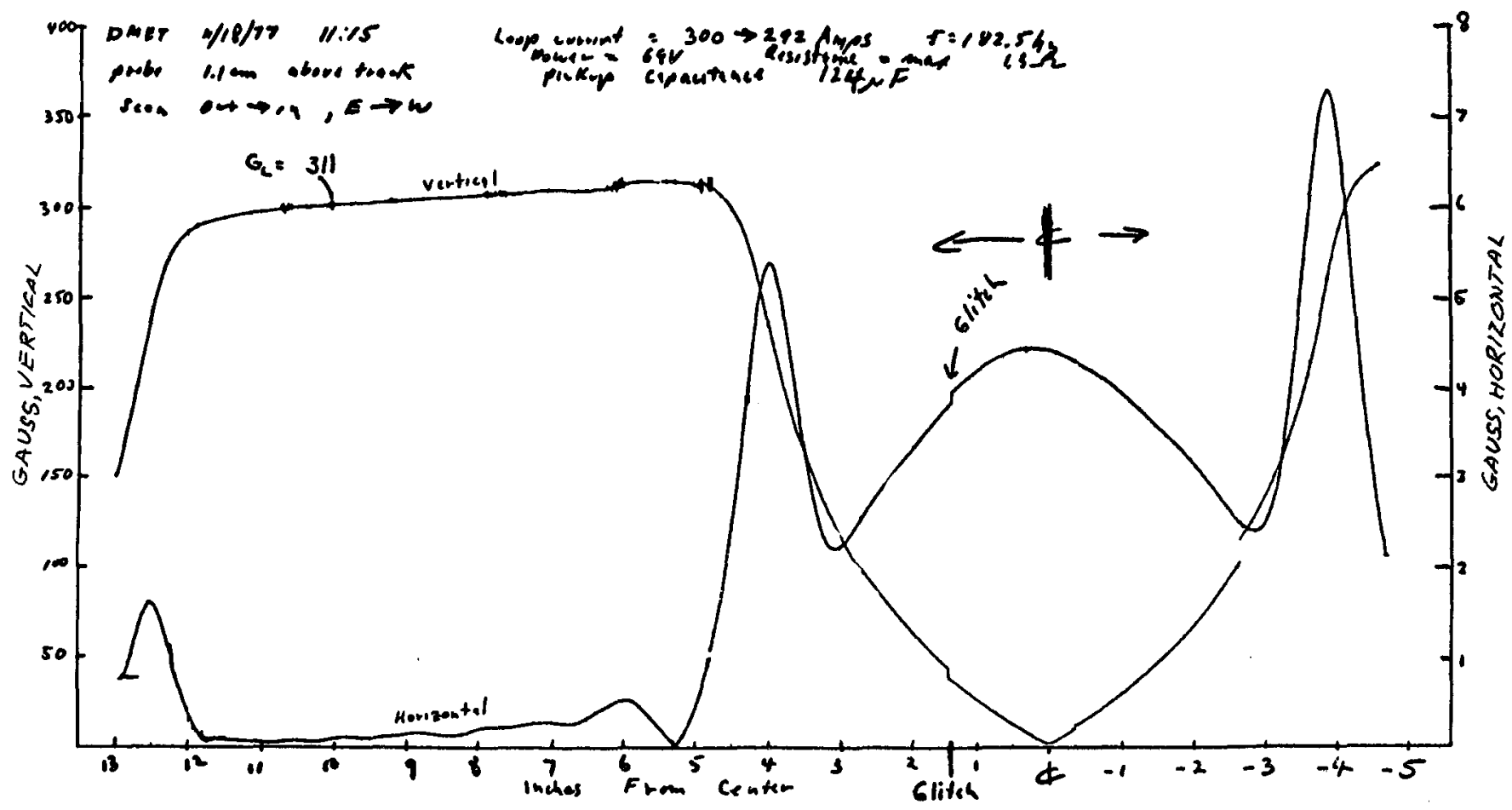

Chart Recording of (Hall probe) Magnetic Field Measurement Above the Coupled Source.

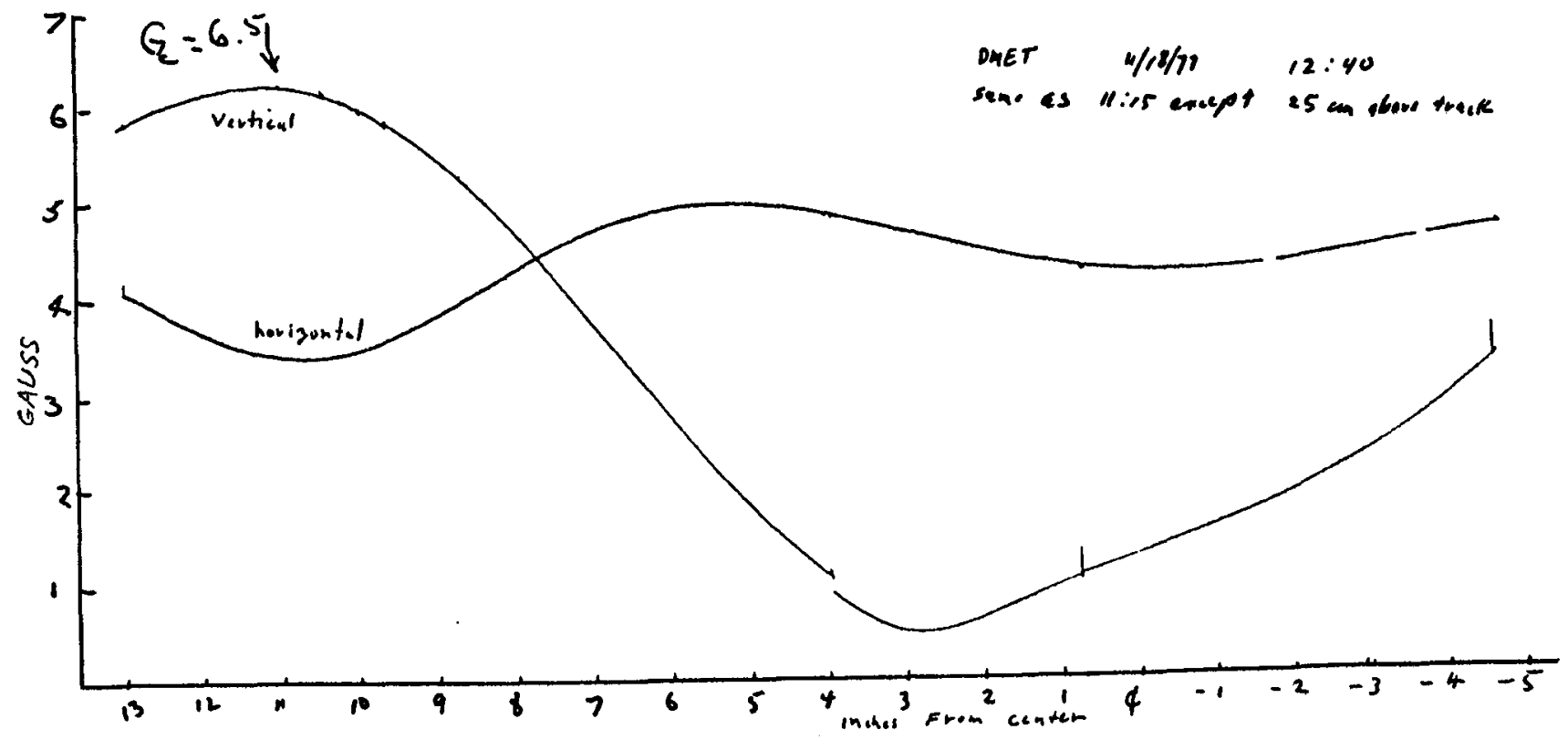

Chart Recording of (Hall probe) Magnetic Field Measurement $25 \mathrm{~cm}$ Above the Coupled Source. 


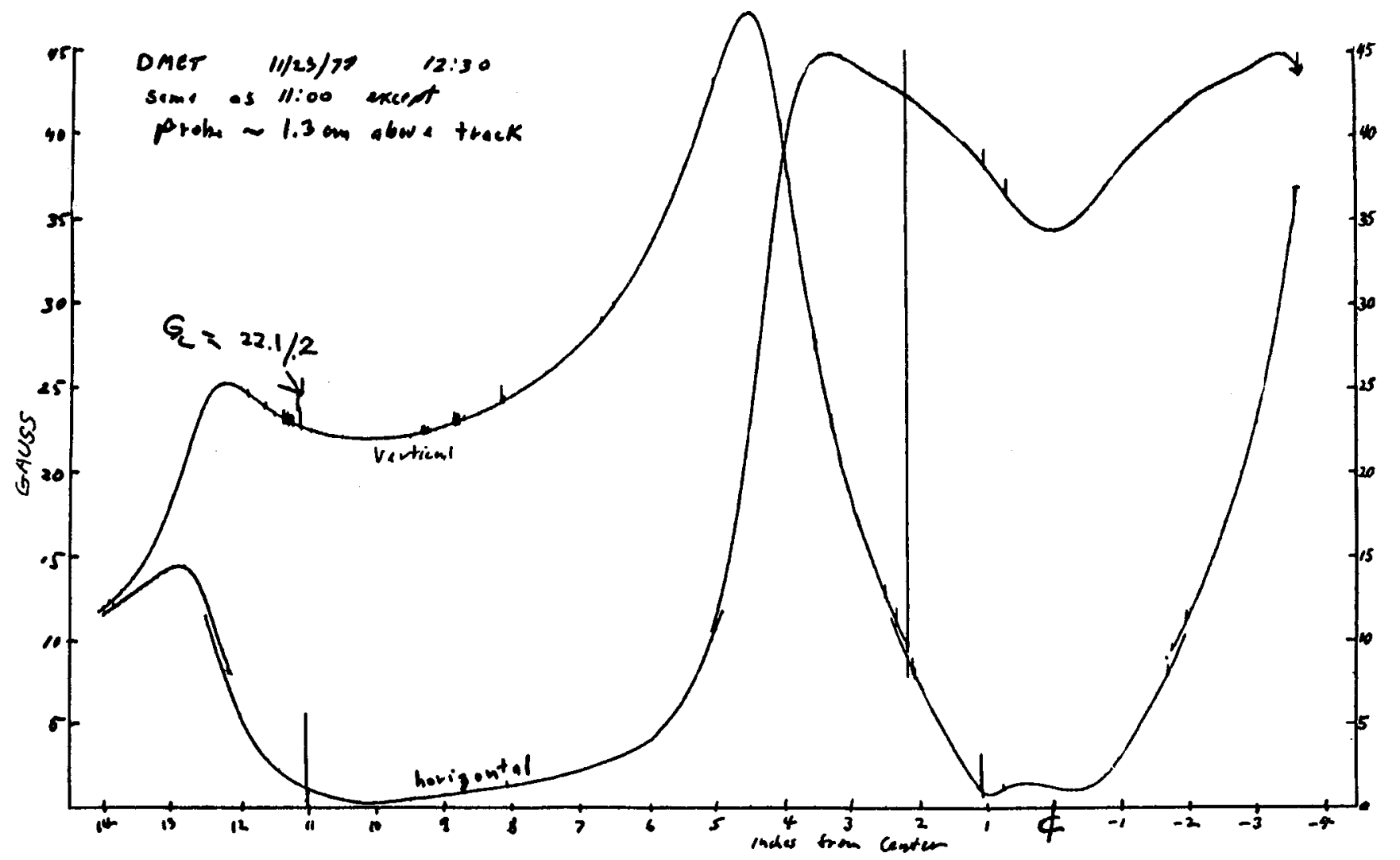

Chart Recording of (Hall probe) Magnetic Field Measurement Above the Uncoupled Source with a Horizontal Steel Sheet $23 \mathrm{~cm}$ Above the Source.

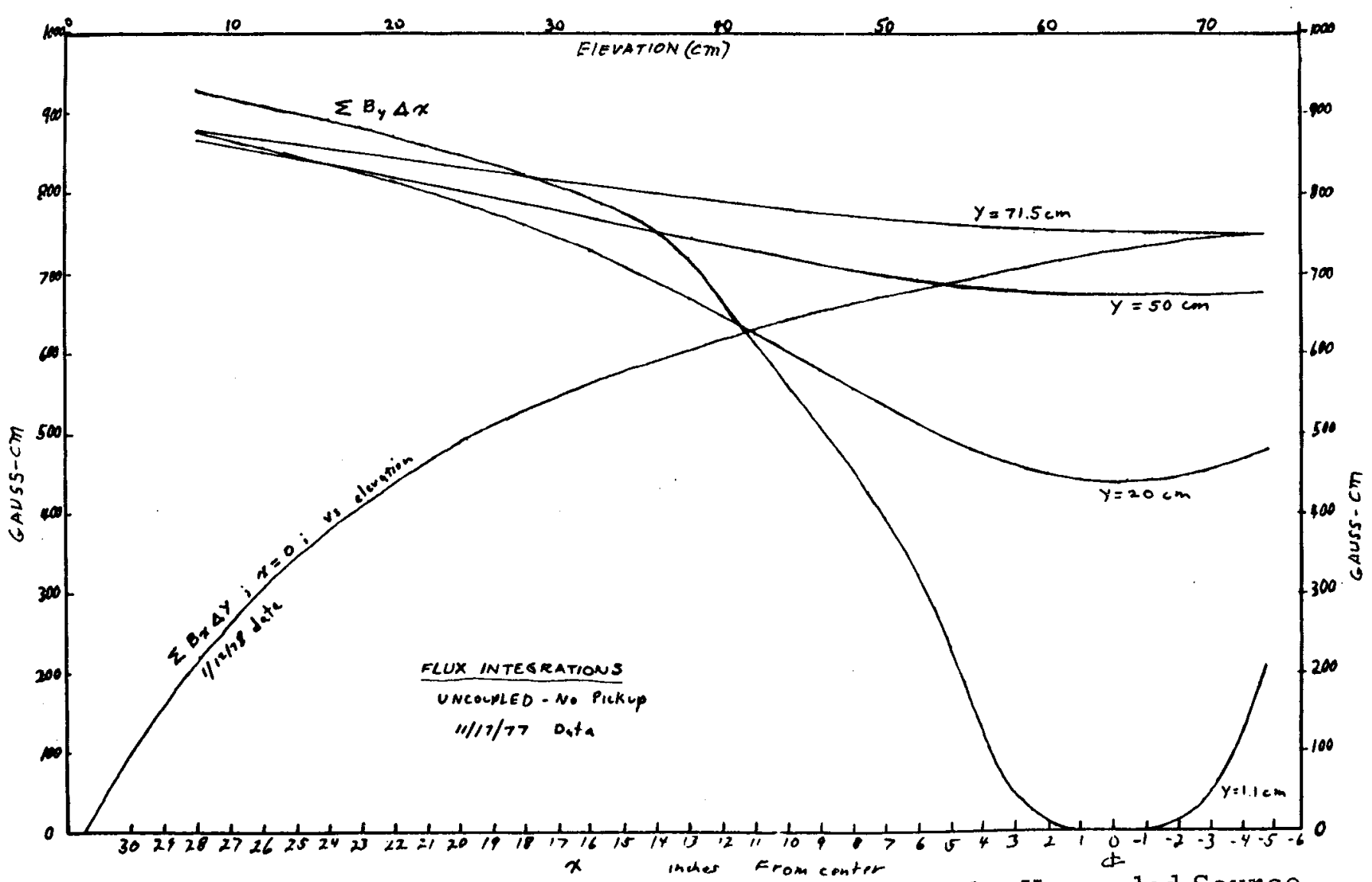

Plots of Integrated Horizontal and Vertical Flux Above the Uncoupled Source. 


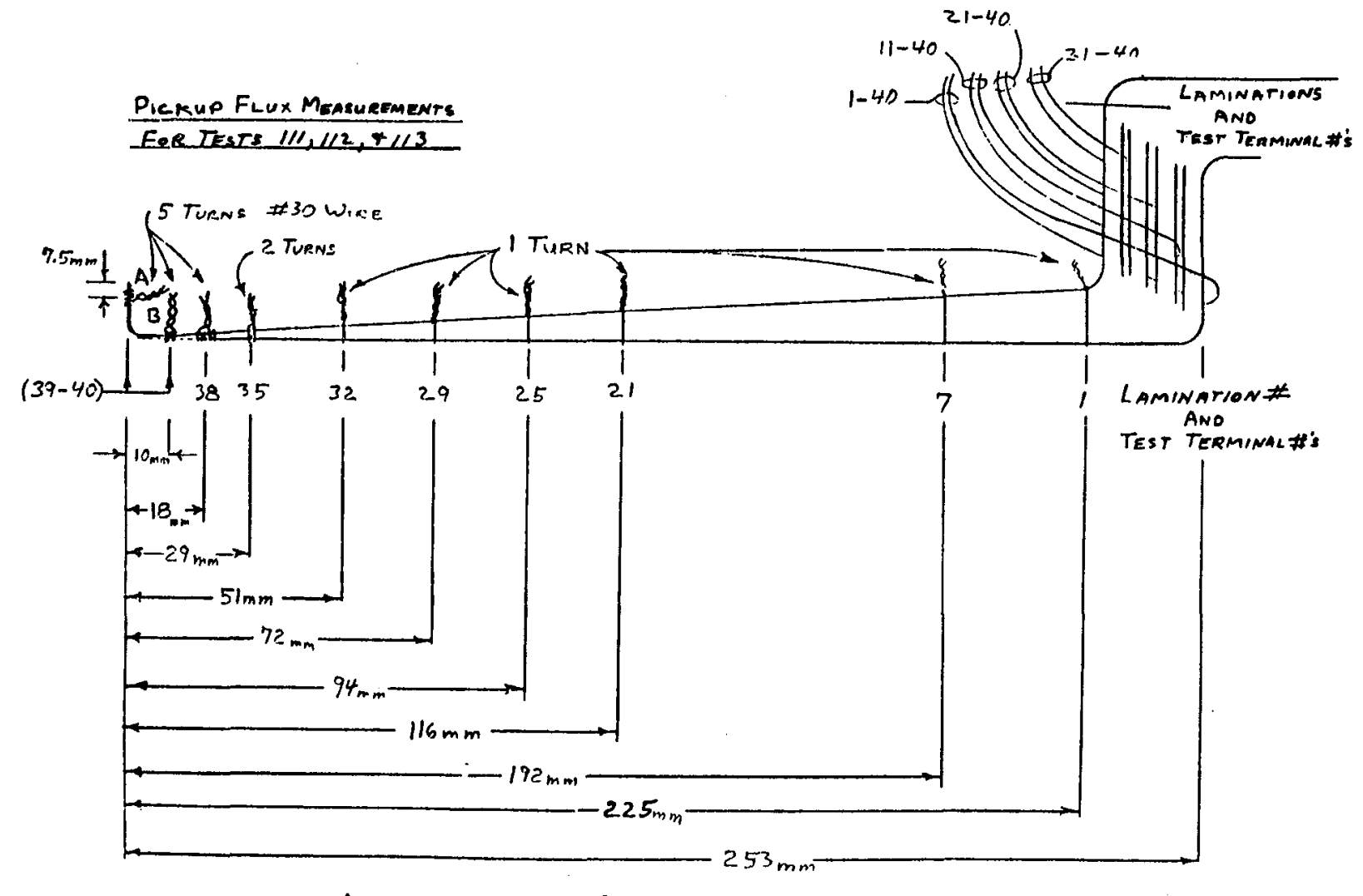

Arrangement of Windings on Pickup Core.

TEST \#104

$$
10-18-77
$$

MAGNETIC FLUX - LaMINATIONS

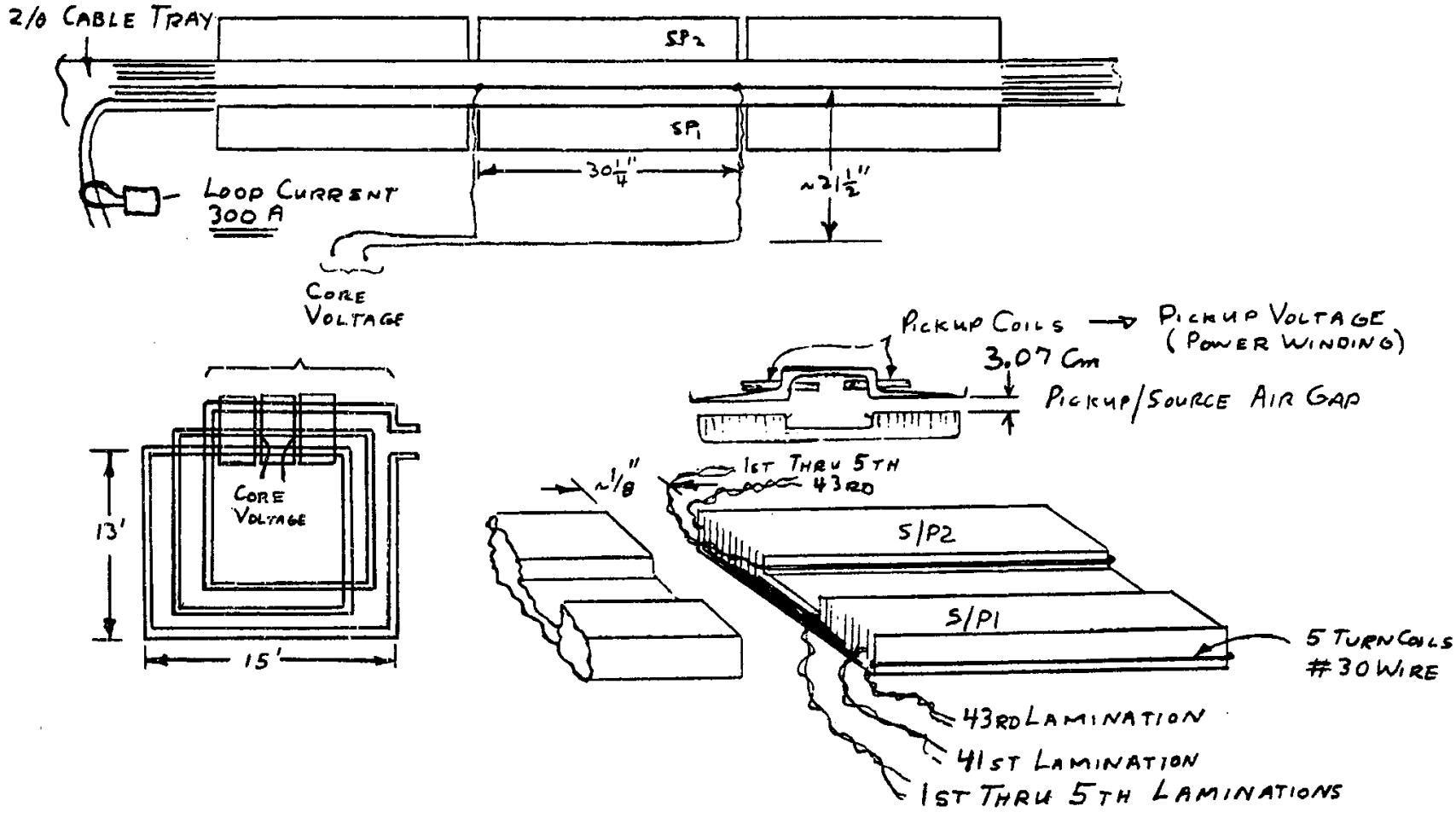

Arrangement of Windings on Source Core. 


\section{E. THERMAL TESTS}

\section{Test Conditions:}

Figure 42

Test No. $157,158,159,160$ and 161

Source ampere turns - 900

Frequency - $185 \mathrm{~Hz}$

Method: See figure 41 for test arrangement. Thermocouples attached to the sheet were monitored with an automatic data logger when the source power was turned on. The rate of rise of temperature in the sheet at time of turn-on was determined from temperature vs. time plots (see pages 61 through 64 ). This rate of rise was related to power input with the calculations on pages 65 through 67 ).

\section{Figure 44}

Test No.

Method: This figure was developed by plotting the data developed for figures 42 and 43 ; i.e., plotting the derived power dissipations against the corresponding magnetic flux densities.

\section{Figure 45}

Test No. $157,158,159,160$ and 161 (see figure 42)

Method: Temperatures at the center of the sheet were plotted (see pages 68,69 , and 70 ). Where temperatures had not reached steady state, estimates were taken from the plots and used for constructing figure 45 . 


\section{Figure 46}

Test No. 207

Source current - 900 ampere turns

Frequency - $180 \mathrm{~Hz}$ nominal

$0.75 \mathrm{~mm}$ thick sheet steel $23 \mathrm{~cm}$ above source. 1/2", 16 gage expanded metal shield $1.6 \mathrm{~cm}$ below the steel sheet.

Method: The expanded metal sheet was supported from the bottom side of the $1 / 2$ inch thick plywood that supported the steel sheet (reference figure 40). Thermal and electrical (flux) measurements were made as for figures 42 and 43.

\section{Figure 47}

Test No. 208

Source - ampere turns 900

Tire - Goodyear DR 7814, 2 Polyester cord and 2 Steel cords

Method: Three thermocouples were inserted into holes in the tire's tread and were in contact with one or more of the cords of the steel belts. The tire was positioned in a vertical plane above the centerline of the source, tangent to the plane of the source poles. 


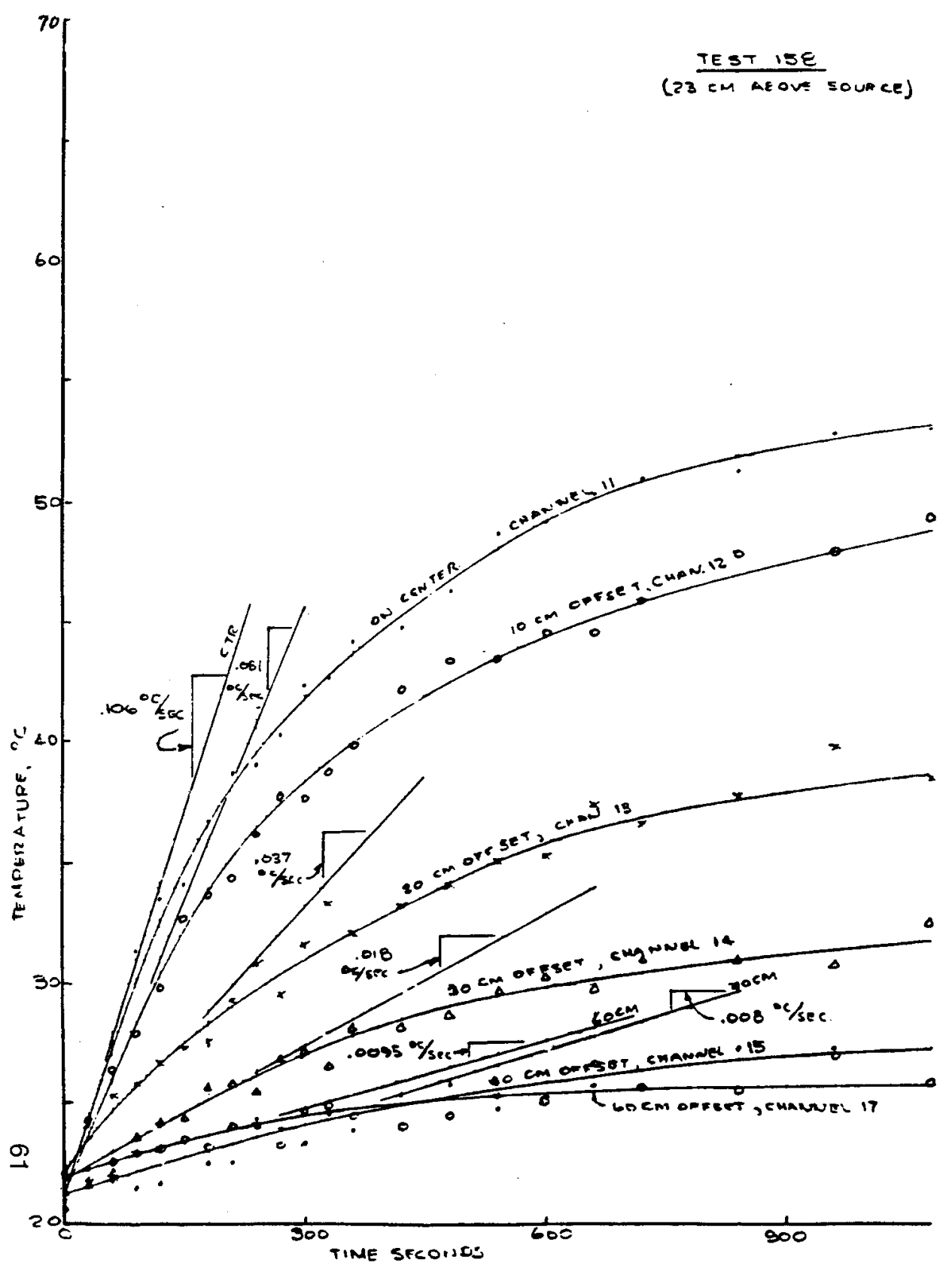

Temperature in Sheet vs Time.

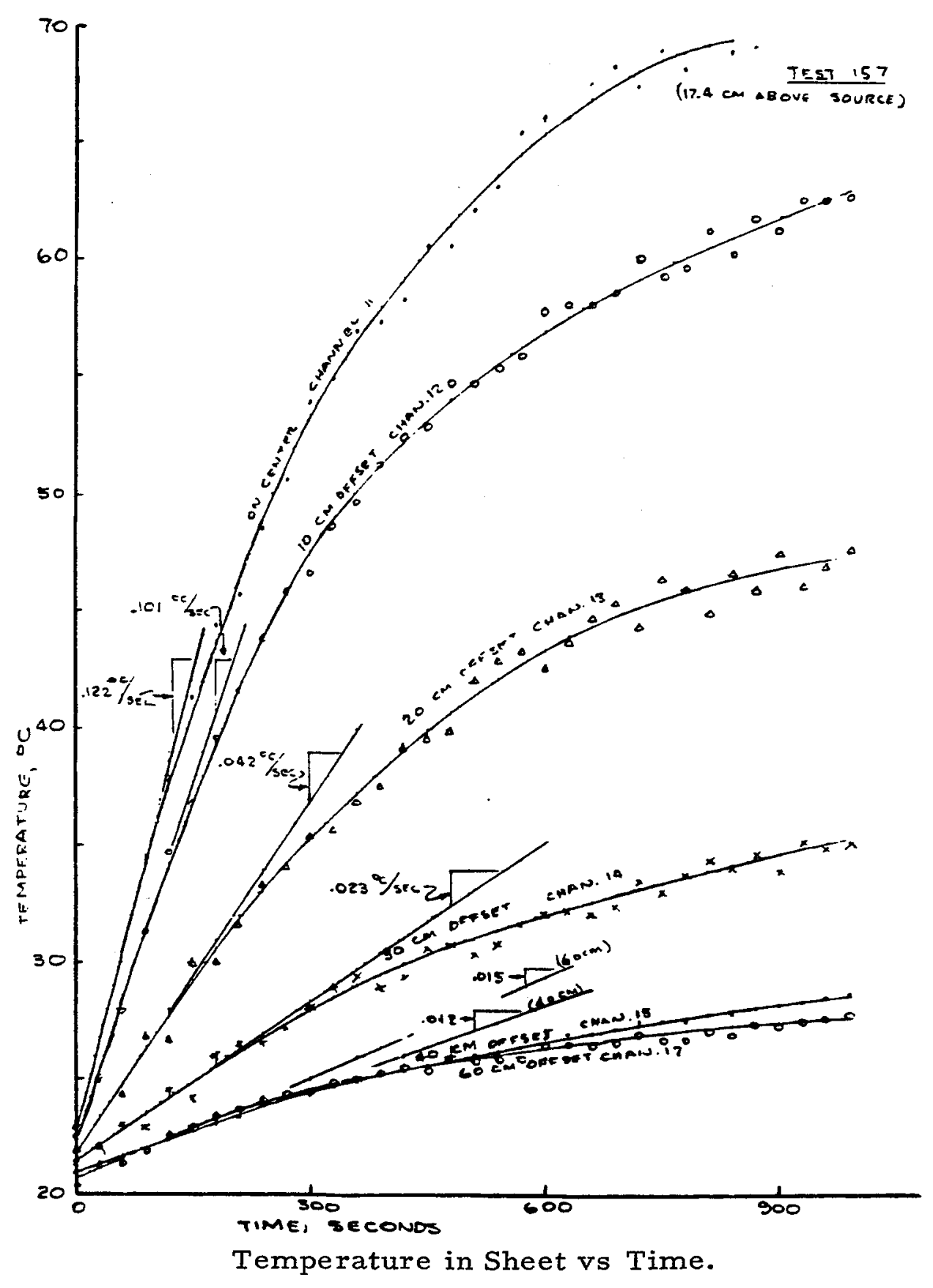




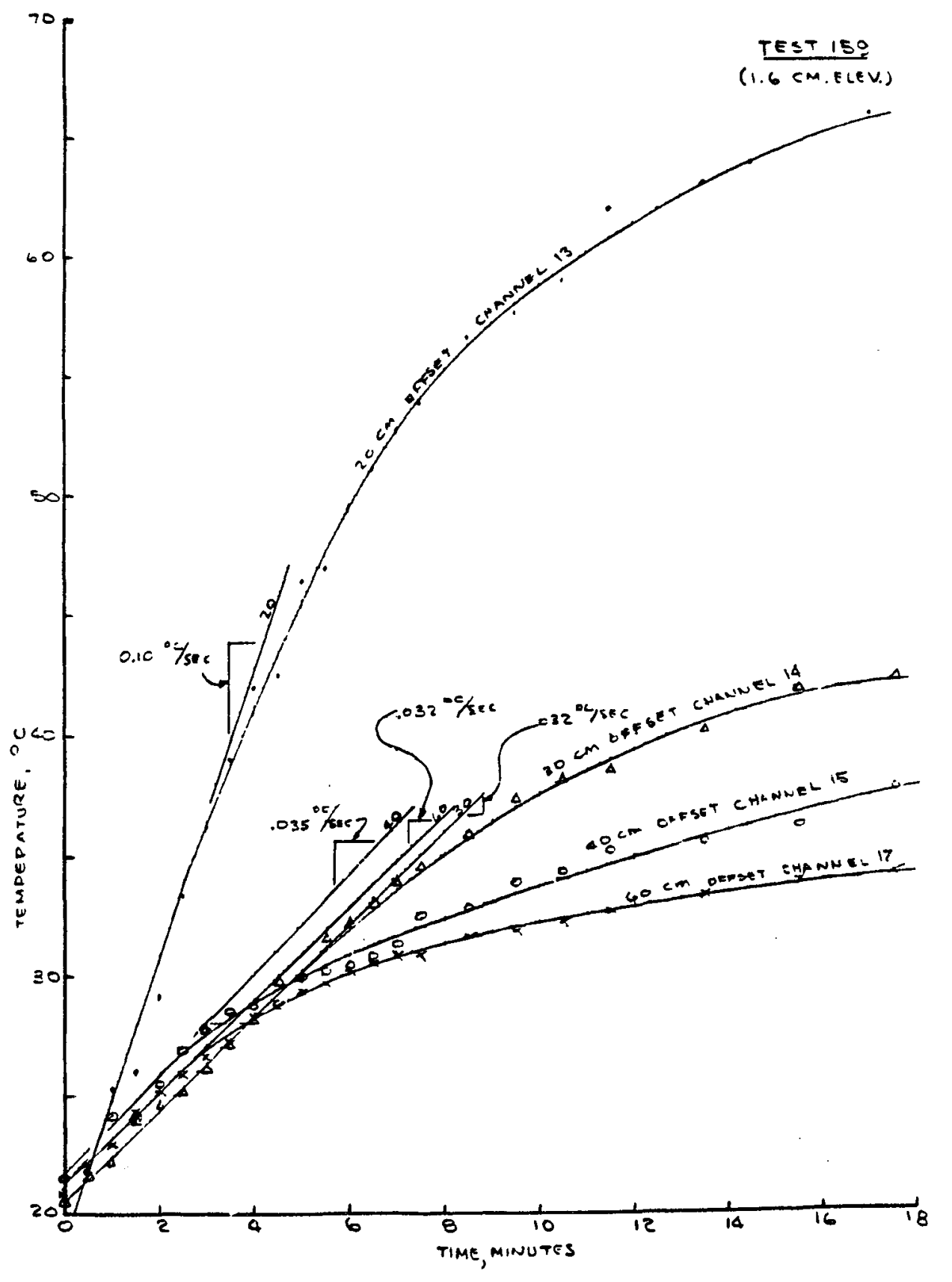

Temperature in Sheet vs Time. 


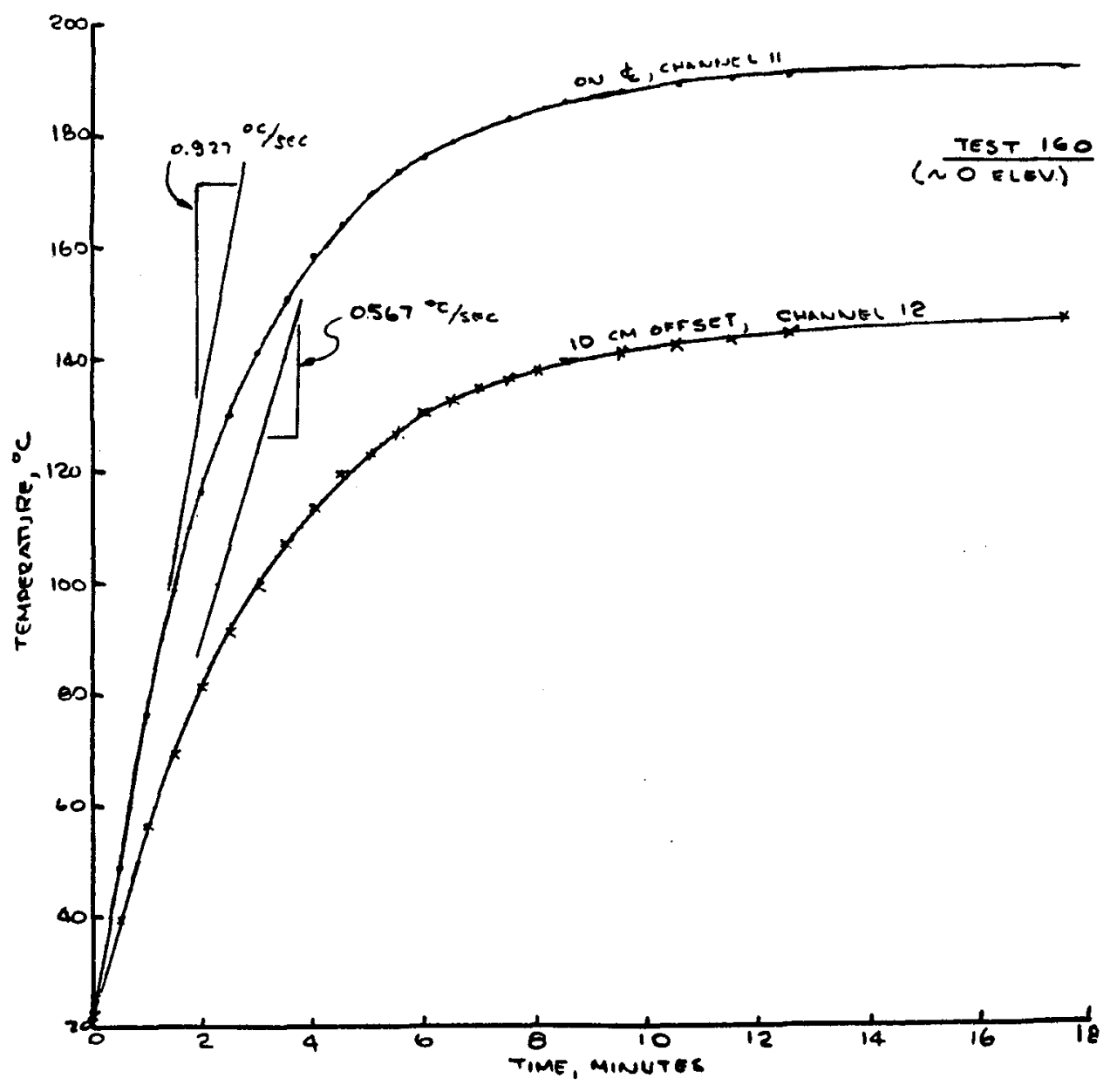

Temperature in Sheet vs Time.

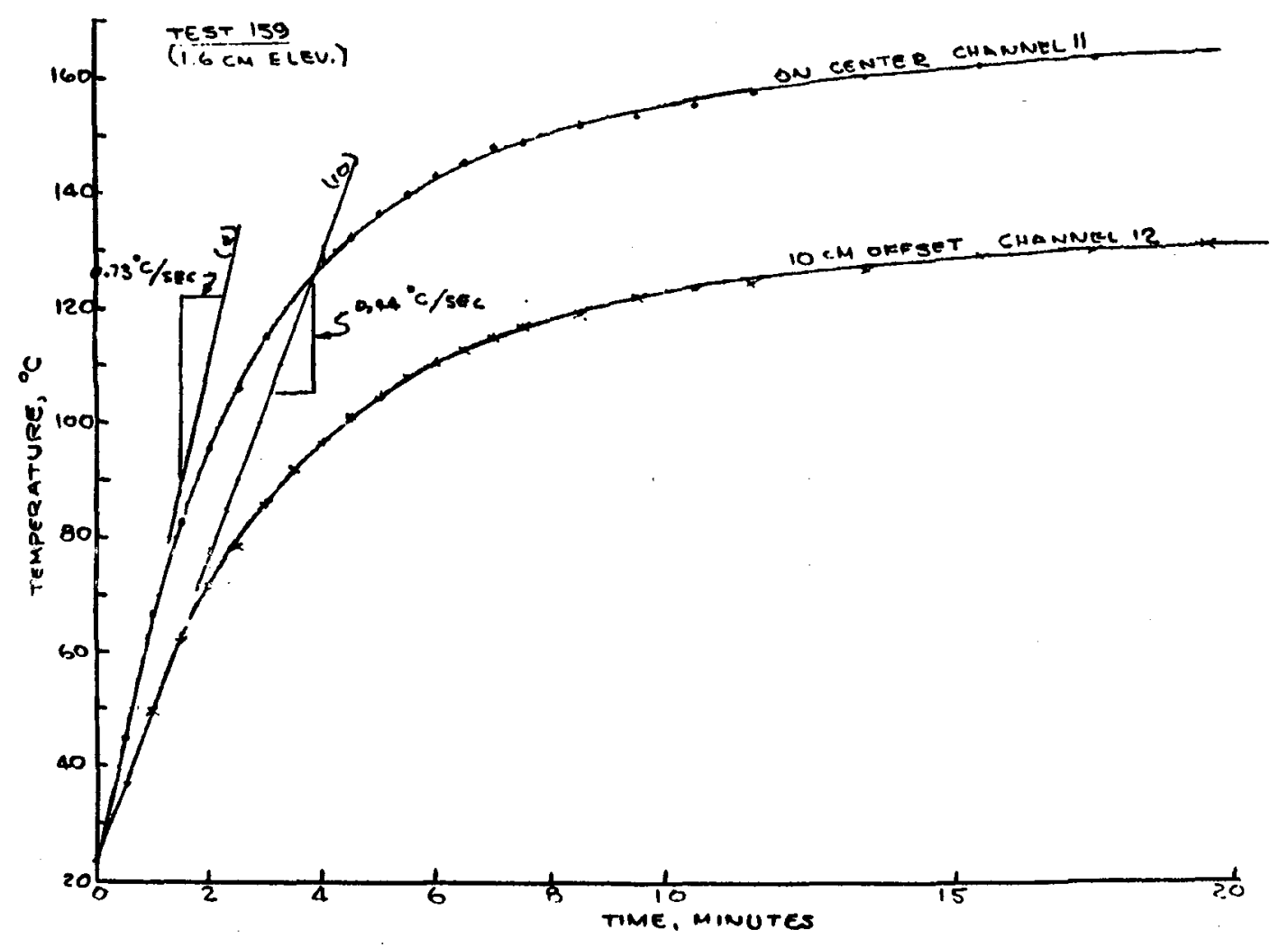

Temperature in Sheet vs Time. 

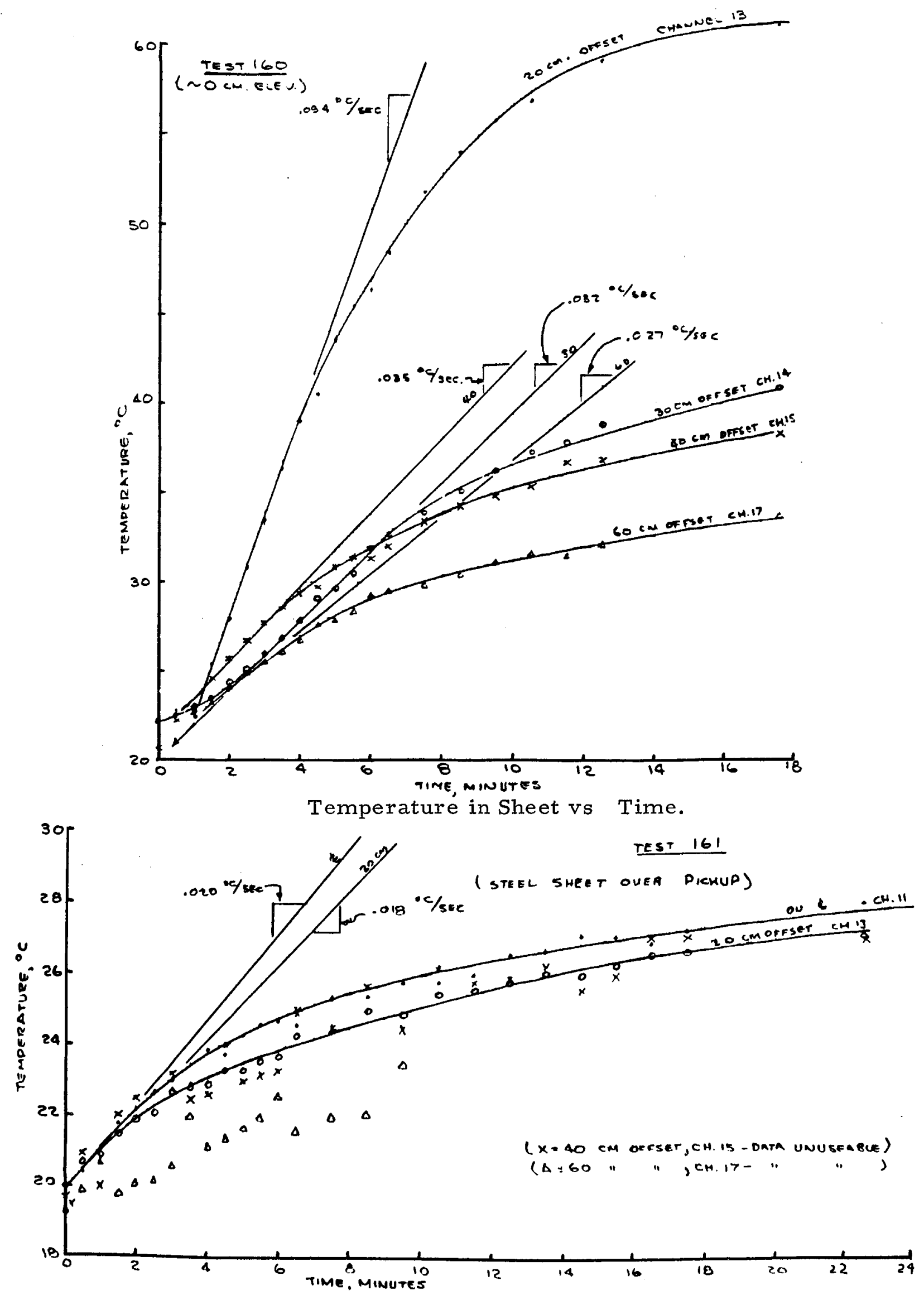

Temperature in Sheet vs Time. 
Calculation of Power Dissipation in Steel Sheet Over Source.

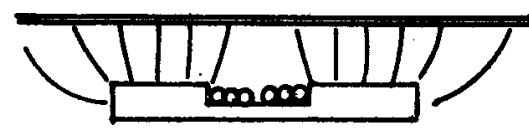

Power can be determined from rate of temp. rise when power is first applied; i.e., at that time the temp. of the sheet ambient so that no transverse conduction, or convection occurs.

$$
\begin{aligned}
P=\frac{d Q}{d t} & W=\text { sheet density, } 1 \mathrm{~b} / \mathrm{in}^{2} \\
=\left(W C \frac{\Delta T}{\Delta t}\right) & \mathrm{C}=\text { sp. heat, BTU/1b }-{ }^{\circ} \mathrm{C}=.108 \mathrm{Btu} / 1 \mathrm{~b}-{ }^{{ }^{\circ} \mathrm{F}} \\
& \Delta T=\text { temperature change, }{ }^{\circ} \mathrm{C} \text { in time } \Delta t, \text { sec. }
\end{aligned}
$$

- For $.0299 \mathrm{in.}$ thick steel, $\mathrm{W} \frac{1.25 \mathrm{lb} / \mathrm{ft}^{2}}{144 \mathrm{in}^{2} / \mathrm{ft}^{2}}=.0087 \mathrm{lb} / \mathrm{in}^{2}$

$$
\begin{aligned}
P & =.0087 \times(.108 \times 1.8) \frac{\Delta T}{\Delta t} \quad \frac{1 b}{i n^{2}} \times \frac{B t u}{1 b^{0} \mathrm{C}} \times \frac{{ }^{0} \mathrm{C}}{\mathrm{sec}}=\frac{\mathrm{Btu}}{\mathrm{in}^{2}-\mathrm{sec}} \\
& =.0017 \mathrm{Btu} / \mathrm{in}^{2}-\mathrm{sec} \\
\text { or } & =.0017 \frac{\Delta T}{\Delta t} \times .2931 \times 3600 \quad \frac{\mathrm{Btu}}{\mathrm{in}^{2}-\mathrm{sec}} \times \frac{\mathrm{WH}}{\mathrm{Btu}} \times \frac{\mathrm{sec}}{\mathrm{H}}=\frac{\mathrm{W}}{\mathrm{in}^{2}} \\
P & =1.785 \frac{\Delta \mathrm{T}}{\Delta \mathrm{t}} \mathrm{W} / \mathrm{in}^{2} \\
& =1.785 \frac{\Delta T}{\Delta t} \times\left(\frac{1}{2.54}\right)^{2} \mathrm{~W} / \mathrm{cm}^{2} \\
& =0.2767 \frac{\Delta T}{\Delta t} \mathrm{~W} / \mathrm{cm}^{2}
\end{aligned}
$$


Test 156, with sheet $28.5 \mathrm{~cm}$ above source

\begin{tabular}{|c|c|c|c|}
\hline Position (offset from $d$ ), $\mathrm{cm}$ & $\Delta \mathrm{T} / \Delta \mathrm{t},{ }^{\circ} \mathrm{C} / \mathrm{S}$ & Power, $w /$ in $^{2}$ & $\mathrm{P}, \mathrm{w} / \mathrm{cm}^{2}$ \\
\hline $\begin{array}{l}\$ \\
10 \\
20 \\
30 \\
40 \\
60\end{array}$ & $\begin{array}{l}.070 \\
.044 \\
.023 \\
.016 \\
.012 \\
.0096\end{array}$ & $\begin{array}{l}.125 \\
.079 \\
.041 \\
.029 \\
.021 \\
.017\end{array}$ & $\begin{array}{l}.0194 \\
.0122 \\
.0064 \\
.0044 \\
.0033 \\
.0027\end{array}$ \\
\hline
\end{tabular}

Test 157. Sheet $17.4 \mathrm{~cm}$ above source

Offset
0
10
20
30
40
60

$\Delta T / \Delta t$
.122
.101
.042
.023
.012
.015

\begin{tabular}{|c|c|}
\hline$P, w / i^{2}$ & $P, w / \mathrm{cm}^{2}$ \\
\hline $\begin{array}{l}.218 \\
.180 \\
.07 .5 \\
.041 \\
.021 \\
.027\end{array}$ & $\begin{array}{l}.0603 \\
.0498 \\
.0208 \\
.0113 \\
.0058 \\
.0075\end{array}$ \\
\hline
\end{tabular}

Test $158(23 \mathrm{~cm} \mathrm{elev})$

\begin{tabular}{c} 
Offset, $\mathrm{cm}$ \\
\hline 0 \\
10 \\
20 \\
30 \\
40 \\
60
\end{tabular}

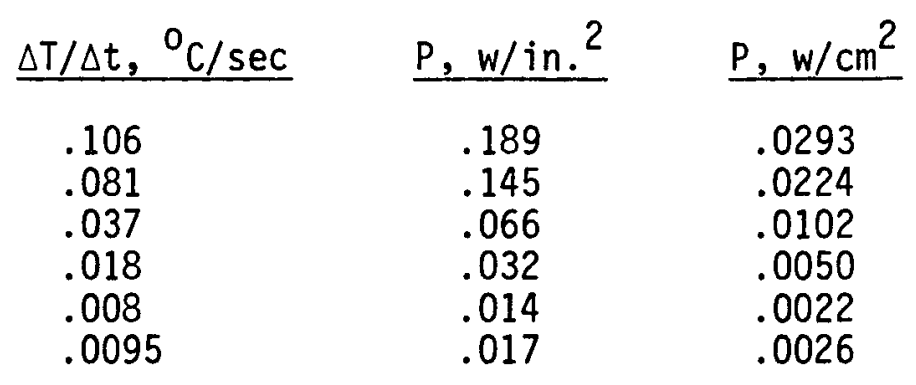

Test $159(1.3 \mathrm{~cm}$ elev.)

\begin{tabular}{c} 
Offset \\
\hline 0 \\
10 \\
20 \\
30 \\
40 \\
60
\end{tabular}

$\frac{\Delta T / \Delta t}{0.73}$
0.44
0.10
0.032
0.035
0.032

\begin{tabular}{l}
$P, w /$ in $^{2}$ \\
\hline 1.30 \\
0.79 \\
0.18 \\
0.057 \\
0.063 \\
0.057
\end{tabular}

P, $w / \mathrm{cm}^{2}$

0.360

0.219

0.0498

0.0158

0.0174

0.0158 
Test $160(\sim 0 \mathrm{~cm}$ elev.)

\begin{tabular}{|c|c|c|c|}
\hline Offset & $\Delta T / \Delta t$ & $P, w /$ in $^{2}$ & $p, w / \mathrm{cm}^{2}$ \\
\hline $\begin{array}{r}0 \\
10 \\
20 \\
30 \\
40 \\
60\end{array}$ & $\begin{array}{l}0.927 \\
0.567 \\
0.094 \\
0.032 \\
0.035 \\
0.027\end{array}$ & $\begin{array}{l}1.65 \\
1.01 \\
0.168 \\
0.057 \\
0.063 \\
0.048\end{array}$ & $\begin{array}{l}0.457 \\
0.279 \\
0.0465 \\
0.0158 \\
0.0174 \\
0.0133\end{array}$ \\
\hline
\end{tabular}

Test 161 (with pickup $-23 \mathrm{~cm}$ elev.)
20
0.020
0.036
0.010
20
0.018
0.032
0.0089

Temperature $\Theta \&$ after $15 \mathrm{~min}$.

\begin{tabular}{|c|c|c|c|}
\hline Test & Elev., $\mathrm{cm}$ & $\mathrm{T},{ }^{\circ} \mathrm{C}$ & $\frac{\mathrm{T},{ }^{\circ} \mathrm{C}}{}$ \\
\hline $\begin{array}{l}156 \\
157 \\
158 \\
159 \\
160 \\
161\end{array}$ & $\begin{array}{l}28.5 \\
17.4 \\
23 \\
1.6 \\
0 \\
23 \text { (with pickup) }\end{array}$ & $\begin{array}{c}40.8 \\
70.0 \\
52.3 \\
161 \\
192 \\
26.9\end{array}$ & $\begin{array}{l}44.3 \\
75 \\
57 \\
167 \text { (est.) } \\
192 \\
30\end{array}$ \\
\hline
\end{tabular}




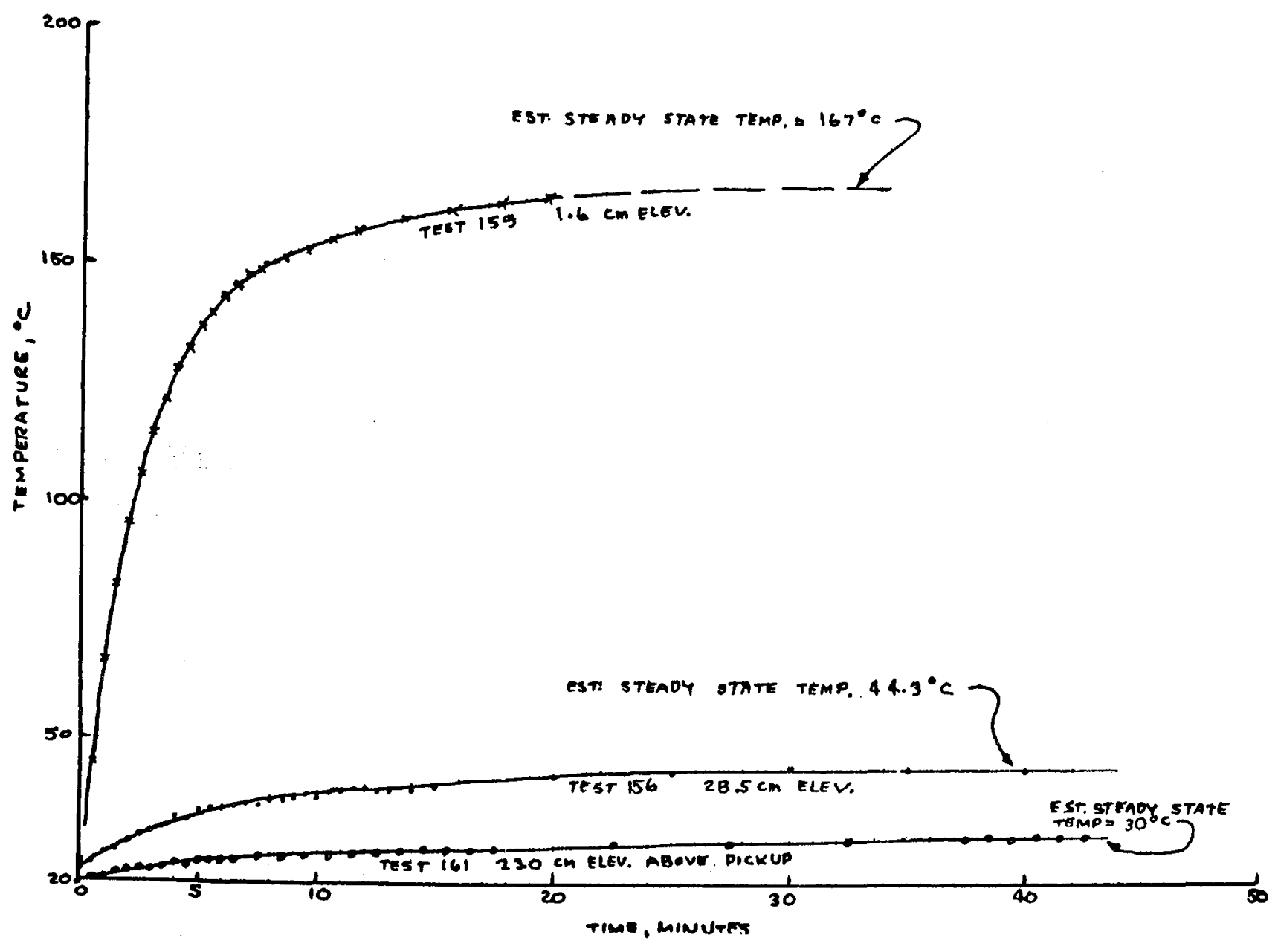

Temperature in Sheet vs Time. 
TEsT 158

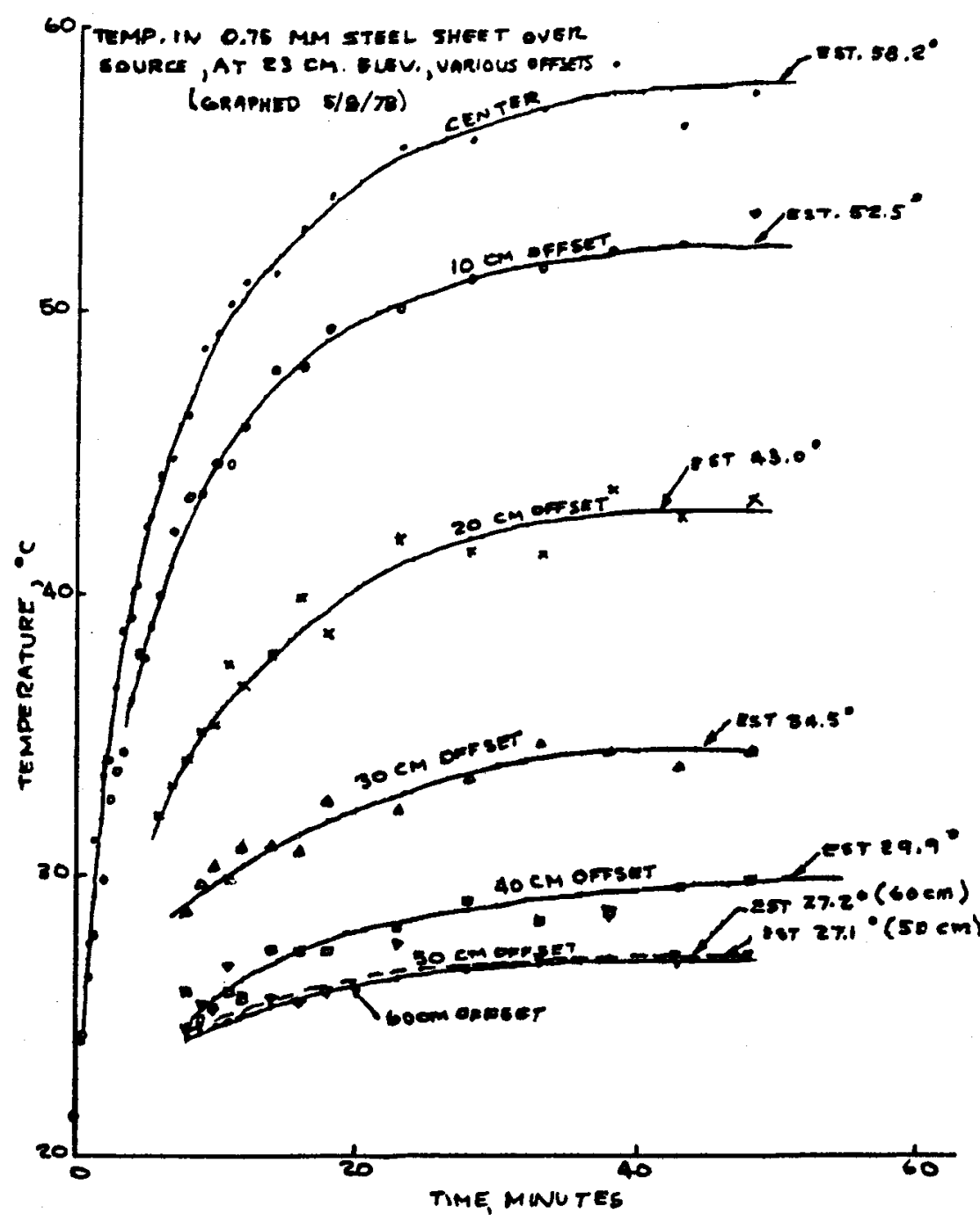

Temperature in Sheet vs Time.

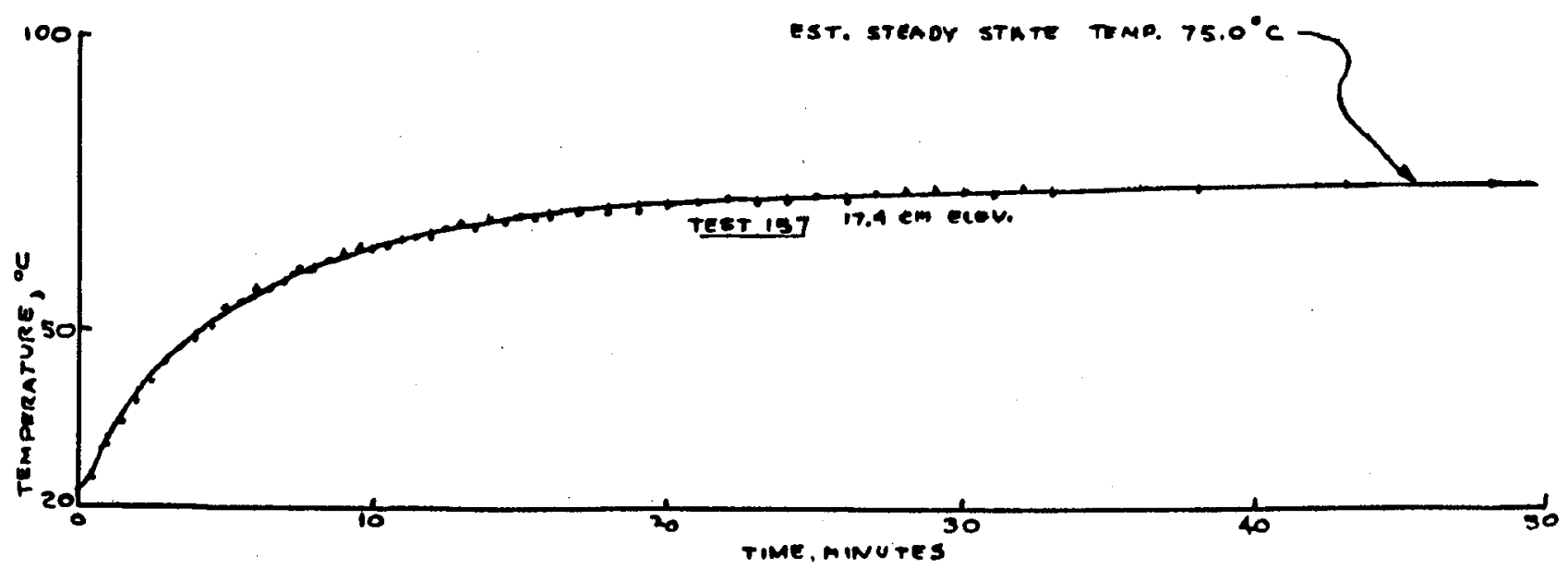

Temperature in Sheet vs Time. 


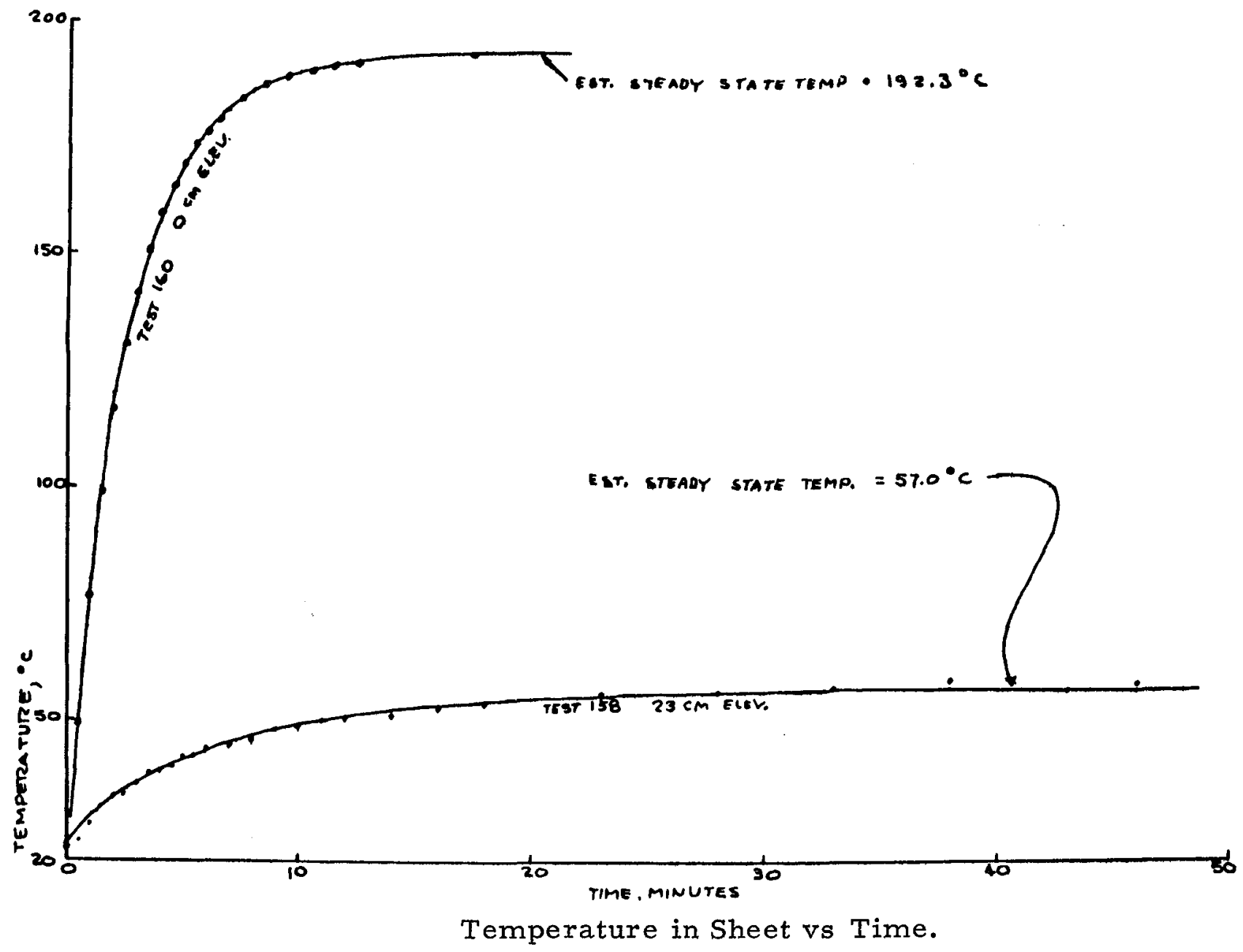

